Differences in Performance and Preference for Object-Oriented vs. Bit-Mapped Graphics Interfaces

by

Michael F. Mohageg

\begin{abstract}
Thesis submitted to the Faculty of the
Virginia Polytechnic Institute and State University

in partial fulfillment of the requirements for the degree of
\end{abstract}

MASTER OF SCIENCE

in

Industrial Engineering and Operations Research

APPROVED:

Harry L. Snyder, ${ }^{\text {C Chairman }}$

Rigbert C. Williges

William H. Muto

March 1, 1989

Blacksburg, Virginia 


\title{
Differences in Performance and Preference for \\ Object-Oriented vs. Bit-Mapped Graphics Interfaces
}

\author{
by \\ Michael F. Mohageg \\ Harry L. Snyder, Chairman \\ Industrial Engineering and Operations Research
}

(ABSTRACT)

This study used a standardized evaluation to compare two direct manipulation graphics interfaces. The interfaces investigated were (1) objectoriented (vector) graphics and (2) bit-mapped graphics (object-oriented graphics interfaces are not to be confused with object-oriented programming or object-oriented data bases). Experienced and novice subjects performed objectively derived benchmark tasks appropriate for two-dimensional graphics packages.

Both performance and preference data were collected. Task completion time, aborted attempts, learning effects, and errors constituted the performance measures. For the preference data, subjects completed questionnaires to rate the interfaces on both an absolute and a relative basis.

Results indicate that the object-oriented graphics interface is superior to the bit-mapped interface. Both the performance and preference measures 
indicate that the object-oriented interface is better suited for manipulation of graphics. 


\section{ACKNOWLEDGEMENTS}

The author would like to thank Dr. Harry L. Snyder, and Dr. William H. Muto for their constant support and insightful comments during the course of this study. My sincere thanks are also extended to the User Systems Engineering Group at Texas Instruments, Inc. Their generosity in allowing me to use TI equipment for data extraction and collection is greatly appreciated. This thesis was funded by a Graduate Internship from Texas Instruments, Inc. to the Virginia Tech Displays and Controls Laboratory. 


\section{ACKNOWLEDGEMENTS}

The author would like to thank Dr. Harry L. Snyder, and Dr. William H. Muto for their constant support and insightful comments during the course of this study. My sincere thanks are also extended to the User Systems Engineering Group at Texas Instruments, Inc. Their generosity in allowing me to use $\mathrm{Tl}$ equipment for data extraction and collection is greatly appreciated. This thesis was funded by a Graduate Internship from Texas Instruments, Inc. to the Virginia Tech Displays and Controls Laboratory. 


\section{TABLE OF CONTENTS}

INTRODUCTION.

1

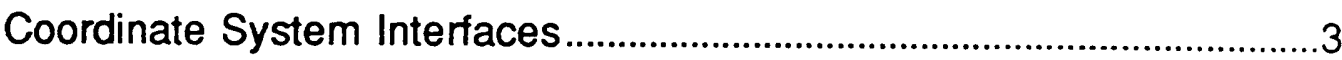

Direct Manipulation Interfaces...............................................................6

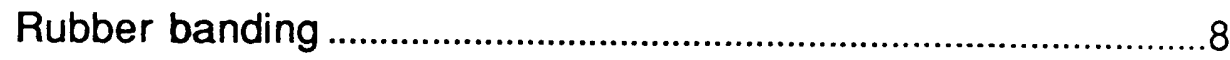

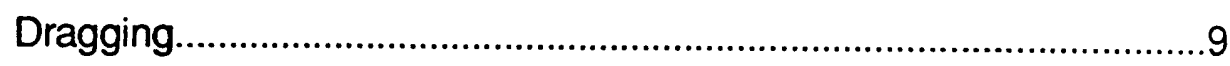

Object-oriented interface ..............................................................

Bit-mapped interface ............................................................... 14

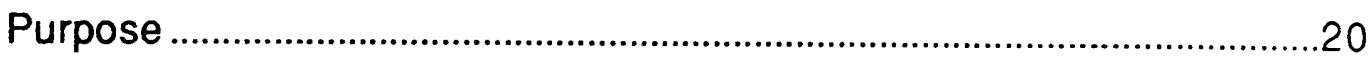

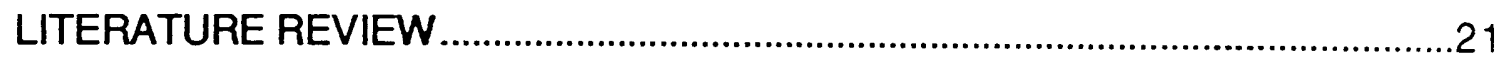

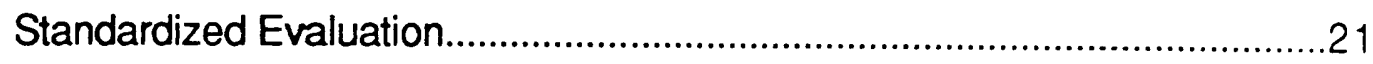

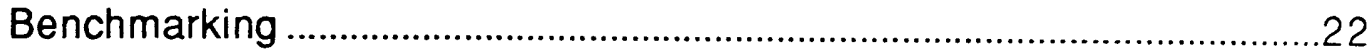

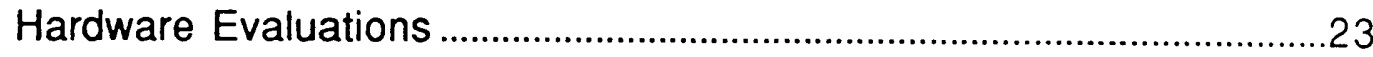

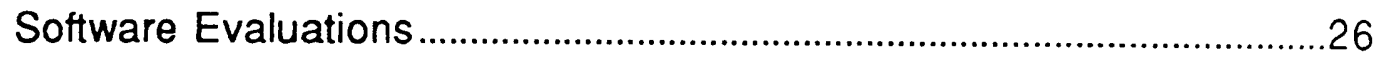

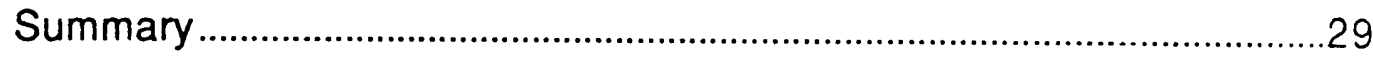

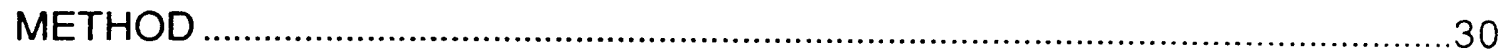

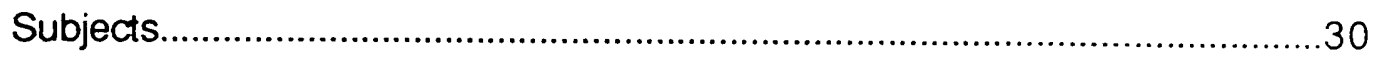


Novices

Experts

Apparatus

Graphics interfaces (software)

Hardware.

Other equipment

Graphics Tasks.

Expert observations

Benchmark tasks.

Task complexity.

Experimental Design

Dependent Measures

Performance measures

Preference measures.

Procedure.

Order of presentation 
Errors of omission

Errors of commission

Learning time.

Preference Measures.

Absolute rating questionnaire

Comparison questionnaire

Overall rating

Task Completion Time

Interface effect

Trial effect

Learning 
Size Deviation Errors

Preference Measures.

Consistency of Results.

Generalization of Results 83

Sensitivity and Validity of Methodology. 85

Conclusions 85

Suggestions for Future Research.

REFERENCES 89

APPENDIX I. Subject Work Files 93

APPENDIX II. Absolute Rating Questionnaire 102

APPENDIX III. Comparison Questionnaire 110

APPENDIX IV. Informed Consent and Photographic Release Form

APPENDIX V. Training Manuals

APPENDIX VI. Test Tasks and Time Requirements.

APPENDIX VII. ANOVA Summary Tables for Task Times 169

APPENDIX VIII. Interface-by-Experience Interactions 199

APPENDIX IX. ANOVA Summary Tables for Errors of Commission 203 
APPENDIX X. ANOVA Summary Tables for Absolute Ratings .........................224

APPENDIX XI. Comparison Questionnaire Responses ...................................259 


\section{LIST OF FIGURES}

Figure 1. Origin locations in coordinate system interfaces 4

Figure 2. Drawing lines with the coordinate system interface .5

Figure 3. Illustration of rubber banding. .10

Figure 4. Illustration of dragging 12

Figure 5. Illustration of graphics in the object oriented interface 13

Figure 6. Illustration of individual pixels in the bit-mapped interface 15

Figure 7. Illustration of grouping pixels in the bit-mapped interface 17

Figure 8. Illustration of grouping pixles in a portion of a graphic. 18

Figure 9. Illustration of graphic primitives in the bit-mapped interface 19

Figure 10. Task complexity continuum 40

Figure 11. Experimental design used for data collection 42

Figure 12. Task completion times as a function of subject experience and trial for line moving and line enlargement. 64

Figure 13. Task completion times as a function of subject experience and trial for for circle manipulations and menu drawing 65 


\section{LIST OF TABLES}

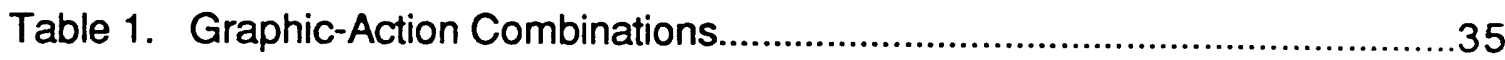

Table 2. Observed Graphic-Action Combinations ...............................................37

Table 3. Mean Task Completion Time for Each Task for Each Interface..........50

Table 4. Mean Task Completion Time for Each Interface by Subject

Experience

Table 5. Significant Sources of Variance from Each Task's Time ANOVA

Summary Table .52

Table 6. Frequency of Repeated Attempts for each Interface. .56

Table 7. Significant Sources of Variance from each Task's Error ANOVA

Summary Table.

Table 8. Linear Size Errors

Table 9. Area Size Errors 60

Table 10. Frequency of Positioning Errors for each Interface 62

Table 11. Mean Rating Assigned for each Absolute Questionnaire Item 68

Table 12. Subjects' Interface Preferences for Task Performance 71 


\section{INTRODUCTION}

Graphics packages are among the most popular and most used types of software for computer systems (Grillo and Robertson, 1985; McComb and Smith, 1985). Graphics capabilities such as computer-aided design tools have long been used in engineering, drafting, and art (Foley and Van Dam, 1982; Harris, 1984; Scott, 1982). Many such packages are available with varying capabilities and interface types. Often, interface types significantly affect the ease with which graphics packages are used. The interface type refers to the method by which the software allows users to make inputs and complete tasks, for instance, the method by which one draws and edits graphic figures in a given system.

Norman (1986) specifies seven stages (of user activity) in performing and evaluating a task:

1. Establishing the goal (of the task)

2. Forming the intention

3. Specifying the action sequence

4. Executing the action

5. Perceiving the system state

6. Interpreting the state 
7. Evaluating the system state with regard to the goals and intentions. Norman claims that task goals are mental representations of the desirable outcome. The user must translate the goals to physical actions in interacting with the system interface. The users' physical manipulations of the system enable goal achievement.

The user interface for any software package or application heavily influences stages three and four of Norman's model. In two-dimensional computer graphics, specifying an action (stage 3), execution of the action (stage 4), and perception of the system state (stage 5) are performed differently depending on the interface type.

The most widely known and used two-dimensional graphics interfaces are the (1) coordinate system interface (used in computer-aided design systems, computer-aided machining systems, Prodesign IITM , SNAP!TM, (2) object-oriented (also known as vector graphics) interface (e.g., MacDraw ${ }^{\mathrm{TM}}$, MacDraw $\|^{T M}$, Adobe lllustrator ${ }^{T M}$, and (3) bit-mapped interface (e.g., Dr. Halo $^{T M}$, PCPaint $^{T M}$, MacPaint ${ }^{T M}$, FullPaint ${ }^{T M}$, Microsoft Paint Brush ${ }^{T M}$, Modern Artist ${ }^{T M}$, SuperPaint ${ }^{T M}$. To better understand the differences among the aforementioned interface types, a brief introductory description of each is provided below.

[Note: the object-oriented (vector) graphics interface is not to be confused with object-oriented programming or object-oriented data bases.] 


\section{Coordinate System Interfaces}

Users of coordinate system graphics interfaces employ a Cartesian coordinate system as the frame of reference for making inputs. For example, some systems treat each screen pixel as an addressable point. Other systems which require yet higher precision use a programmer defined coordinate system called world coordinates. World coordinates are useful for applications requiring precision beyond that of the display (i.e., pixel coordinates). Using this coordinate system, users may address imaginary points/areas on the screen. Usually the lowest and left-most point on the screen is the coordinate system's origin (designated as 0,0 ). Some systems use the upper, left-most point as the origin (see Figure 1 for an illustration). In this interface type each point has a specific position which is determined by its distance from the origin along the horizontal and vertical axes.

Line drawing is one of the most basic tasks performed with graphics packages. One can understand the philosophy of the coordinate system by analyzing line drawing and editing tasks. For instance, in some computeraided design (CAD) and computer-aided machining (CAM) systems, users draw lines by entering the coordinates of two points and instructing the system to draw a line between these two points. On other systems users perform the same operation by inputting one point's coordinates, then specifying an angle and a line length. The system draws a line starting at the specified point with specified angle and length (see Figure 2a). 


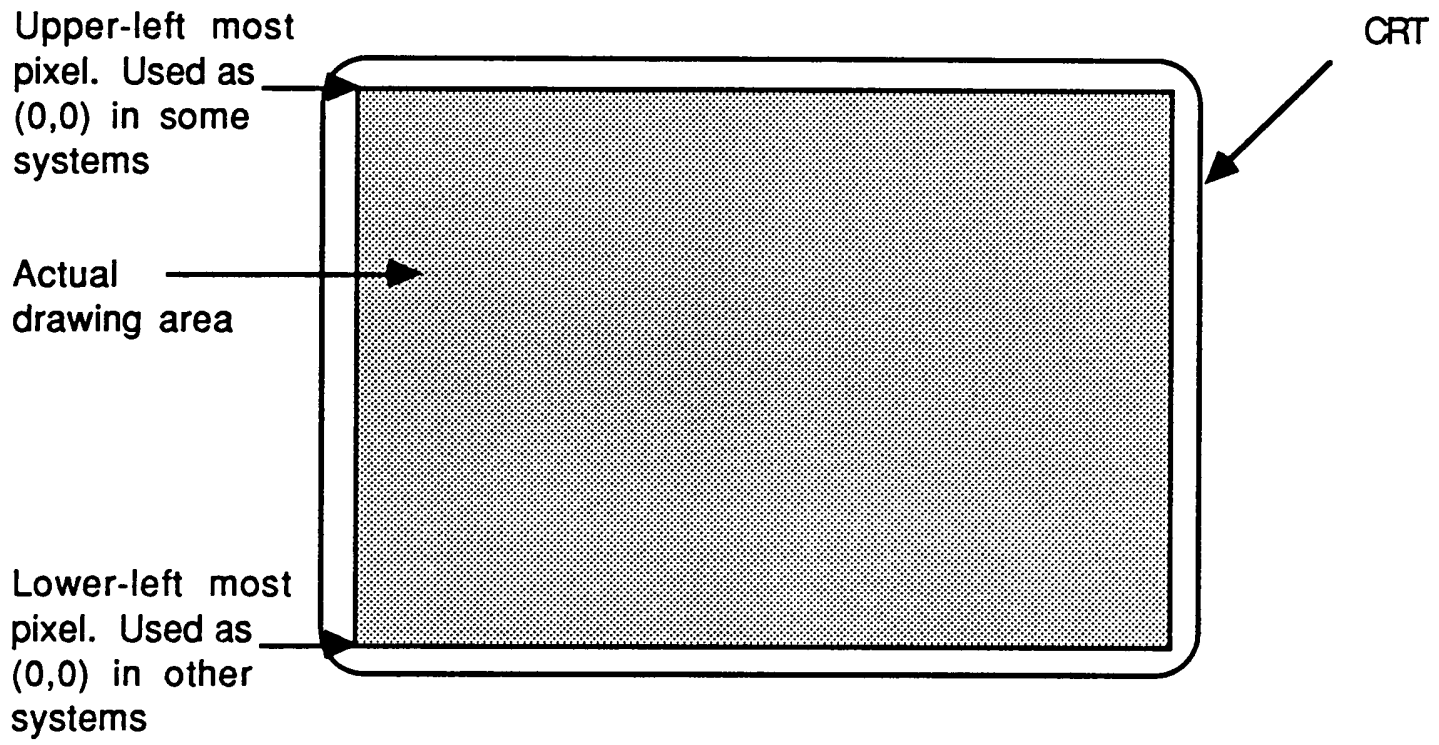

Figure 1. Two origin locations in coordinate system interfaces. 


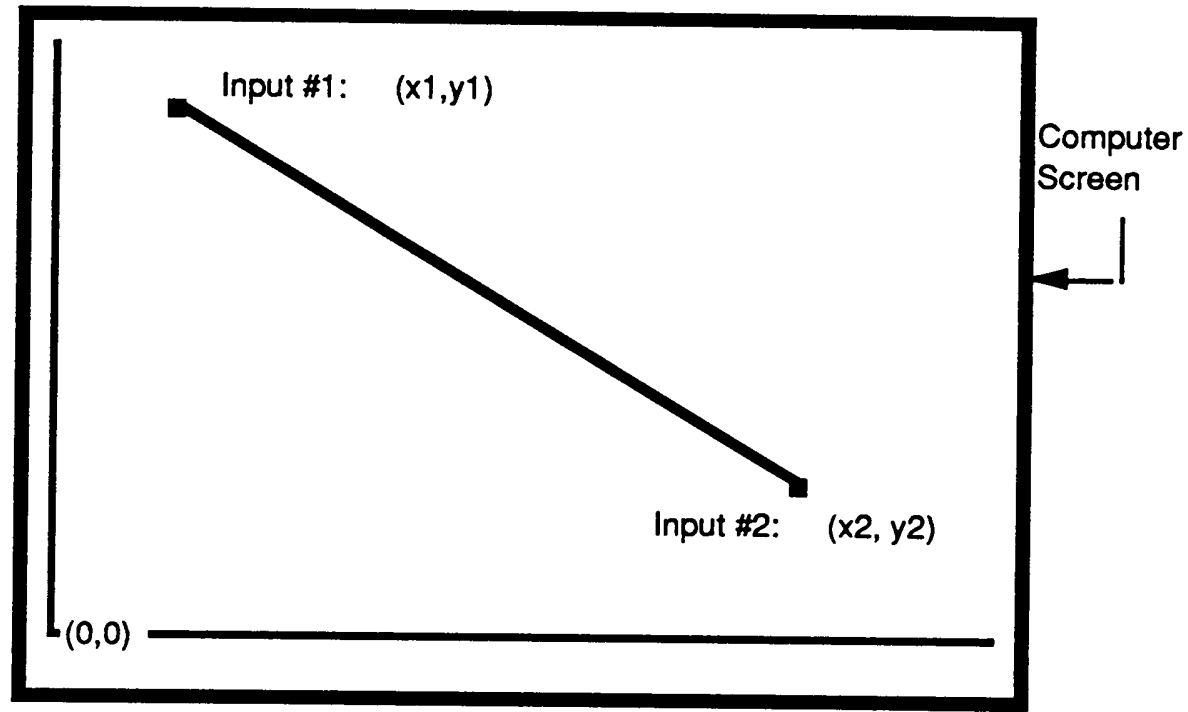

(a)

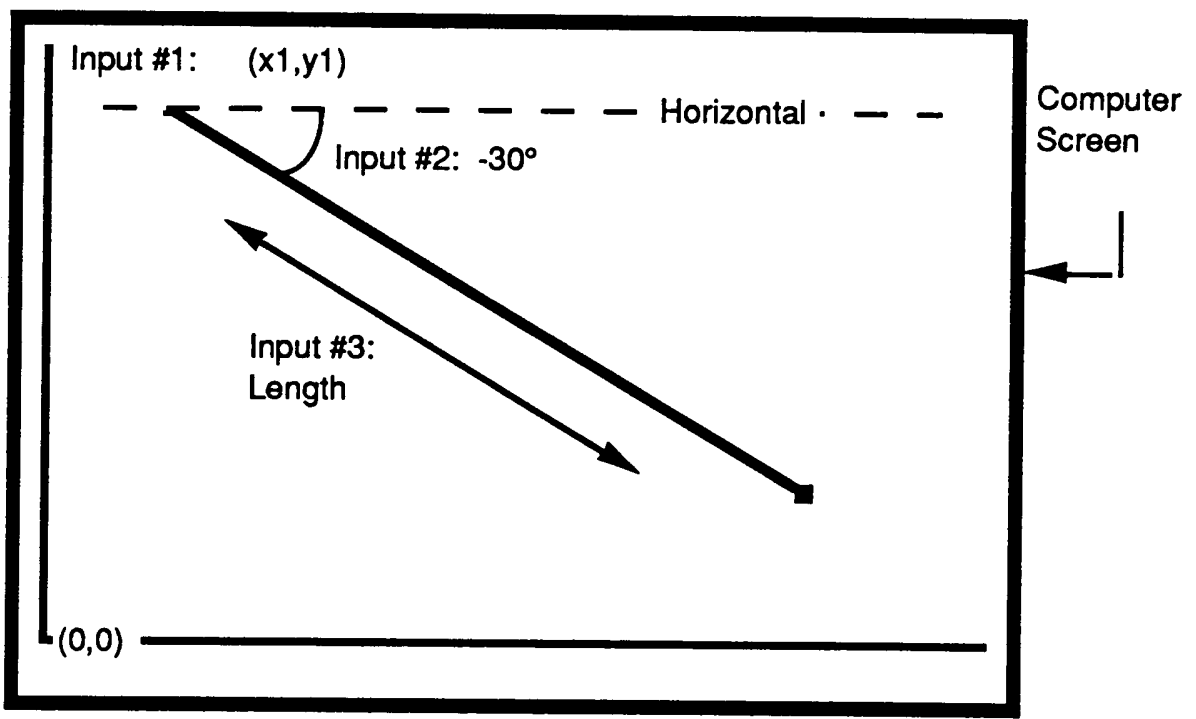

(b)

Figure 2. Line drawing between two point coordinates is illustrated in (a); line drawing with one coordinate point, angle, and distance is illustrated in (b). 
Editing a line is accomplished in a similar manner. For example, the user commands the system to locate the line with end points $\left(x_{1}, y_{1}\right)$ and $\left(x_{2}, y_{2}\right)$, and redraw it such that the end points become $\left(x_{1}, y_{1}\right)$ and $\left(x_{3}, y_{3}\right)$. In other systems the user might select point $\left(x_{2}, y_{2}\right)$ and move it to point $\left(x_{3}, y_{3}\right)$. In effect, the user has redrawn the previous line.

Exacting drawings and figures require high precision. CAD/CAM systems software, for example, uses the coordinate system interface in drafting, engineering sketches, and machining graphics. These applications require very precise graphics; thus, the pin-point accuracy of the coordinate system interface is a necessity.

\section{Direct Manipulation Interfaces}

Although CAD/CAM applications typically require a high degree of precision, other graphics applications do not. Creating presentation sketches, general engineering sketches (e.g., rough drafting, functional flow diagrams), layout drawings, and software prototyping are some of the applications of graphics packages where exact precision is not a necessity. In performing these tasks speed and ease of use are more important than pin-point accuracy. The interfaces most commonly used for these applications are two direct manipulation interfaces: bit-mapped and objectoriented (vector) graphics.

Norman (1986) indicates that in using computer systems there is a gap between the goals (and intentions) of the user and the physical 
mechanisms/interface that the user must employ to achieve his/her goal. Norman refers to this gap as the Gulf of Execution. Direct Manipulation Interfaces (DMIs) help bridge this gap by simplifying action sequence specification and action execution (stages 3 and 4 of Norman's model). Shneiderman (1987), Hutchins, Hollan, and Norman (1986), and Rutkowski (1982) characterize DMls by traits such as:

0 visibility of objects and actions

- rapid reversible actions

- direct manipulation (with cursor control devices) of the object of interest

- immediate display of the results of an action

- WYSIWYG: what you see is what you get

0 invisibility of the tool for the user.

These DMI characteristics assist in bridging the Gulf of Execution. Direct manipulation graphics interfaces such as MacDraw, PCPaint, Dr. Halo, Microsoft PaintBrush, MacPaint, and SuperPaint have become increasingly popular for applications such as rough drafting, engineering sketches, and prototyping.

As opposed to the coordinate system interface, in DMls the coordinates of graphics are not explicitly employed in creating or manipulating graphics. DMI users can employ cursor control devices, such as a mouse 
or trackball, to create and manipulate figures/graphics. As the cursor moves on the screen, immediate feedback is provided on the display. Additionally, a user can use the cursor to select graphics and manipulate them directly rather than indirectly as in the coordinate system interface. In effect the computer's role as an intermediary is reduced due to the immediacy of feedback and the ability of the user to deal with graphics directly. The following sections describe the two most important functions used for creating and manipulating graphics in direct manipulation graphics interfaces: rubber banding and dragging. These descriptions should provide the reader with a better understanding of the difference between the DMI and coordinate system interfaces. For description of these concepts, the use of a computer system with a cursor control device (i.e., mouse or trackball) is presumed. Without a cursor control device, the DMI loses many of its characteristic traits.

Rubber banding. In direct manipulation interfaces graphics are typically created and edited by "rubber banding." Rubber banding is a technique by which the system allows the user to attach a graphic object to the cursor (Foley and Van Dam, 1982; Scott, 1982). In drawing a line, for example, the user employs the cursor control device to move the cursor to a desired point, and anchors the origin of the line at that desired point (typically by pressing a mouse or trackball button). As the user moves the cursor away from the anchored point a line is extended on the screen in the direction of cursor movement. The user can complete the drawing by pressing the 
mouse button once again (see Figure 3a). To edit the line the user must attach one end of the line to the cursor and move the cursor till the desired configuration is achieved. Figure 3 provides an illustration of rubber banding.

Dragging. "Dragging" is a technique used in moving a graphic. In dragging, the user attaches the cursor to a graphic/figure and moves it to the desired position simply by moving the cursor. As the cursor moves across the screen the attached graphic is transported in the same relative manner (Foley and Van Dam, 1982; Scott, 1982). The user then places the graphic by releasing the graphic from the cursor (usually done by releasing a mouse button). Figure 4 illustrates dragging.

Rubber banding and dragging are common to both object-oriented and bit-mapped interfaces. However, these two interface types differ in their approaches to dealing with graphic objects/figures. The following sections delineate the differences in interface philosophy for each of these interfaces.

Object-oriented interface. Software packages that use this type of interface recognize each graphic primitive as a unit. A graphic primitive is the most basic graphic figure on the screen. Lines, rectangles, circles, and triangles are examples of graphic primitives. The interface does not break 


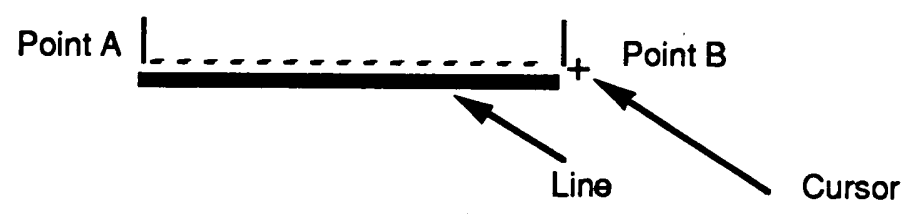

(a)

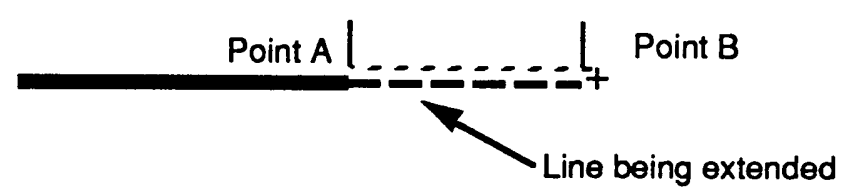

(b)

Figure 3. Figure 3(a) illustrates drawing a line by rubber banding. The user anchors the line at Point $A$ and as the cursor moves towards point $B$ the line is drawn. Figure $3(b)$ illustrates editing the line (making it longer) by rubber banding from Point $A$ to Point $B$. 
down each graphic primitive into its component pixels. For instance, a square graphic is recognized as a singular unit, not an organized arrangement of component pixels.

Users have the ability to select a graphic primitive, move it, and/or edit it as one unit (see Figure 4). For instance, to move a square, the user places the cursor on any part of the square and drags it into position. The entire square moves since the user selected that unit. Group manipulations are possible as well. The user must select the group of graphics of interest. Once the graphics are grouped they may be manipulated simultaneously. Moving portions of a graphic primitive is not be possible in the objectoriented interface since the entire graphic primitive is a singular unit. Manipulation of any portion of a unit would not be possible without affecting the entire unit. The author refers to this interface characteristic as all or nothing manipulations.

Each graphic primitive (a line, a box, a circle, etc.) remains a singular entity despite any changes or manipulations to which it may be subjected. For example, one may move a box and place it over a circle so that it covers half of the circle (see Figure 5). Although part of the circle is covered by the box, the circle retains its integrity. If one were to move the box away from the circle (as in Figure 5), the entire circle would become visible with all its parts intact. The interface treats such an arrangement as one object on top of another, and since each object is a unit no part of either object is altered. 


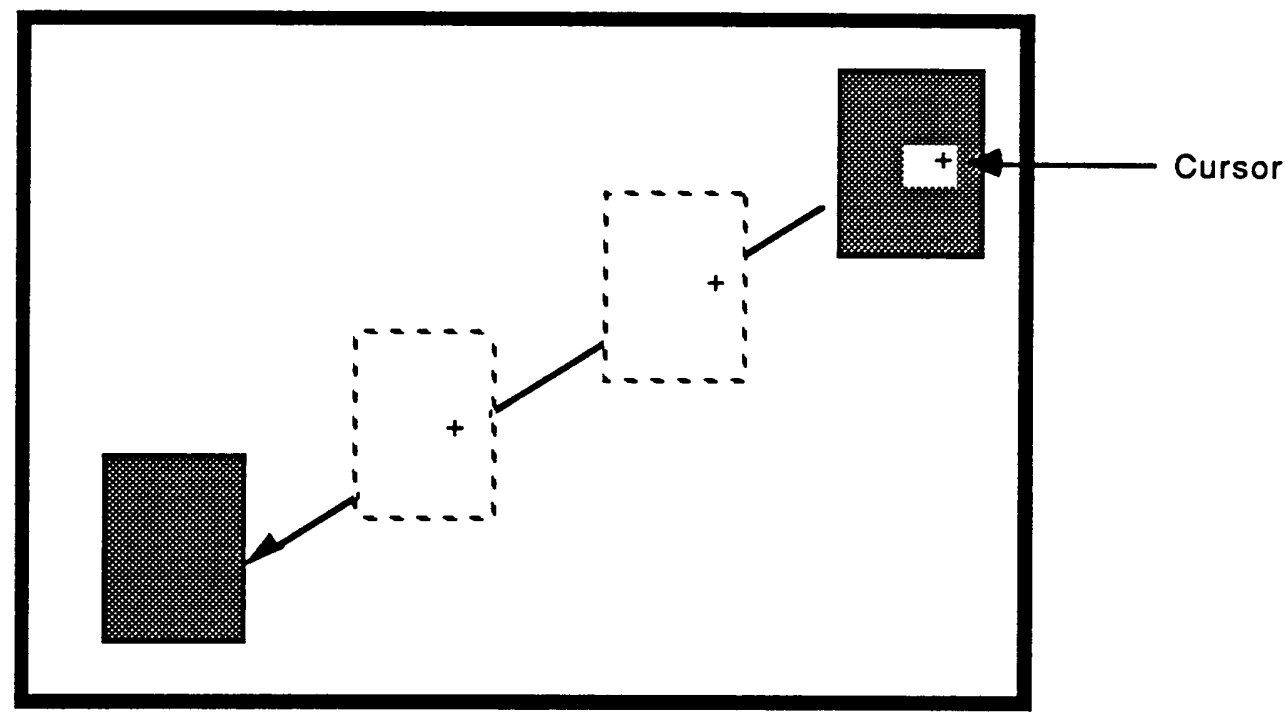

Figure 4. An example of "dragging" a square into position. The cursor is attached to the graphic of interest; as the cursor moves the graphic is transported with the cursor. 


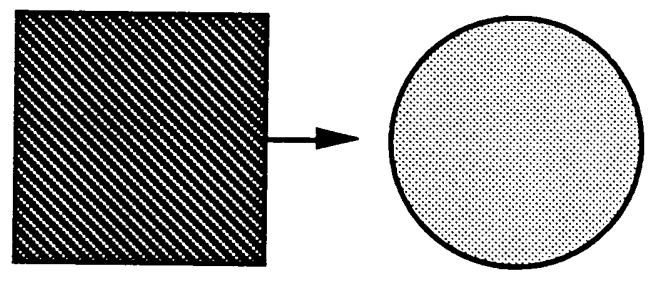

(a)

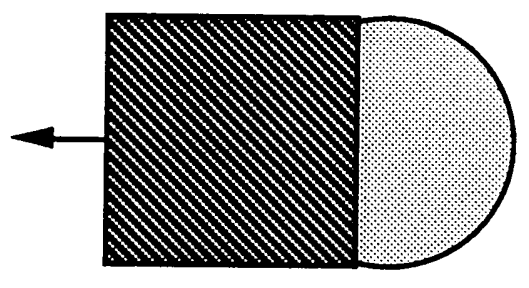

(b)
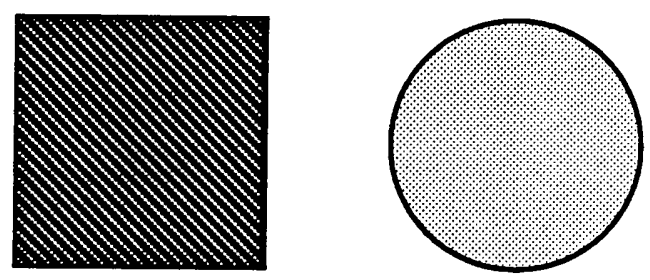

(c)

Figure 5. Each graphic primitive remains a unit despite any manipulations. 
The following list provides a summary of the most important objectoriented characteristics:

1. Each graphic primitive (entity) is a singular unit.

2. Each graphic primitive remains a unit despite any manipulations to which it may be subject.

3. "All or nothing" manipulations.

Bit-mapped interface. Bit-mapped interfaces incorporate a different underlying approach. The bit-mapped interface does not recognize graphics primitives per se. This interface recognizes each illuminated pixel as a unit. The user may perceive a graphic primitive to be a square, but the interface does not recognize the square as an individual entity. This interface treats each pixel (many of which constitute the square) as a single unit (see Figure 6). Those pixels constituting the square graphic are not differentiated from other pixels on the screen.

To manipulate a graphic primitive, the user must select the pixels that constitute that particular graphic primitive and treat those pixels as a group. Most bit-mapped interfaces allow users to group together a set of pixels. The group of pixels may be manipulated together only while they are grouped. Note that grouped pixels do not constitute a unit; they are only a set of pixels that are temporarily grouped together. For example, to move a square, the user must select the combination of pixels that constitute that 


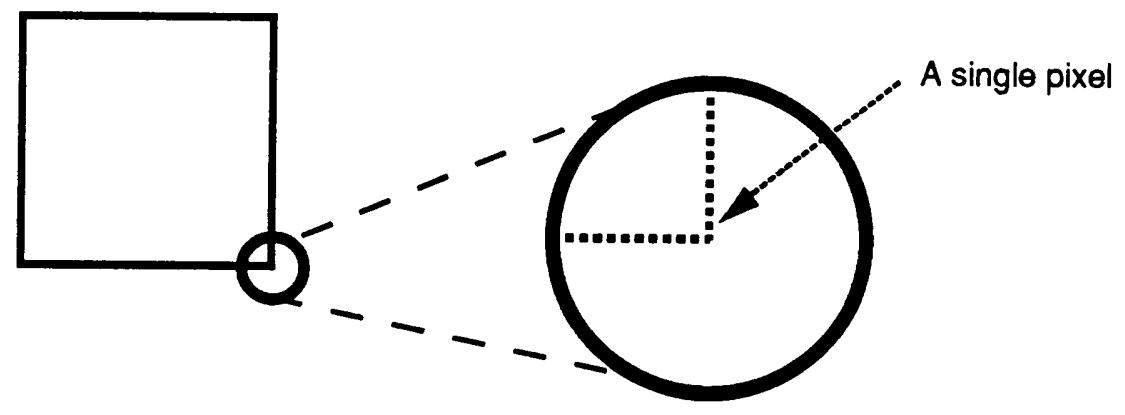

Figure 6. An enlarged view of the box shows the individual pixels. In the bit-mapped interface each pixel is a singular unit. 
square. Once the appropriate pixels are selected (grouped), the user may drag the group to the desired location (see Figure 7). Additionally, if a user desired to move only half of the square, he/she could group the pixels in the portion of interest and move them (see Figure 8).

However, If one were to move or create a graphic so that it was superimposed on another, the pixels contained in the covered part would be lost (see Figure 9). Again, the bit-mapped interface only recognizes illuminated pixels. In Figure 9, since the pixels that comprise the square are combined with those that comprise the circle, their individual identities are in essence lost. In other words, the area behind the box will no longer be recognized by the interface because its pixels are not differentiable from any others.

In summary, the underlying difference between the bit-mapped and object-oriented interfaces is that the bit-mapped interface does not recognize a graphic primitive as such. This interface recognizes only pixels, and does not differentiate one graphic object from another. Users of bit-mapped interfaces must view this interface with quite a different conceptual model compared to that of the object-oriented interface.

The following list provides a summary of the most important bit-mapped interface characteristics:

1. Each pixel is a singular unit. 


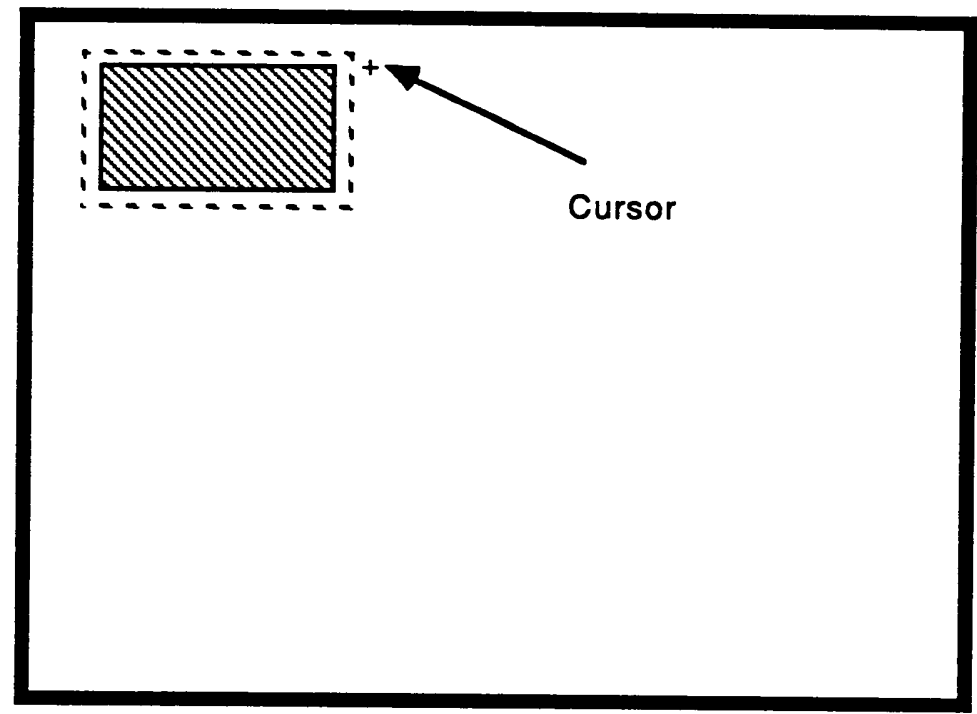

(a)

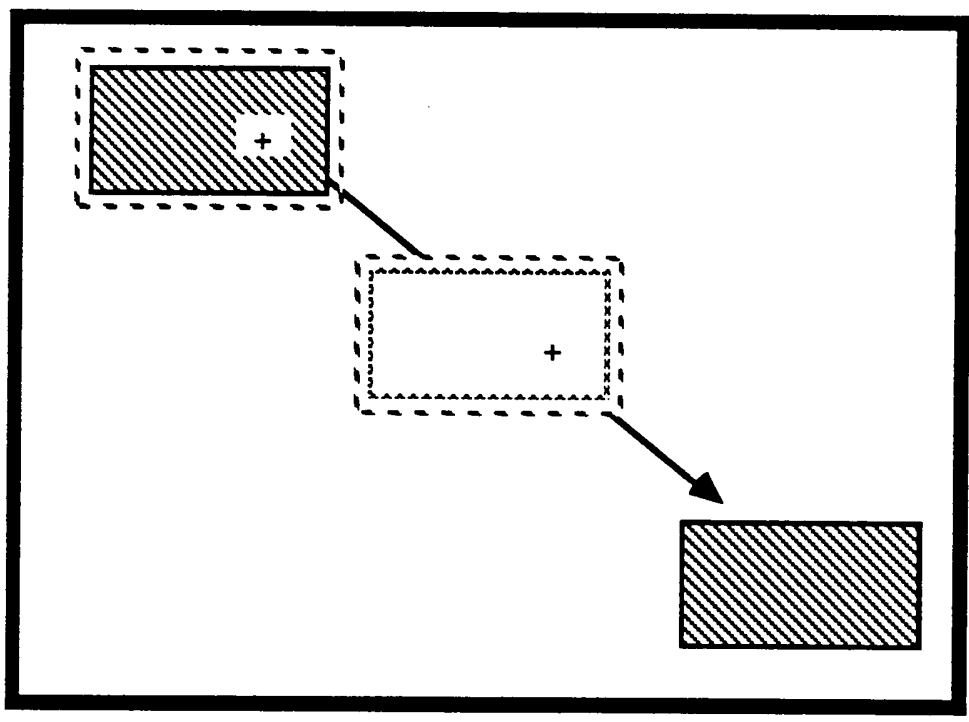

(b)

Figure 7. The bit-mapped interface requires the user to group the desired set of pixels (a) and then manipulate that group (b). 


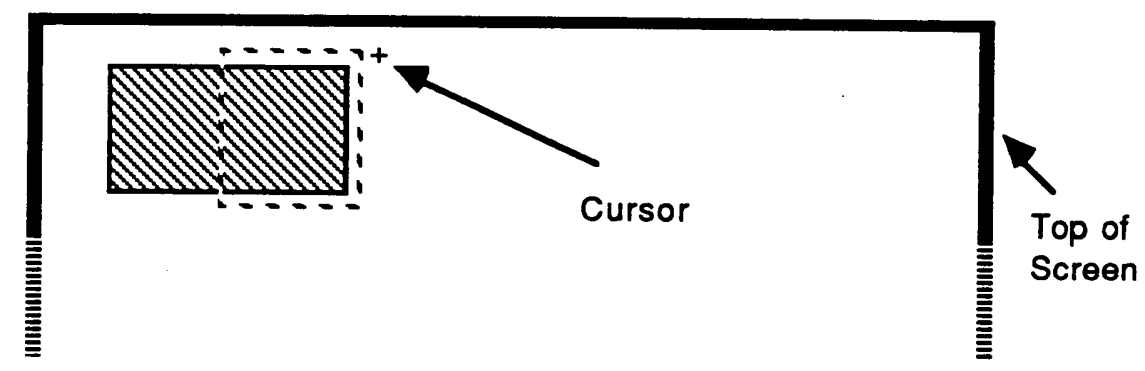

(a)

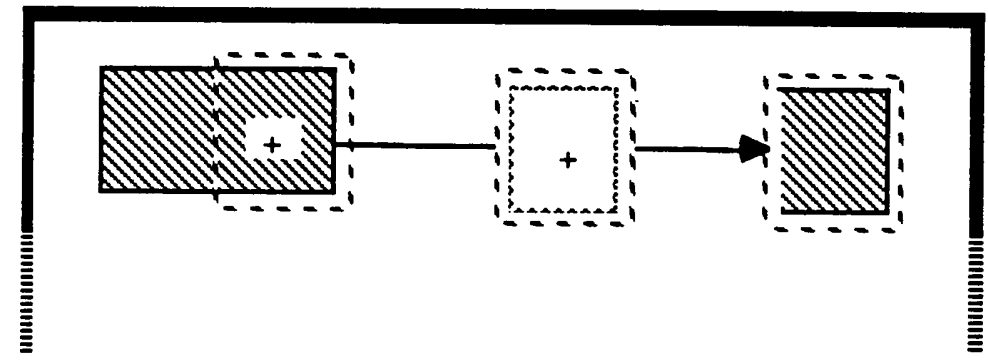

(b)

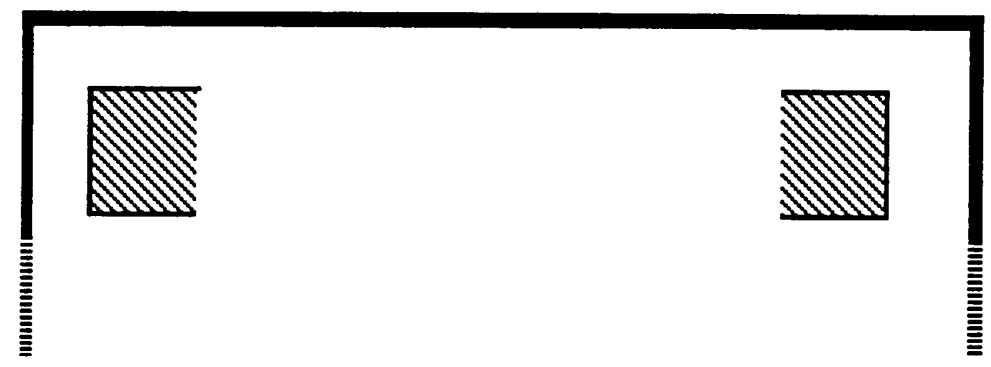

(c)

Figure 8. As seen in this figure, any group of pixels may be manipulated. 


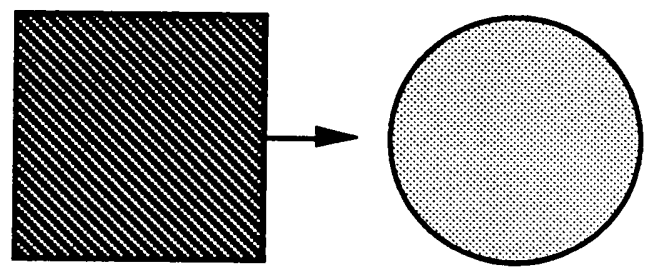

(a)

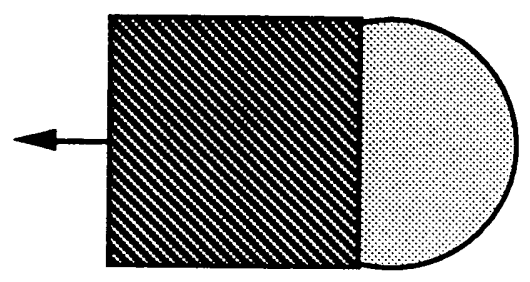

(b)
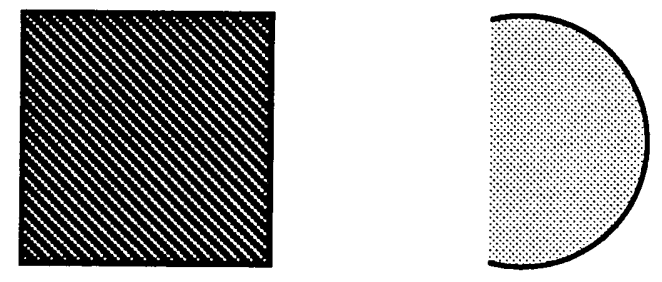

(c)

Figure 9. In the bit-mapped interface if one graphic is placed over another, the latter graphic will lose its integrity. In other words, the pixels underneath are no longer recognized. 
2. The interface recognizes only pixels and does not recognize graphic primitives or objects per se.

3. Any portion of a graphic or any pixel(s) may be manipulated independently.

\section{Purpose}

This thesis is concerned with the differences between object-oriented and bit-mapped interfaces and how these differences affect performance and preference of users. The focus of this study is on the different ways of drawing and manipulating graphics in each interface type. The types of tasks of interest are common to most applications; however, art applications are excluded from the realm of interest. In this context art applications include those tasks dominated by free-hand drawings, pictorial drawings, and other applications where users require artistic skills.

In short, the purposes of this study were twofold: (1) to develop some representative benchmark tasks for these two types of graphics interfaces, and (2) to evaluate which types of tasks are best handled on each interface. To date, no specific performance or preference data are available to support the advantages of one interface type over the other. The current study collected data using a set of benchmark tasks performed using both interfaces. 


\section{LITERATURE REVIEW}

Comparisons of various hardware configurations, software, and systems are not uncommon in human-computer interaction $(\mathrm{HCl})$ research. In previous studies researchers have compared text editing software and relevant hardware such as cursor control devices (Card, English, and Burr, 1978; Card, Moran, and Newell, 1980; Epps, 1986, 1987; Roberts and Moran, 1983). This section will describe the $\mathrm{HCl}$ literature where comparisons have been made. Of particular interest are the approaches and the items under investigation in these studies.

\section{Standardized Evaluation}

The comparison philosophy employed by most comparison and/or evaluation studies is the standardized evaluation. The standardized evaluation is contrasted with the specific evaluation (Roberts and Moran, 1983). A specific evaluation compares interfaces (or systems) with respect to a particular situation or condition. Thus, the idiosyncrasies of the interfaces may be of value and importance. In contrast, the standardized evaluation makes no specific assumptions about the interfaces being compared, nor about the specifics of the tasks they perform. In a standardized evaluation the goal is to focus on some basic and fundamental abilities that are common to the interfaces of interest, for 
example, methods by which the graphics interfaces allow users to rotate a line or scale (resize) a box. One may then compare the interfaces with respect to those basic, yet common abilities. Roberts and Moran (1983) cite the example of the Environmental Protection Agency (EPA) rating of automobile gas mileage to further explain the standardized evaluation. The EPA gas mileage rating is based on driving conditions that are common to most driving situations. Although these conditions do not perfectly match those that any one driver might encounter, they are adequately general to allow a comparison among cars (with respect to gas mileage).

Similarly, users of the object-oriented and bit-mapped interfaces may draw and manipulate graphics in both interfaces. Yet, for each interface type, users must use a different approach in manipulating the graphics. The current study uses the concept of standardized evaluations to compare graphics interfaces by comparing the differences in performing identical and generically typical graphics tasks.

\section{Benchmarking}

Benchmarking is a method for evaluating users' performance based on a fairly representative group of tasks. In system comparisons, most standardized evaluations are performed with the use of benchmark tasks. The underlying contention is that, given standard (benchmark) tasks, it is possible to perform direct comparisons among systems or software (Lewis 
and Crews, 1985). Lewis and Crews (1985) suggest that benchmark tasks be used for the evaluation of entire systems. However, other researchers have made a strong case for the use of benchmarks in comparing and evaluating interactive software interfaces (e.g., Gaylin, 1986; Magers, 1983; Roberts and Moran, 1983; Williges, Williges, and Elkerton, 1987).

Gaylin (1986) studied users of a windowing system to create representative windowing benchmark tasks. He observed and recorded tasks performed by nine expert users of the system. From the observations, Gaylin obtained windowing command frequencies and windowing types. The users rated each task (command) on the basis of frequency of use, usefulness, friendliness, complexity, naturalness, and importance. Based on the results of these ratings and the frequency of various commands (gathered from recorded performances), Gaylin (1986) was able to construct empirically based windowing benchmark tasks. He also indicated that the three most pertinent measures for creation of benchmark tasks are frequency of use, importance, and usefulness. Gaylin (1986) pointed out that objectively derived benchmark tasks are superior to benchmarks that are based on the experimenters' opinions.

\section{Hardware Evaluations}

Hardware comparisons have mostly evaluated cursor control and selection devices. These devices have been tested in use with both text editors and graphics software. In text editing the cursor control device is 
used mostly for text selection. Cursor control devices are used for drawing, selection, movement, etc. when used in conjunction with graphics software.

Card, English, and Burr (1978) compared four cursor control devices for a text selection task. Card et al. (1978) claimed that previous research had ignored certain factors of importance in cursor manipulation (through a cursor control device). These researchers compared a mouse, a ratecontrolled isometric joystick, step keys (arrow keys), and text keys for selecting a highlighted word or group of words in a page of text. The subjects' task was to notice the target word(s) and position the cursor on the target using each of the aforementioned cursor control devices. Card et al. (1978) took into consideration variables such as distance to target, target size, and approach angle. These researchers concluded that the mouse was the superior device for positioning time and error rates. In addition, Card et al. found that of the four devices the mouse rate of movement was near maximum for information processing capabilities of the eye-hand guidance system.

Albert (1982) studied the effect of 10 cursor control (graphical input) devices on user performance in a cursor positioning task. He compared three variations of a touchscreen, two variations of a lightpen, a data tablet, a trackball, a position joystick, a force joystick, and a keyboard. Subjects used these cursor control devices to place a cursor inside a 65-by-65-pixel target. Albert (1982) found that there was a definite speed-accuracy tradeoff. He found the trackball to be the most accurate device, yet it was 
one of the slowest as well. The touchscreen was the fastest device and among the least accurate.

In a study more directly related to graphics software, Epps (1987) compared six individually optimized cursor control devices on graphics editing tasks. The cursor control devices of interest were a mouse, a trackball, an absolute touchpad, a relative touchpad, a force joystick, and a displacement joystick. Subjects performed basic graphics tasks on a direct manipulation bit-mapped interface (Dr. Halo) using each of the cursor control devices. The graphics tasks included actions like drawing rectangles and lines, target acquisition, and other basic tasks. Epps (1987) found that the trackball and mouse were faster than the other devices and that they were preferred by subjects. However, no significant performance differences were found between the mouse and the trackball.

Sperling and Tullis (1987) evaluated the mouse and trackball with regard to speed and accuracy on generic tasks such as random selection, cursor positioning (in a box), and path tracing (following a semi-random path). For both the random selection and cursor positioning tasks, the mouse performed significantly faster than the trackball. However, there were no significant error rate differences. At the time of their report, Sperling and Tullis (1987) had not finished data collection on the path tracing task; however, they indicated that preliminary results showed the mouse is faster and less erroneous than the trackball.

These studies compared cursor control and selection devices in text editors (word processing software) and graphics software. The results 
suggest that, at least for the types of tasks these researchers used, the mouse compares favorably to other devices. In fact, Card et al. (1980) assumed the use of a mouse in their keystroke-level model.

\section{Software Evaluations}

Text editor software comparisons are well suited for the standardized evaluation. One of the most well known methodologies for the evaluation and comparison of text editors is that of Roberts and Moran (1983). These researchers used a standardized evaluation to compare nine different text editors for variables such as time to perform tasks, errors, learning, and functionality. Roberts and Moran (1983) selected a set of benchmark core editing tasks (developed by Roberts, 1980) as the basis from which to compare the editors. Some of the tasks they included in their benchmark were:

0 insert character(s)

0 insert word(s)

o delete word(s)

- move a line

- address a specified location

- make a document available for editing. 
The researchers attempted to exclude the types of tasks that might reflect the skill of the user rather than the quality of the text editor. This methodology was introduced as an easy-to-use means of comparing and evaluating text editors. The current study draws from Roberts and Moran (1983) the concept of the standardized evaluation through the use of benchmark tasks.

Card, Moran, and Newell (1980) presented the keystroke-level model to evaluate/compare performance with interactive systems. This model was introduced as a method for predicting the length of time required by an expert user to perform error-free work on a given computer system. The model takes into account such variables as typing speed, target acquisition (pointing) speed, homing and drawing speed, time for the users' mental preparation, and system response time. The researchers maintain that the time to execute an operation is simply the sum of each of the aforementioned time variables as they relate to the operation. Although the model does not address other parameters of user performance (such as errors, functionality, interface type, learning), it does provide for a method of comparing task performance times on different systems. This model was suggested for evaluating and comparing word processing, graphics, and other types of software and related hardware (both existing and in-design).

Using a similar approach, Whiteside, Jones, Levy, and Wixon (1985) evaluated high-level (e.g., file management) user interfaces on the parameters of ease of use, ease of learning, performance, and preference. Whiteside et al. used a benchmark file manipulation task (based on 
Magers, 1983) to compare the following software interfaces: command line, menu driven, and iconic. The task that subjects were required to perform was composed of subtasks such as operations on text files, displaying files, and merging and sending files to other users. These researchers found no ease-of-learning vs. ease-of-use tradeoff. In addition, they found that all the user interfaces suffered from identical interface problems in computer systems.

The important factor in this research is the Whiteside et al. (1985) use of a standard benchmark to test the interfaces. These researchers adopted a holistic approach in their standardized evaluation. That is, they compared the interfaces of interest and their respective systems as one package. Whiteside et al. (1985) claimed that the comparison of systems in their entirety would be more valid than testing the systems by comparing their component parts.

A similar approach in text editor comparisons was utilized by Downing, Jorna, Lloyd, Mohageg, and Snyder (1987) in a comparison of electronic memory typewriters. In this study, the researchers compared the Xerox memory typewriter (i.e., the Xerox 6020 Memorywriter) to those of three leading competitors. Downing et al. (1987) used benchmark tasks and the standardized evaluation approach to compare the typewriters' ease of use for both keyboard design and software issues. Subjects used the typewriters to perform typical office tasks similar to those used by Roberts and Moran (1983). The tasks included:

- table creation 

- block manipulations
- document accessing
o document creation.

\begin{abstract}
All subjects learned to use two machines: the Xerox typewriter and one of the others. Subjects performed the typical office tasks on both memory typewriters. Subsequently, the subjects completed questionnaires to provide subjective preference data about the two machines. Results indicated that the Xerox 6020 to be easier to use than the other three machines. The questionnaire data were found to be consistent, sensitive indicators of differences among typewriters.
\end{abstract}

\title{
Summary
}

The literature indicates that, for comparing interactive systems and/or software, the most valid method is to conduct a standardized evaluation with the use of appropriate benchmark tasks. Yet, it is in those exact areas that a void exists with respect to graphics software: (1) lack of objectively derived benchmark tasks and (2) lack of standardized evaluations of graphics software. This study fills those gaps by developing an appropriate set of objectively derived benchmark tasks and comparing two direct manipulation graphics interfaces through a standardized evaluation. 


\section{METHOD}

\section{Subjects}

Twenty-four subjects participated in the study. All subjects were volunteers from the Virginia Tech community and were compensated for their time.

Novices. Of the 24 subjects participating in this study 12 were classified as novices. A novice subject was one who had never used twodimensional graphics software. Some novices were aware that twodimensional graphics packages existed and had seen output (hard copy) from these packages. All novices had been exposed to computers, and most used other types of computer software for word processing, accounting, etc. None of the novices had used an Apple Macintosh ${ }^{\text {TM }}$ computer for any type of work. ${ }^{1}$

Experts. Experienced users of direct manipulation graphics interfaces constituted the second half of the subjects. All of the expert subjects had 1.5 to 2 years of experience with direct manipulation graphics software that

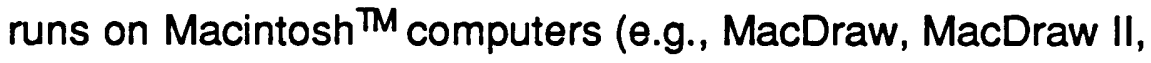

1 One subject indicated that he had used a Macintosh Plus ${ }^{T M}$ twice to perform some word processing. For the purposes of this study he was considered a novice. 
MacPaint, FullPaint, SuperPaint, etc.). Additionally, these subjects were required to meet predetermined time requirements before they were allowed to participate. Methods for deriving the time criteria and presentation of these criteria are described later.

\section{Apparatus}

Graphics interfaces (software). The object-oriented and bit-mapped interfaces were represented by two commercially available twodimensional graphics software packages. The MacDraw graphics program was selected to represent the object-oriented interface, while the bitmapped feature of the SuperPaint graphics package was used to represent the bit-mapped interface. Each program has its particular idiosyncrasies, special functions, and special capabilities. However, in adhering to the standardized evaluation concept, the package-specific functions were not investigated.

Hardware. The graphics software packages run on an Apple Macintosh II ${ }^{\mathrm{TM}}$ computer. Subjects used the Macintosh during all trials with both interfaces. Whiteside et al. (1985) indicated that many factors, including terminal used, keyboard used, size, character size, and presentation mode, may affect user performance in comparing interfaces. Thus, the Macintosh ${ }^{\mathrm{T}} \mathrm{TM}^{\mathrm{M}}$ served to standardize the hardware and to eliminate any confounds introduced through using the software packages on non-uniform hardware. 
The Macintosh II had an extended QWERTY keyboard, a mouse, and a 15-inch (diagonal) E-Systems monochrome CRT monitor. Eight subject work files contained both stimulus and work material. The standard Macintosh II monitor is only 9 inches, and subjects would have been required to scroll through the file while performing the tasks. The 15-inch monitor allowed subjects to view their entire work file without scrolling. Thus, an otherwise confounding variable (i.e., inconsistent scrolling) was eliminated.

Other equipment. A video (General Electric VHS) camera recorded all trials. The video camera was placed on a tripod and focused on the monitor to record all tasks performed by the subjects. These recordings were reviewed at a later date to extract the task completion time and repeated attempts data.

A Panasonic AG-7300 Super VHS video casette recorder was used to time the subjects' performance. The AG-7300 has the capability to play back standard play (SP) recordings at varying speeds (slower and faster than SP) and displays the frame count as it advances the tapes. Thus, the experimenter reviewed the recordings at the speed necessary to obtain accurate frame counts for each subject on every task. Since each frame is $1 / 30 \mathrm{~s}$, task completion times were computed by multiplying the frame count by $1 / 30 \mathrm{~s}$. The AG-7300 is capable of advancing tapes in frame-by-frame increments (i.e., $1 / 30$ of a second). This level of accuracy was especially 
helpful for determining the beginning and end of tasks and for task completion times of less than 3 seconds.

\section{Graphics Tasks}

Expert observations. Gaylin (1986) suggested the use of objective measures in creating benchmark tasks. For the present study, 20 expert users of the interfaces of interest were observed to determine the types of tasks that subjects should perform in the experiment (none of these experts were subjects in the experiment). These experts were mostly students (19 students and 1 staff member) from the Virginia Polytechnic Institute and State University community, and came from a variety of educational backgrounds: architecture, business administration, chemistry, computer science, electrical engineering, geology, human factors engineering, industrial engineering, mechanical engineering, and psychology. The author traveled to various campus computer laboratories or departments where direct manipulation graphics interfaces were widely used. The researcher approached individuals who were working with the interfaces and requested their permission to observe and record their activities (i.e., tasks) for 10-12 minutes. All observed experts had at least three years of experience with the package of interest and used the package on a regular basis. Half of these experts were users of object-oriented packages, while the other half were users of bit-mapped packages. Some of the graphics packages were Macintosh based while others were IBM $\mathrm{PC}^{\mathrm{TM}}$ or $\mathrm{P} / \mathrm{S}^{\mathrm{TM}}$ based. The focus of these observations was the basic tasks (graphic-action 
pairs) such as those listed in Table 1. Any (logical) application of the actions to the basic graphics primitives were considered suitable benchmark tasks. Examples of suitable benchmark tasks include:

- move a box

- rotate a line

- place a box within a circle.

The intention was to record the graphic-action combinations that experts were performing during their normal use of the graphics packages. These recordings were later reviewed to determine the tasks to be included in the benchmark.

Benchmark tasks. The process of creating a set of benchmark tasks was loosely based on research performed by Gaylin (1986) in creating windowing benchmark tasks. Gaylin stated that three factors were instrumental in determining which tasks should be included in the benchmark: usefulness, importance, and frequency of use. For the purposes of this study frequency of use (of graphic-action combinations) was the sole determinant for the tasks to be included in the benchmark. 
Table 1. Possible Graphic-Action Combinations.

\section{GRAPHICS}

Line

Box

Circle

Text

Groups

Part of graphic

\section{ACTIONS}

Increase size

Decrease size

Move

Copy

Rotate

Erase (delete)

Erase portion

Place within other object

Place adjacent to other object 
Gaylin's study focused on higher level windowing commands such as:

o cycling through windows

- switching edit buffers

o deleting menu window.

Since this investigation is somewhat different from that of Gaylin, only frequency of tasks was used since this dimension was believed to be most informative regarding tasks to be included in the benchmark. In contrast to Gaylin (1986), this thesis concentrated on low level tasks such as those in Table 1. Presumably, performing each of these tasks is important and useful in any graphics system; however, their frequency was unknown. Each graphic-action pair (task) frequency was determined by analysis of recorded user observations. Any task that appeared with a (rounded) frequency of more than $4.5 \%$ of the total number of tasks was included in the benchmark. Table 2 presents a list of the tasks performed by the observed experts; the rounded frequency of each task is also included. A brief description of some sample benchmark tasks is presented below:

- Draw a circle (or other graphic). Subjects drew a circle to within a tolerance level. For example, the subject was instructed to draw a circle such that it fit between two pre-existing circles on the screen.

- Move a box (or other graphic). For this task, subjects moved a box to a predetermined location on the screen. The box was to be positioned at the location within a specified tolerance limit. 
Table 2. Frequency of Tasks Recorded During Expert Observations. Tasks with Rounded Frequencies of $4.5 \%$ and Above were Included in the Benchmark.

\section{TASK}

Aligning Graphics

Copying Groups of Graphics

Copy Graphics

Copying Portions of Graphics

Copy Text

Draw Circle

Draw Curved Line

Draw Line

Draw Multisided Figure

Draw a graphic within another

Draw Box

Erase Graphics

Erase Portion of Graphics

Fill Graphics

Fine Manipulation

Move Groups of Graphics

Move a Graphic

Move one Graphic Adjacent to another

Move (Place) one Graphic inside another

Overlaying Graphics

Paste Graphics

Resize Graphics

Resizing as a Group

Rotate Graphics

Use of Text

Use Text inside Graphics

TOTAL

\section{RAW FREQ.}

PERCENTAGE

6

14

22

2

2

15

5

18

15

8

18

10

6

5

11

15

24

18

3

3

9

15

14

15

19

3

2.03

4.75

7.46

0.68

0.68

5.08

1.69

6.10

5.08

2.71

6.10

3.39

2.03

1.69

3.73

5.08

8.14

6.10

1.02

1.02

3.05

5.08

4.75

5.08

6.44

1.02

295.00

100.00 
- Resize (scale) a line (or other graphic). To resize a line, subjects altered the size of pre-existing lines to meet specified dimensions. Rulers were included in all files that required subjects to match specific dimensions.

- Copy, resize, and move circle. Subjects copied an existing circle, resized the circle to specific dimensions, and, finally, moved it to a predetermined location.

- Create menu. To complete this complex task, subjects used the interfaces to create a computer menu. A hard copy of the menu was provided to the subjects as stimulus material. The necessary dimensions and requirements were also included. Subjects were asked to match the specifications of the hard copy menu as closely as possible.

Appendix I includes printed samples of the computer files that subjects were given to complete the tasks. Instructions for task completion were included in each file. A review of this appendix will provide the reader with a better understanding of the types of tasks included in the benchmark. In all there were 29 tasks distributed among 8 files (as illustrated in Appendix 1). Subjects opened a file, completed the task(s) therein, saved the file (and their manipulations), and advanced to the next file.

Task complexity. Task complexity refers to the number of different actions performed to complete a graphics task. The benchmark tasks were classified into three levels of complexity: basic, mid-range, and 
complex. These three levels may be viewed as "locations" on a task complexity continuum (Figure 10). Basic tasks were operationally defined as those requiring the use of less than two graphic-action combinations to reach the goal (Table 1), such as moving a box to a specified location on the screen. Mid-range tasks were defined as involving three or four graphic-action combinations. Moving a box, resizing it, and attaching it to a pre-drawn line is an example of a mid-range task. Complex tasks required subjects to use more than four different actions to achieve the goal. Based on these criteria it is possible that a graphic which appears simple may require the user to perform many differing operations, while a "complicated looking" graphic might be done with repetitive use of one or two simple operations. Thus, a task requiring the use of 4 different actions is more complicated than a task requiring 12 repetitions of a single action. Each higher level task automatically includes (and requires) the use of lower levels tasks; they are differentiated based solely on the number of different manipulations per task.

The classifications of basic, mid-range, and complex are used to identify groups of benchmark tasks. Of the 29 benchmark tasks 23 were basic, 4 were mid-range, and 2 were complex.

\section{Experimental Design}

A three-way factorial mixed-factors design was used for data collection on each task. The independent variables were interface type, trials, and 


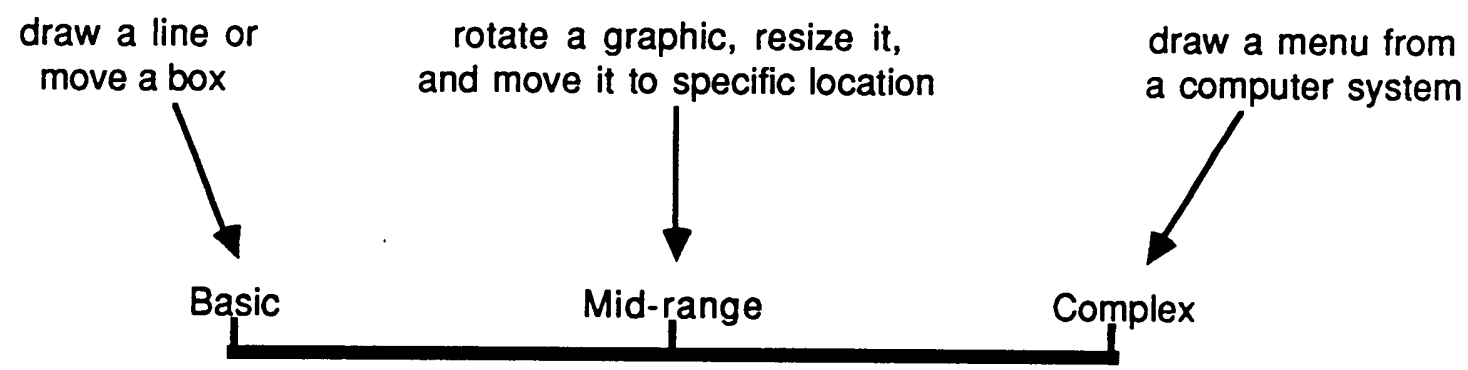

TASK COMPLEXITY CONTINUUM

Figure 10. The task complexity continuum. 
user experience. Interface type and trials were within-subject variables. Interface type had two levels: object-oriented and bit-mapped interfaces. Subjects performed each benchmark task five times. Thus, the trial variable had five levels (trials 1 through 5). User experience was a between-subjects variable with two levels: novice and experienced. Figure 11 illustrates the experimental design for each of the 29 tasks.

\section{Dependent Measures}

The goal of the study was to collect both objective and subjective data; therefore, dependent measures were of two types: (1) performance and (2) preference.

Performance measures. Performance measures consisted of (1) task completion time, (2) number of repeated attempts to perform the task, (3) errors, and (4) learning time. Completion time for each task was measured in seconds per graphics task. Each task's completion time was measured by converting frame counts (counted by the Panasonic AG-7300 VCR) to time.

For task timing purposes the start and end of task performance were defined as follows. The first press of the mouse to begin the action signaled the start of the task, and the point at which the subject had achieved satisfactory results signaled the end of the task. Multiple attempts 


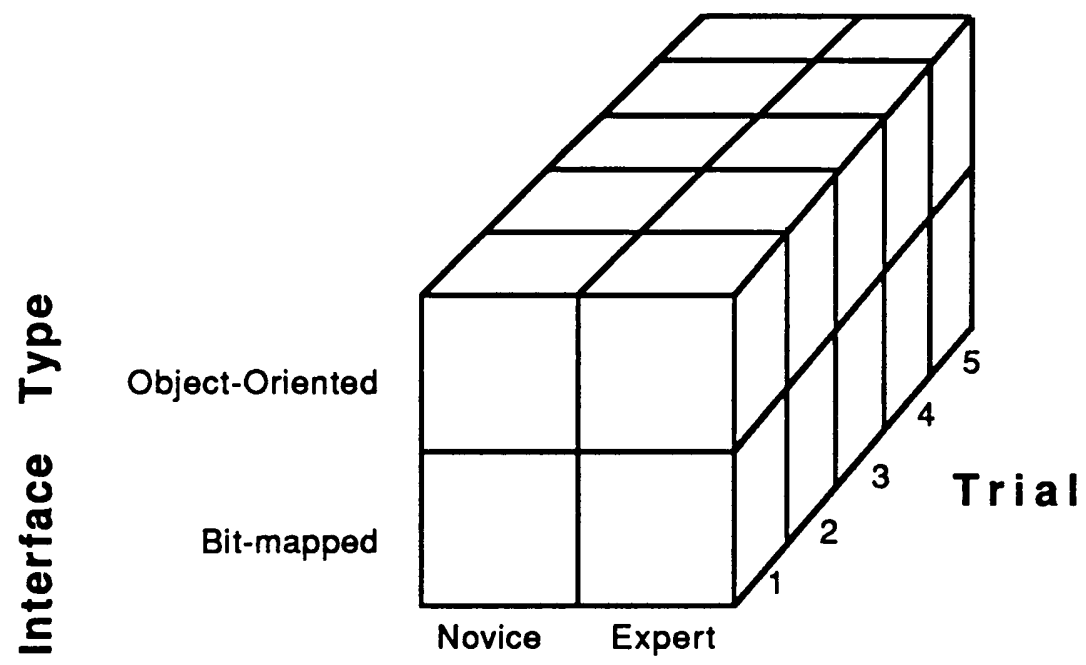

Subject Experience

Figure 11. The experimental design used for data collection on each task. 
to perform the task were not included as part of task completion time. Only correct performance (i.e., subject's final attempt) was timed. The number of attempts to complete the task was recorded as a separate measure. For example, a subject may start a task, but not complete it on that attempt. The subject may then decide to start the task again from the beginning. The first attempt was not included in the task completion time, but the frequency of failed/aborted attempts was recorded.

Errors were the third performance measure. In this study two types of errors were recorded: errors of omission and errors of commission. Any part of a task that the subject failed to perform was considered an error of omission. For instance, a task might require the subject to rotate and move a graphic. If the subject only moved the graphic, then failure to rotate it was considered an error of omission. The frequency of these errors was recorded on every task for each subject.

An error of commission occurred if the subject completed a task, but committed observable errors. For the purposes of this study there were two types of commissive errors: size errors and positioning errors. In many tasks the subjects were required to draw or resize graphics to match specified dimensions. Deviations (in drawing or resizing) of 1/16 in. (1.6 $\mathrm{mm}$ ) or greater were recorded as errors of commission. Measurements of deviation were made by using the graphics packages' rulers, and the amount of deviation was recorded. In the case of line measurements inches were the unit of measure. Square inches were the unit of measure in dealing with boxes and circles (i.e., the area). Where necessary, the 
subjects were provided with identical rulers for both interfaces during task performance.

Positioning errors were classified dichotomously as either inside or outside pre-specified tolerance boundaries. In some tasks subjects positioned or moved graphics. If the graphic was positioned within tolerance limits no error was recorded; however, in cases where placement was outside the limits an error was recorded. No measurement of the size of these deviations was necessary.

Learning was measured in terms of changes in task completion time over trials. The subjects performed five trials for each of the 29 tasks. These repetitions are represented by the trials in Figure 7.

Preference measures. Subjects' preferences were measured through two types of questionnaires. First, subjects had an opportunity to rate each interface type on an absolute basis. Subjects rated the interface (i.e., software package) after using each to perform the tasks. The questionnaire used a bipolar rating scale (interval data) ranging from 1 to 7 to measure subject ratings for ease of use. The scale was anchored with the adjectives "easy to do" and "hard to do" (see Appendix II for this questionnaire).

After subjects performed the trials on both interfaces, they completed a comparison questionnaire. In this questionnaire subjects made a relative choice between the two interfaces for performing the various tasks (see Appendix III for the comparison questionnaire). In addition, subjects rated 
each interface on a scale on 1 to 10 for overall preference, 1 being the lowest rating and 10 being highest.

\section{Procedure}

The experiment was divided into two sessions. During the first session subjects were informed about the study and required to sign informed consent and photographic release forms (see Appendix IV for forms). Novice subjects started training on the first software package immediately. Subjects were trained to perform only the benchmark tasks. Novices were given a training manual which taught them how to perform the types of tasks that would be required of them in the study. The training materials for the two interfaces were identical in number of useful examples, sentence structure, font, graphics, etc. The manuals differed only to the extent that performing tasks differed on the two interfaces (see Appendix $V$ for training manuals). All novice subjects read through the manuals and performed the practice tasks outlined therein. Training lasted about one hour.

Following the training, subjects were timed, with a stopwatch, on performing some basic reference tasks. The experimenter timed the subjects to certify that a minimum standard of learning had occurred, and that all novices could meet those minimum criteria. The time criteria for the tasks were based on task completion times obtained from 3 novice pilot subjects (see Appendix VI for a list of these tasks and the time requirements). The subjects' task times were required to be within one 
standard deviation of the pilots' mean times. One subject was released and replaced for failure to meet the time criteria.

Upon successful completion of training, subjects performed the 29 benchmark tasks five times on the first interface, and completed the absolute rating questionnaire. This brought the first session to an end.

During the second session the same training, timing, data collection, and questionnaire completion procedure was used. At this session the second interface was tested, and subjects completed the absolute rating for the second interface. Subjects then completed the comparison questionnaire in which they made relative comparisons. Finally, subjects were debriefed and paid.

The experimental procedure was similar for experienced subjects. However, training was replaced with a test of the subjects' expertise on the interfaces. In addition to having 1.5 to 2 years of experience with both graphics packages, all experienced subjects were timed for their performance on 3 reference tasks before participating in the study. These reference tasks were identical to those performed by novices after their training period. Subjects classified as experts were required to meet predetermined time criteria. The time criteria were based on task times as performed by the 20 expert users who were observed prior to the study. Experienced subjects were not allowed to participate unless their times were within one standard deviation of the sample experts' mean times (see Appendix VI). Two subjects claiming to be experienced did not meet the time criteria and were replaced. 
The above described scheme is not a proven methodology for determining user expertise for graphics software. The criteria were established for the purposes of this study, and served solely to ensure that all so-called "experienced" subjects were above a minimum baseline.

Order of presentation. The order of presentation of the interface types was counterbalanced to minimize any systematic learning or order effects. Half the subjects used the object-oriented interface first, while the other half used the bit-mapped interface first.

The presentation of benchmark tasks was organized in a basic-tocomplex progression. All subjects started with the basic tasks, moved on to the mid-range tasks, and finished with the complex tasks. Subjects completed the tasks five times (trials) in this order. That is, subjects performed all tasks once, then performed all tasks a second time, and so forth till the fifth trial. This progression was used so subjects could become familiar with the types of tasks required of them by beginning with relatively simple actions. Random presentation of the tasks could have lead to a high degree of variability in the task completion times and was thus avoided. There were four subject work files that contained only basic tasks. In one file subjects simply drew two lines, a rectangle, a circle, and a triangle. For files 2,3 , and 4 subjects manipulated lines, circles, and boxes, respectively. The ordering of these four basic task work files was completely counterbalanced. 
BLANK PAGE 


\section{RESULTS}

The nature of the different dependent measures determined the type of statistical test used to analyze the data. This section lists each dependent measure separately, discusses the statistical tests used for the measure, and presents the results thereof.

\section{Performance Measures}

Task completion time. For each of the benchmark tasks, a three-way analysis of variance (ANOVA) was used to test the effects of the independent variables (i.e., interface, experience, trials, and their interactions) on the task completion times. Appendix VII presents the ANOVA summary tables for each task (29 in all). Table 3 presents the mean task completion times for the two interfaces and indicates the respective significant p-values. Table 4 presents the mean task completion times on each interface for the two groups of subjects. Table 5 presents a list of tasks and the sources of variance that were significant for each ANOVA. The main results are summarized as follows:

1. The object-oriented interface had significantly smaller task completions times than the bit-mapped interface for all 29 tasks except for the following basic drawing tasks: drawing a line, drawing a box, drawing a circle, drawing a triangle, a mid-range task where grouping and moving graphics was required, and a complex 
Table 3. Mean Task Completion Times (s) for Each Interface and the Resulting p-Values.

\begin{tabular}{|l|r|r|l|}
\hline \multicolumn{1}{|c|}{ ThSK } & $\begin{array}{r}\text { OBJECT } \\
\text { ORIENTED }\end{array}$ & $\begin{array}{c}\text { BIT- } \\
\text { MAPPED }\end{array}$ & p \\
\hline Draw single horizontal line & 2.37 & 2.47 & \\
Draw single vertical line & 2.21 & 2.22 & \\
Draw a box & 3.36 & 3.53 & \\
Draw a circle & 4.58 & 5.05 & \\
Draw a triangle & 9.94 & 10.96 & \\
Move and position a line & 3.82 & 7.58 & 0.0001 \\
Move line 1 & 3.73 & 8.05 & 0.0001 \\
Move line 2 & 4.47 & 8.62 & 0.0001 \\
Enlarge line 1 to specified dimension & 9.55 & 18.48 & 0.0001 \\
Enlarge line 2 to specified dimension & 10.12 & 14.51 & 0.0003 \\
Reduce line 3 to specified dimension & 9.35 & 16.70 & 0.0001 \\
Reduce line 4 to specified dimension & 7.74 & 16.06 & 0.0001 \\
Position line adjacent to box & 4.92 & 8.35 & 0.0001 \\
Move box & 4.11 & 8.67 & 0.0001 \\
Position box adjacent to another & 3.89 & 7.52 & 0.0001 \\
Enlarge box to specified dimensions & 18.12 & 36.66 & 0.0001 \\
Reduce box to specified dimensions & 23.55 & 32.39 & 0.0002 \\
Move and position box & 4.19 & 8.21 & 0.0001 \\
Position circle adjacent to another & 3.57 & 6.79 & 0.0001 \\
Move and position circle & 4.15 & 6.76 & 0.0001 \\
Enlarge circle to specified dimension & 18.82 & 37.17 & 0.0001 \\
Reduce circle to specified dimension & 21.58 & 33.06 & 0.0002 \\
Move circle & 4.37 & 6.65 & 0.0001 \\
Copy, resize, and move circle & 37.96 & 62.05 & 0.0001 \\
Copy, resize, and move group of boxes & 61.92 & 72.57 & \\
Rotate and move group of graphics & 30.86 & 32.68 & \\
Draw and position simple graphic & 125.13 & 170.90 & 0.0014 \\
Rotate, resize, position, and organize & 178.33 & 314.21 & 0.0001 \\
graphics & & & \\
Draw and position graphics & 323.57 & 366.09 & 0.0161 \\
\hline
\end{tabular}


Table 4. Mean Task Completion Times (s) for Each Interface by Subject Experience.

\begin{tabular}{|c|c|c|c|c|}
\hline \multirow[b]{2}{*}{ TASK } & \multicolumn{2}{|c|}{ OBJECT-ORIENTED } & \multicolumn{2}{|c|}{ BIT-MAPPED } \\
\hline & EHPER. & NOUICES & EHPER. & NOUICES \\
\hline Draw single horizontal line & 1.99 & 2.76 & 2.16 & 2.78 \\
\hline Draw single vertical line & 1.87 & 2.56 & 1.99 & 2.45 \\
\hline Draw a box & 2.98 & 3.73 & 3.06 & 4.01 \\
\hline Draw a circle & 3.48 & 5.68 & 3.90 & 6.20 \\
\hline Draw a triangle & 9.33 & 10.55 & 10.69 & 11.23 \\
\hline Move and position a line & 3.17 & 4.48 & 6.22 & 8.94 \\
\hline Move line 1 & 3.43 & 4.04 & 6.51 & 9.59 \\
\hline Move line 2 & 3.97 & 4.96 & 7.34 & 9.89 \\
\hline Enlarge line 1 to specified dimension & 8.01 & 14.39 & 11.09 & 22.57 \\
\hline Enlarge line 2 to specified dimension & 8.33 & 11.91 & 12.82 & 16.20 \\
\hline Reduce line 3 to specified dimension & 7.81 & 10.81 & 14.54 & 18.85 \\
\hline Reduce line 4 to specified dimension & 7.17 & 13.72 & 8.31 & 18.39 \\
\hline Position line adjacent to box & 4.02 & 5.83 & 7.08 & 9.63 \\
\hline Move box & 3.71 & 5.11 & 7.17 & 10.17 \\
\hline Position box adjacent to another & 3.53 & 4.24 & 6.30 & 8.73 \\
\hline Enlarge box to specified dimensions & 15.13 & 21.11 & 28.11 & 45.21 \\
\hline Reduce box to specified dimensions & 19.18 & 27.91 & 26.87 & 37.91 \\
\hline Move and position box & 3.83 & 4.56 & 6.95 & 9.47 \\
\hline Position circle adjacent to another & 3.34 & 3.80 & 5.53 & 8.06 \\
\hline Move and position circle & 3.63 & 4.68 & 5.92 & 7.60 \\
\hline Enlarge circle to specified dimension & 15.17 & 22.46 & 29.21 & 45.13 \\
\hline Reduce circle to specified dimension & 17.41 & 25.75 & 26.86 & 39.26 \\
\hline Move circle & 4.06 & 4.67 & 6.55 & 6.75 \\
\hline Copy, resize, and move circle & 29.94 & 46.68 & 49.29 & 74.80 \\
\hline Copy, resize, and move group of boxes & 38.51 & 85.32 & 57.52 & 87.62 \\
\hline Rotate and move group of graphics & 22.78 & 38.95 & 25.91 & 39.45 \\
\hline Draw and position simple graphic & 94.00 & 156.25 & 140.07 & 201.73 \\
\hline $\begin{array}{l}\text { Rotate, resize, position, and organize } \\
\text { graphics }\end{array}$ & 140.29 & 216.38 & 251.40 & 377.02 \\
\hline Draw and position graphics & 269.00 & 334.63 & 368.13 & 395.54 \\
\hline
\end{tabular}


Table 5. Significant Sources of Variance From Each Task's ANOVA Summary Table. "A," "B," and " $\mathrm{C}$ " indicate significance values of $<0.05,<0.01$, and $<0.001$, respectively. Interface, Experience, and Trial are denoted by "I," "E," and " $T$ ", respectively.

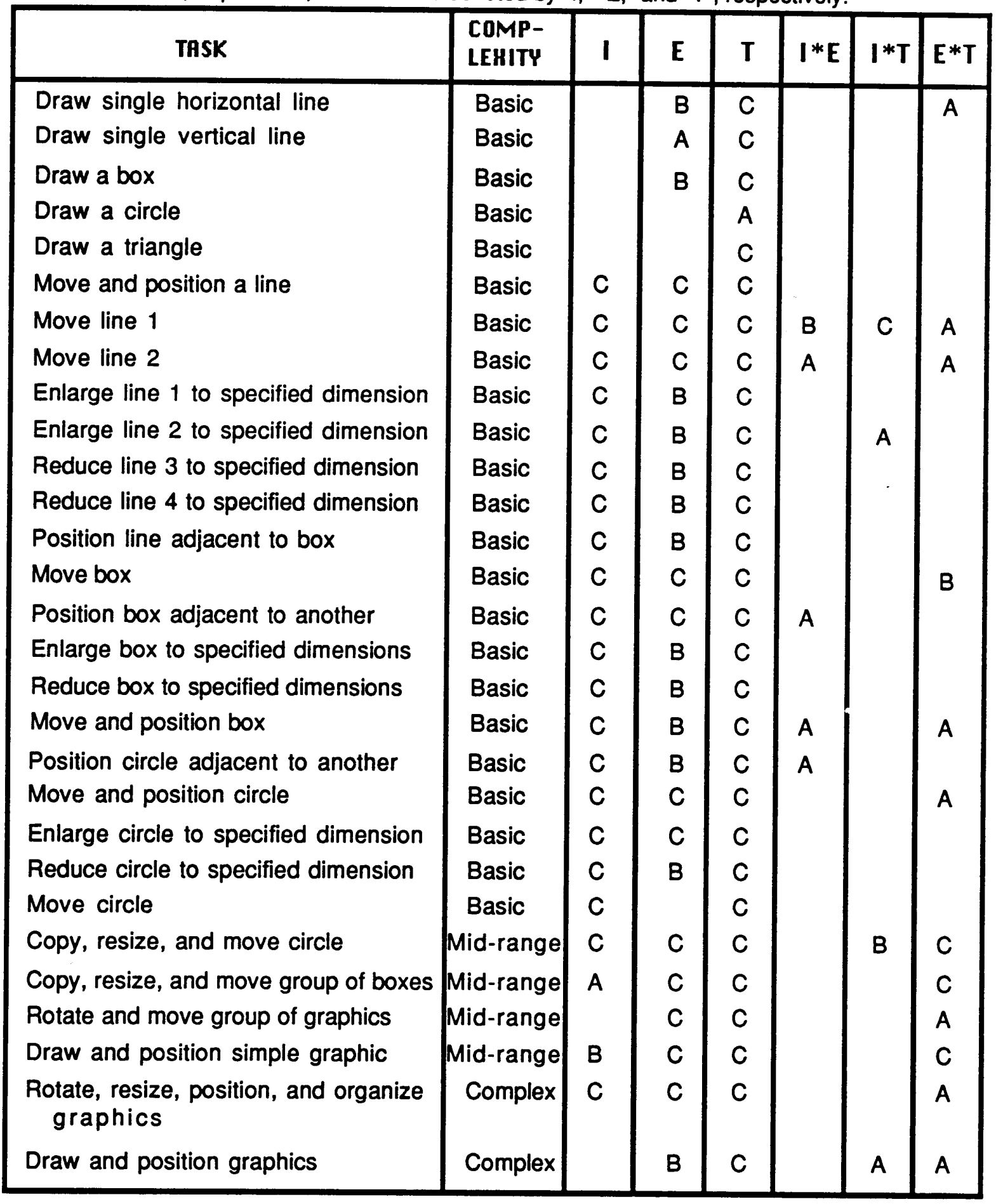


drawing task.

2. Except for drawing a circle, drawing a triangle, and moving a circle, experienced subjects completed tasks more quickly than novice subjects.

3. The trial effect was significant in every task. A Newman-Keuls post hoc test $(p \leq 0.05)$ revealed that for most tasks there were significant differences among trials 1, 2, and 3; however, for the most part no differences existed among trials 3,4 , and 5 . In no case was there a significant difference between trials 4 and 5 . Thus, one may surmise that subjects achieved asymptotic task performance by the third or fourth trial.

4. The interface-by-experience interaction was significant for five tasks. These tasks were moving lines 1 and 2 , placing a box adjacent to another, moving and positioning a box, and placing a circle adjacent to another. Figures 1, 2, and 3 in Appendix VIII illustrate these interactions. A Newman-Keuls test revealed that in every case the difference between experts' and novices' mean task completion times was nonsignificant for the object-oriented interface. However, novices perform significantly slower than experts on the bit-mapped interface.

5. Four of the 29 tasks had a significant interface-by-trial interaction. The significant time differences among the blocks for each interface 
provided an indication of learning. These interactions will be discussed in detail later.

6. The experience-by-trial interaction was significant for 10 tasks. Newman-Keuls tests indicated that for these tasks the experts' task completion times dropped more rapidly over the 5 trials than did those of the novices. This issue is not of great significance since it was expected that experienced subjects, due to their knowledge of the interfaces, would reach asymptotic performance earlier than novices.

7. The interface-by-experience-by-trial interaction was not significant for any tasks.

The ANOVAs for each task were repeated to investigate differences in task completion times for asymptotic performance (i.e., the mean of trials 4 and 5 only). Here, the ANOVAs had two independent variables: interface and subject experience. For asymptotic performance the sources of variance for the ANOVAs were identical to their previously described counterparts. Each effect that was significant for the overall task completion times was also significant for asymptotic (practiced) performance. The only exception was that no task completion time difference existed between the interfaces for the menu drawing task (the final task in the benchmark).

Number of repeated/aborted attempts. As stated previously, task completion time for correct performance was recorded. The number of repeated or restarted tasks that a subject performed was recorded as 
repeated/aborted attempts. The frequency of these attempts was recorded for each subject on each interface per task per trial. With the data classified by interface, task, and trial for each subject, the assumptions of many statistical tests were not met. Thus, the data were collapsed across trial and subject, and a binomial test was used to test for differences between the two interfaces on each task. Table 6 lists the number of attempts for each task and presents the binomial test results ( $p$-values) for the tasks. Sixteen of the 29 tasks yielded a significant difference in frequency of repeated/aborted attempts. For all of the 16 significant differences, there were fewer repeated attempts for the object-oriented interface. Additionally, a binomial test of the total repeated attempts showed that there were significantly fewer total repeated/aborted attempts for the objectoriented interface (58) than for the bit-mapped (310), $z=13.136, p=$ 0.00003 . Expert subjects required significantly fewer attempts (144) than did novice subjects (224), $z=4.17, p=0.00003$.

Errors of omission. Potentially, a subject may have committed 35 errors of omission per trial. In all there were 24 subjects, and 10 trials per subject (5 on each interface). Thus, there were 8400 possible errors of omission. However, during the course of the entire study subjects committed only three errors of omission ( 2 on the object-oriented interface and 1 on the bitmapped interface). Since the frequency of these errors was extremely small no statistical analyses were conducted. This measure was considered insensitive to the independent variables. 
Table 6. Frequency of Repeated/Aborted Attempts for Each Interface and p-Values.

\begin{tabular}{|l|c|c|c|}
\hline \multicolumn{1}{|c|}{ ThSK } & $\begin{array}{c}\text { OBJECT- } \\
\text { ORIENTED }\end{array}$ & BIT-MAPPED & D \\
\hline Draw single horizontal line & 0 & 0 & \\
Draw single vertical line & 1 & 1 & \\
Draw a box & 1 & 2 & \\
Draw a circle & 26 & 54 & 0.0018 \\
Draw a triangle & 4 & 7 & \\
Move and position a line & 1 & 19 & 0.001 \\
Move line 1 & 0 & 14 & 0.001 \\
Move line 2 & 0 & 6 & 0.032 \\
Enlarge line 1 to specified dimension & 2 & 12 & 0.012 \\
Enlarge line 2 to specified dimension & 0 & 6 & 0.032 \\
Reduce line 3 to specified dimension & 0 & 5 & \\
Reduce line 4 to specified dimension & 0 & 6 & 0.032 \\
Position line adjacent to box & 0 & 14 & 0.001 \\
Move box & 1 & 35 & 0.00006 \\
Position box adjacent to another & 1 & 17 & 0.001 \\
Enlarge box to specified dimensions & 0 & 5 & \\
Reduce box to specified dimensions & 0 & 3 & \\
Move and position box & 0 & 10 & 0.002 \\
Position circle adjacent to another & 0 & 12 & 0.001 \\
Move and position circle & 0 & 13 & 0.001 \\
Enlarge circle to specified dimension & 2 & 15 & 0.002 \\
Reduce circle to specified dimension & 0 & 34 & 0.00006 \\
Move circle & 3 & 1 & \\
Copy, resize, and move circle & 2 & 11 & 0.022 \\
Copy, resize, and move group of boxes & 6 & 7 & \\
Rotate and move group of graphics & 8 & 2 & \\
Draw and position simple graphic & 0 & 0 & \\
Rotate, resize, position, and organize & 0 & 3 & \\
graphics & & 3 & \\
Draw and position graphics & 0 & & \\
\hline
\end{tabular}


Errors of commission. The size deviations were analyzed similarly to the task completion time data. In all there were 20 possible deviation errors. A three-way ANOVA was used to test the size deviations for each of the 20 errors. Appendix IX presents the ANOVA summary tables for each size error (20 in all). Table 7 lists the errors and indicates which sources of variance were significant in their respective ANOVAs. Tables 8 and 9 present the mean deviation for each error. A few important conclusions may be gathered from reviewing these data:

1. The interface type had an effect on size deviation in 10 of the 20 possible errors, and all of these tasks indicated significantly smaller deviation for the object-oriented interface than for the bit-mapped interface.

2. Trials was a significant effect only when enlarging and reducing a box. Trials was not a significant factor for any other tasks.

3. Except for two tasks, experience did not have a significant effect on size deviations. In both instances experienced subjects had significantly smaller error than their novice counterparts.

4. The experience-by-trial interaction was the only two-way interaction that yielded a significant effect. This interaction was significant for three tasks. Newman-Keuls tests indicated that in these tasks experienced and novice subjects had similar amounts of error during the 1 st trial (not significantly different at $p<0.05$ ). On subsequent trials the amount of error steadily and significantly declined for 
Table 7. Significant Sources of Variance From Each Error's Summary Table. "A," "B," and " $C$ " indicate significance values of $<0.05,<0.01$, and $<0.001$, respectively. Interface, Experience, and Trial are denoted by "I," "E," and "T", respectively.

\begin{tabular}{|c|c|c|c|c|c|c|c|}
\hline SIZE ERROR & $\begin{array}{l}\text { COMP- } \\
\text { LEHITY }\end{array}$ & I & $\mathbf{E}$ & $\mathbf{T}$ & $I * E$ & $\mathbf{I} * \mathbf{T}$ & E*T \\
\hline Lines enlarged to incorrect size & Basic & A & & & & & \\
\hline Lines reduced to incorrect size & Basic & & & & & & \\
\hline Box enlarged to incorrect size & Basic & A & A & & & & \\
\hline Box reduced to incorrect size & Basic & A & A & & & & \\
\hline Circle enlarged to incorrect size & Basic & c & & & & & \\
\hline Circle reduced to incorrect size & Basic & B & & & & & \\
\hline Circle size is incorrect & Mid-range & A & & & & & \\
\hline Group's horizontal dimension is off & Mid-range & & & & & & A \\
\hline Group's vertical dimension is off & Mid-range & A & & & & & \\
\hline Vertical lines drawn to incorrect size & Mid-range & & & & & & \\
\hline Horizontal lines drawn incorrectly & Mid-range & & & & & & \\
\hline Left box size is incorrect & Mid-range & & & c & & & B \\
\hline Right box size is incorrect & Mid-range & & & $\mathrm{C}$ & & & B \\
\hline Desk size is incorrect & Complex & B & & & & & \\
\hline Desk return size is incorrect & Complex & A & & & & & \\
\hline Book size is incorrect & Complex & B & & & & & \\
\hline Menu bar size is incorrect & Complex & & & & & & \\
\hline Menu size is incorrect & Complex & & & & & & \\
\hline Menu position is incorrect & Complex & & & & & & \\
\hline Menu circle size is incorrect & Complex & & & & & & \\
\hline
\end{tabular}


Table 8. Size Deviation Errors (in.) for Items With Linear Errors.

\begin{tabular}{|l|c|c|c|}
\hline \multicolumn{1}{|c|}{ ERAOR } & $\begin{array}{c}\text { OBJECT- } \\
\text { ORIENTED }\end{array}$ & $\begin{array}{c}\text { BIT- } \\
\text { MAPPED }\end{array}$ & p \\
\hline Lines enlarged to incorrect size & 0.011 & 0.042 & 0.0129 \\
Lines reduced to incorrect size & 0.019 & 0.030 & \\
Group's horizontal dimension is off & 0.002 & 0.010 & \\
Group's vertical dimension is off & 0.001 & 0.009 & 0.0365 \\
Vertical lines drawn to incorrect size & 0.006 & 0.008 & \\
Horizontal lines drawn incorrectly & 0.002 & 0.003 & \\
\hline
\end{tabular}


Table 9. Size Deviation Errors (Sq. Inches) for Area Errors.

\begin{tabular}{|l|c|c|c|}
\hline \multicolumn{1}{|c|}{ ERROR } & $\begin{array}{c}\text { OBJECT- } \\
\text { ORIENTED }\end{array}$ & $\begin{array}{c}\text { BIT- } \\
\text { MAPPED }\end{array}$ & p \\
\hline Box enlarged to incorrect size & 0.009 & 0.043 & 0.0377 \\
Box reduced to incorrect size & 0.004 & 0.015 & 0.0174 \\
Circle enlarged to incorrect size & 0.003 & 0.249 & 0.0001 \\
Circle reduced to incorrect size & 0.020 & 0.135 & 0.0019 \\
Circle size is incorrect & 0.002 & 0.015 & 0.0278 \\
Left box size is incorrect & 0.001 & 0.006 & \\
Right box size is incorrect & 0.002 & 0.007 & \\
Desk size is incorrect & 0.016 & 0.120 & 0.0022 \\
Desk return size is incorrect & 0.002 & 0.025 & 0.0486 \\
Book size is incorrect & 0.001 & 0.021 & 0.0019 \\
Menu bar size is incorrect & 0.036 & 0.040 & \\
Menu size is incorrect & 0.026 & 0.035 & \\
Menu position is incorrect & 0.002 & 0.034 & \\
Menu circle size is incorrect & 0.000 & 0.017 & \\
\hline
\end{tabular}


experienced subjects, while novice errors were erratic, on some trials being significantly greater than and others being similar to the expert errors.

As with the aborted attempts, the frequency of position errors was recorded for each subject on each interface per task for each trial. With the data classified by interface, task, and trial for each subject, the assumptions of many statistical tests were not met. Consequently, the data were collapsed across trial and subject experience, and a binomial test was used to test for differences between the two interfaces on each positioning error. Table 10 lists the number of occurrences for each positioning error and presents the binomial test results for each error. A binomial test was used to also compare the total number of positioning errors for the interfaces and subject experience. Results yielded significantly fewer total positioning errors for the object-oriented $(9)$ interface than for the bitmapped interface (32), $z=3.44, p<0.0006$. In addition, experienced subjects committed fewer errors (14) than did novice subjects (27), $z=2.03$, $p<0.0424$.

Learning time. Differential learning effects were observed in four of the 29 tasks (as indicated by the interface-by-trial interactions). These tasks were moving a line; enlarging a line; a mid-range task of copying, resizing, and moving a circle; and a complex task in which subjects created 
Table 10. Frequency of Positioning Errors.

\begin{tabular}{|c|c|c|c|}
\hline TASK & $\begin{array}{l}\text { OBJECT- } \\
\text { ORIENTED }\end{array}$ & BIT-MAPPED & p \\
\hline Horizontal line drawn beyond limit & 0 & 1 & \\
\hline Vertical line drawn beyond limit & 0 & 0 & \\
\hline Box drawn out of tolerance & 0 & 0 & \\
\hline Circle drawn out of tolerance & 1 & 10 & 0.022 \\
\hline triangle drawn out of tolerance & 0 & 2 & \\
\hline Line positioned incorrectly & 2 & 1 & \\
\hline Lines touching outer edges & 4 & 7 & \\
\hline Line is not adjacent & 0 & 2 & \\
\hline Box is positioned out of tolerance & 0 & 2 & \\
\hline Box is not placed adjacent & 0 & 1 & \\
\hline Moved box is out of position & 1 & 5 & \\
\hline Circle not adjacent & 0 & 1 & \\
\hline Circle is positioned out of tolerance & 0 & 0 & \\
\hline Moved circle is out of position & 0 & 0 & \\
\hline Group is positioned incorrectly & 1 & 0 & \\
\hline TOTALS (Aggregate Test) & 9 & 32 & 0.0006 \\
\hline
\end{tabular}


a menu (a complex task). As seen in Figures 12 and 13, the differential learning effects favor the the object-oriented interface. However, some consistent patterns emerge from reviewing these interactions which, will be discussed here in detail. Newman-Keuls tests were performed to investigate differences among the various trials as well as between the interfaces. The results of the test for each task are presented below.

Figure 12(a) illustrates subject performance for moving a line. This figure and the Newman-Keuls test indicate that the drop in task completion time from trial 1 to trial 2 was significant $(p<0.05)$ for the bit-mapped interface, but not for the object-oriented interface. Trials 2 through 5 within each interface were not significantly different from one another; however, all trials on the object-oriented interface were significantly faster than those of the bit-mapped interface. Thus, the interaction for this task was a result of the significant decline in task completion time from trial 1 to trial 2 on the bit-mapped interface.

Figure 12(b) presents the results for enlarging a line. For this task the Newman-Keuls test indicated that there was a significant $(p<0.05)$ decline from trial 1 to 2 on the object-oriented interface, but trials 2 through 5 were not significantly different from each other. For the bit-mapped interface there was no significant difference $(p>0.05)$ in task completion time between trials 1 and 2; however, there was a significant difference between trials 2 and 3 . Moreover, trials 3 through 5 on the bit-mapped interface were not significantly different from one another (but different from 1 and 2) Hence, subjects initially started similarly on both interfaces, but achieved 


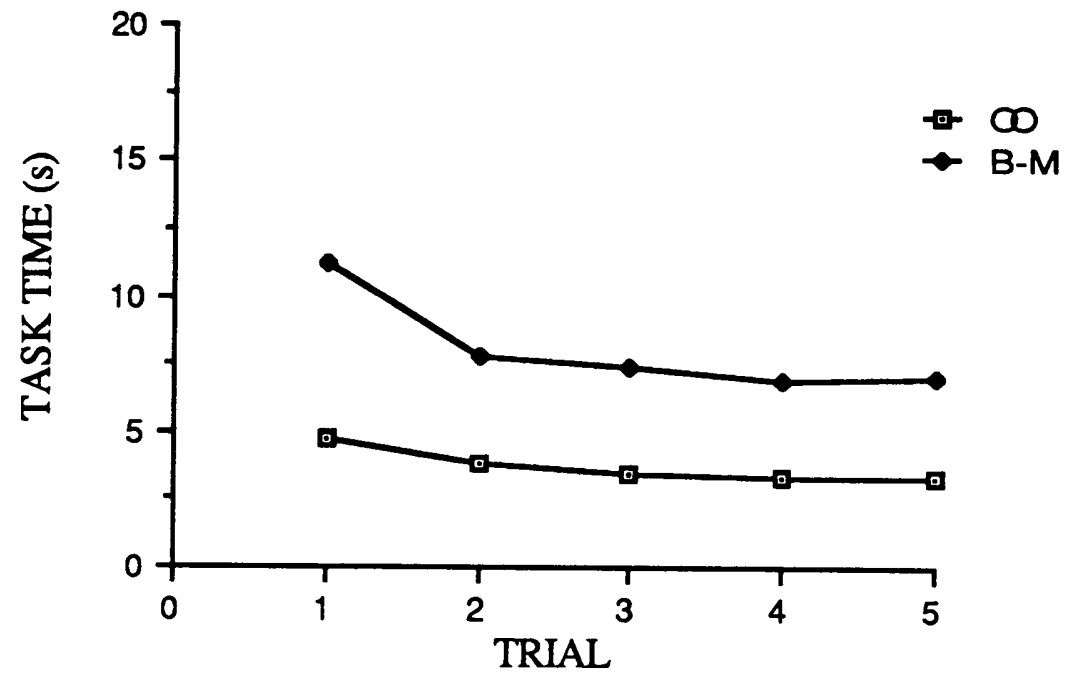

(a)

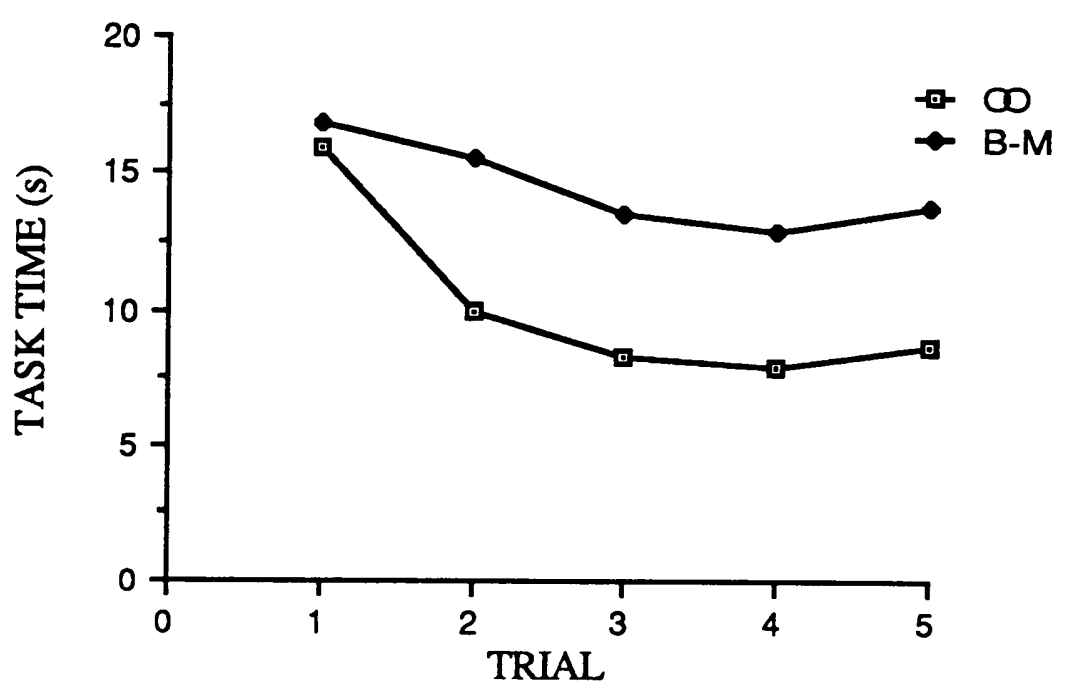

(b)

Figure 12. Task completion times from the line moving task (a) and the line enlargement task (b). OO and B-M stand for object-oriented and bit-mapped, respectively. 


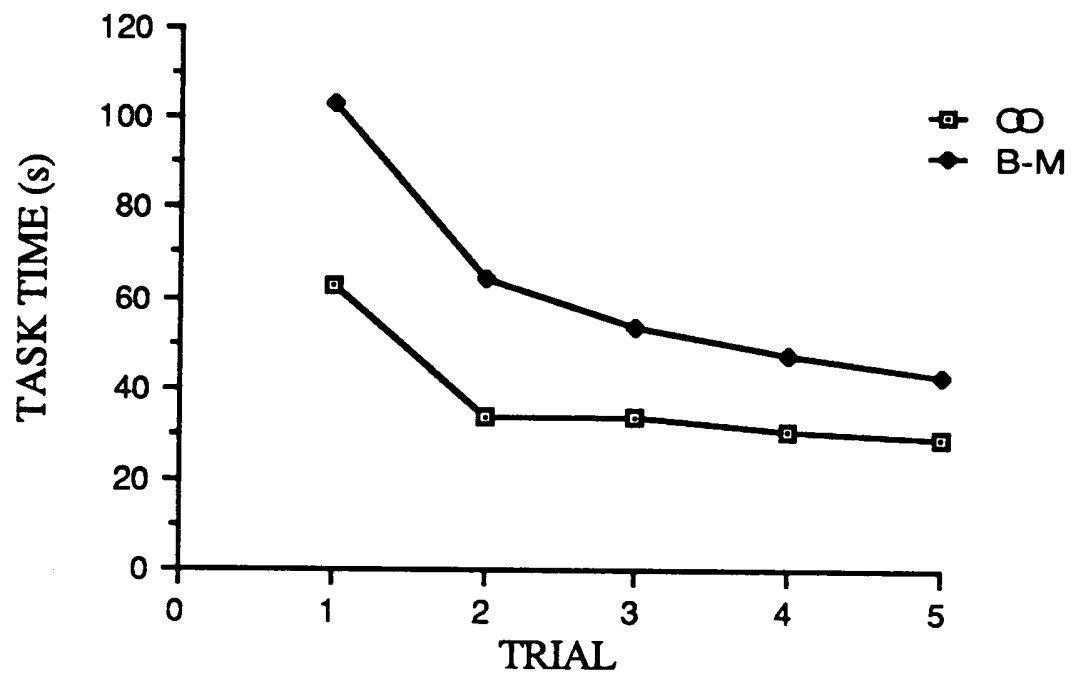

(a)

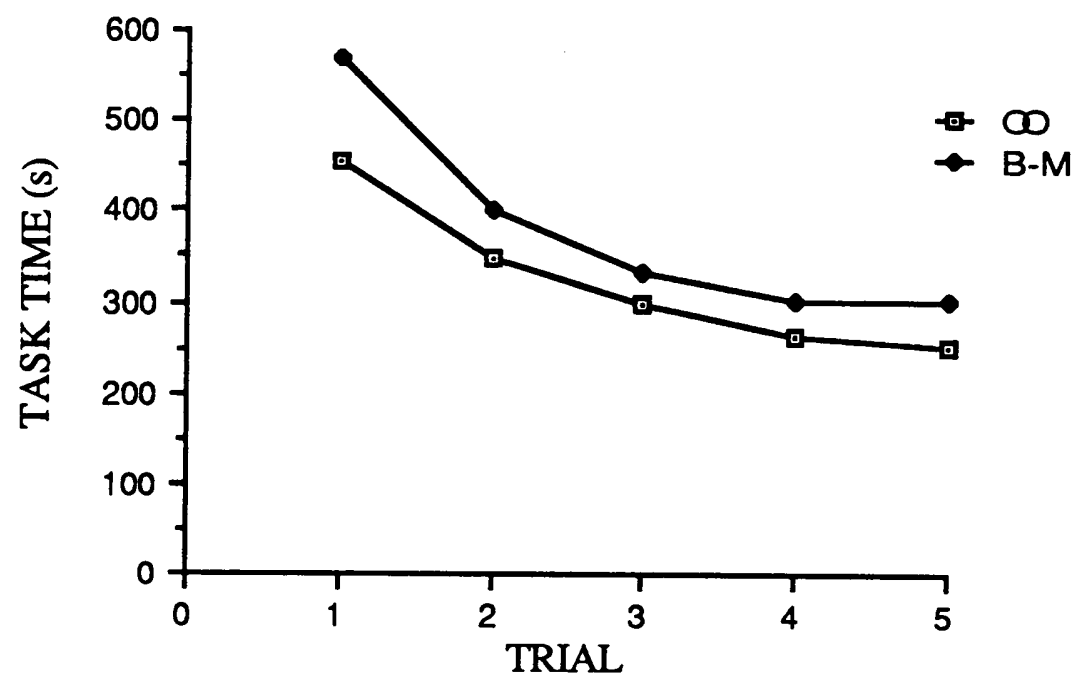

(b)

Figure 13. Task completion times from the circle manipulations task (a) and the menu drawing task. $\mathrm{OO}$ and $\mathrm{B}-\mathrm{M}$ stand for object-oriented and bit-mapped, respectively. 
lower asymptotic levels on the 2nd trial for the object-oriented interface. In contrast, the task completion times dropped from the 2 nd to 3 rd trials on the bit-mapped interface, indicating that asymptotic performance was not reached till trial 3.

Figure 13(a) presents subject performance for copying, resizing, and moving a circle. For this task there was a significant reduction in task completion time from trial 1 to trial 2 on both interfaces. Yet, while subjects reached asymptotic performance at trial 2 on the object-oriented interface, for the bit-mapped interface task completion times continued to decline significantly from trial 2 to 3 and 3 to 4 . These factors contributed to the significant interface-by-trial interaction for this task. Note that although the task completion times repeatedly declined for the bit-mapped interface they were still significantly longer than those of the object-oriented interface. In fact, in all three tasks described above the times were significantly slower on the bit-mapped interface for every trial (except trial 1 on the line enlargement).

Figure 13(b) illustrates the data from the menu drawing task. There was a significant decline in task completion times from trial 1 to 2 and 2 to 3 on both interfaces. Subjects achieved asymptotic performance at trial 3 on both interfaces. The interface-by-trial interaction for this task was due to the following factors. At trials 1 and 2 there was a significant difference between the interfaces (the object-oriented interface being significantly faster). However, the difference between the interfaces dissipated as both reached asymptotic performance. From trial 2 on there was no difference 
between the interfaces. Thus, the task completion time curves were initially different, but began to merge as subjects gained experience with the task. The menu drawing task was the only one of the four where asymptotic performance was not significantly different between the two interfaces.

Two factors of interest emerge from these data. First, subjects reach asymptotic performance levels sooner when using the object-oriented interface. Secondly, in all but the last task the object-oriented interface had significantly shorter task completion times than the bit-mapped interface. The superiority of the object-oriented interface for this measure is clear.

\section{Preference Measures}

Absolute rating questionnaire. This questionnaire required subjects to provide an absolute rating for the ease of task performance on each interface. Subjects rated each task on a bipolar scale ranging from 1 to 7 . The scale was anchored with the terms "Easy to do" (for a rating of 1) and "Hard to do" (for a rating of 7). The resulting data from this questionnaire were considered interval scale data and each item was analyzed using a three-way ANOVA. The independent variables were order of presentation, subject experience, and interface. Appendix $X$ presents the ANOVA summary tables for each question. The order main effect and its interaction with the interface and subject experience variables were not significant for any questionnaire item. The interface main effect was significant for 19 tasks. Table 11 presents a list of the questionnaire items and the mean 
Table 11. The Mean Rating Assigned to Each Absolute Questionnaire Item and Resulting p-Values.

\begin{tabular}{|c|c|c|c|}
\hline ITEM & $\begin{array}{l}\text { OBJECT- } \\
\text { ORIENTED }\end{array}$ & $\begin{array}{c}\text { BIT- } \\
\text { MAPPED }\end{array}$ & p \\
\hline Drawing a line & 1.17 & 1.13 & \\
\hline Drawing a box & 1.33 & 1.17 & \\
\hline Drawing a circle & 2.63 & 1.83 & 0.0274 \\
\hline Drawing a polygon & 2.00 & 1.79 & \\
\hline Moving a circle & 1.20 & 1.79 & 0.0136 \\
\hline Fine positioning a circle & 1.54 & 1.96 & \\
\hline Resizing a circle & 2.63 & 4.67 & 0.0002 \\
\hline Resizing a group of graphics & 3.38 & 4.63 & 0.0059 \\
\hline Moving a group of graphics & 1.92 & 2.29 & \\
\hline Rotating a group of graphics & 1.71 & 1.71 & \\
\hline Rotating a single graphic & 1.25 & 1.71 & 0.0169 \\
\hline Copying a group of graphics & 1.71 & 2.21 & \\
\hline Copying a box & 1.29 & 2.13 & 0.0073 \\
\hline Copying a line & 1.33 & 2.17 & 0.0047 \\
\hline Copying a circle & 1.38 & 2.17 & 0.0157 \\
\hline Copying a polygon & 1.46 & 2.17 & 0.0290 \\
\hline Erasing graphics & 3.50 & 2.04 & 0.0075 \\
\hline Moving a line & 1.25 & 1.83 & 0.0004 \\
\hline Resizing a line & 2.08 & 3.50 & 0.0002 \\
\hline Fine positioning a line & 1.63 & 2.08 & 0.0262 \\
\hline Moving a box & 1.21 & 1.58 & 0.0180 \\
\hline Resizing a box & 2.08 & 3.92 & 0.0001 \\
\hline Fine positioning a box & 1.54 & 2.17 & 0.0067 \\
\hline Typing text & 2.00 & 1.71 & \\
\hline Mcving text & 1.58 & 2.04 & \\
\hline Fine positioning text & 2.75 & 2.79 & \\
\hline
\end{tabular}


Table 11. (Cont.)

\begin{tabular}{|l|c|c|c|}
\hline \multicolumn{1}{|c|}{ ITEM } & $\begin{array}{c}\text { OBJECT- } \\
\text { ORIENTED }\end{array}$ & $\begin{array}{c}\text { BIT- } \\
\text { MAPPED }\end{array}$ & D \\
\hline Rate each of these general tasks: & & & \\
Drawing graphics & 1.70 & 1.75 & \\
Moving graphics & 1.25 & 2.00 & 0.0003 \\
Resizing graphics & 2.42 & 4.58 & 0.0001 \\
Resizing a group of graphics & 2.42 & 4.58 & 0.0001 \\
Erasing/deleting a graphic & 1.63 & 1.92 & \\
Text manipulations & 2.45 & 2.54 & \\
Copying graphics & 1.88 & 2.17 & \\
Rotating graphics & 1.25 & 2.02 & 0.0001 \\
\hline
\end{tabular}


rating corresponding to each interface (appropriate p-values are included). With the exception of erasing graphics, all significant differences were in favor of the object-oriented interface. The differences were consistent across subject groups. This fact is illustrated by the minimal occurrence (only 1) of an experience main effect and the complete absence of an experience-by-interface interaction.

Subject experience was significant for erasing graphics. Not only did the object-oriented interface receive a significantly poorer rating, also expert subjects rated the interface lower than did novices for this item. However, this was the only case of 34 possible items.

Comparison questionnaire. The comparison questionnaire listed the types of tasks that subjects performed and required the subjects to indicate which of the two interfaces they preferred for task performance. The questions included in this questionnaire are presented in Appendix III. A binomial test was used to test for differences between interface choices for each of the questionnaire items. Table 12 presents the results of this test for each questionnaire item (i.e., each task). These results illustrates that 24 significant differences were obtained, of which 23 were in favor of the object-oriented interface (appropriate $p$-values are noted in the table). Fine positioning graphics, rotating graphics, and erasing were the only tasks for which there were no significantly different preferences. Subjects preferred the object-oriented interface for all other actions such as moving, resizing, grouping, and copying graphics. Additionally, 83.3 per cent of subjects selected the object-oriented interface as the preferred interface 
Table 12. The Subject Preferences as Recorded by the Comparison Questionnaire.

\begin{tabular}{|l|r|r|c|}
\hline \multicolumn{1}{|c|}{ QUESTION } & $\begin{array}{r}\text { \% PICKING } \\
\text { OBJECT-OANT }\end{array}$ & $\begin{array}{c}\text { \% PICKING } \\
\text { BIT-MAPPED }\end{array}$ & p \\
\hline Which interface did you prefer for: & & & \\
Drawing a line & 66.7 & 33.3 & \\
Drawing a box & 50.0 & 50.0 & \\
Drawing a circle & 66.7 & 33.3 & \\
Drawing a polygon (triangle) & 45.8 & 54.2 & \\
Moving a circle & 91.7 & 8.3 & 0.001 \\
Fine positioning a circle & 83.3 & 16.7 & 0.002 \\
Resizing a circle & 95.8 & 4.2 & 0.001 \\
Resizing a group of graphics & 83.3 & 16.7 & 0.002 \\
Moving a group of graphics & 87.5 & 12.5 & 0.001 \\
Rotating a group of graphics & 66.7 & 33.3 & \\
Rotating a single graphic & 75.0 & 25.0 & 0.022 \\
Copying a group of graphics & 79.2 & 20.8 & 0.006 \\
Copying a box & 87.5 & 12.5 & 0.001 \\
Copying a line & 87.5 & 12.5 & 0.001 \\
Copying a circle & 87.5 & 12.5 & 0.001 \\
Copying a polygon & 87.5 & 12.5 & 0.001 \\
Erasing graphics & 4.2 & 95.8 & 0.001 \\
Moving a line & 91.7 & 8.3 & 0.001 \\
Resizing a line & 95.8 & 4.2 & 0.001 \\
Fine positioning a line & 75.0 & 25.0 & 0.022 \\
Moving a box & 91.7 & 8.3 & 0.001 \\
Resizing a box & 91.7 & 8.3 & 0.001 \\
Fine positioning a box & 79.2 & 20.8 & 0.006 \\
Moving text & 79.2 & 20.8 & 0.006 \\
Fine positioning text & 54.2 & 45.8 & \\
\hline
\end{tabular}


Table 12. (Cont.)

\begin{tabular}{|l|r|r|c|}
\hline \multicolumn{1}{|c|}{ QUESTION } & $\begin{array}{r}\text { \% PICKING } \\
\text { OBJECT-ORNT. }\end{array}$ & $\begin{array}{c}\text { \% PICKING } \\
\text { BITMPPED }\end{array}$ & p \\
\hline Which interface did you prefer for: & & & \\
Drawing graphics & 62.5 & 37.5 & \\
Moving graphics & 87.5 & 12.5 & 0.001 \\
Resizing a graphic & 91.7 & 8.3 & 0.001 \\
Resizing a group of graphics & 75.0 & 25.0 & 0.022 \\
Erasing/deleting a graphic & 41.7 & 58.3 & \\
Text manipulations & 58.3 & 41.7 & \\
Copying graphics & 91.7 & 8.3 & 0.001 \\
Rotating graphics & 87.5 & 12.5 & 0.001 \\
Overall which would you select to & 83.7 & 16.3 & 0.002 \\
perform your graphics work? & & & \\
\hline
\end{tabular}


for performing their everyday tasks.

These data were also reviewed on the basis of subject experience. Appendix XI presents these data in a format identical to Table 12. The results are very similar to the overall findings and are judged not to warrant a separate discussion.

Overall rating. Subjects provided an overall rating for each interface on the final two items of the comparison questionnaire. Subjects rated the interfaces on a scale of 1 to 10,1 being the lowest rating and 10 being highest. Data from the ratings were treated as interval scale data, and a twoway ANOVA was performed to test for differences between interfaces, subject experience, and their interaction. The ratings assigned to the object-oriented interface (mean $=7.66$ ) were significantly higher than those assigned to the bit-mapped interface $($ mean $=5.22), F(1,22)=26.83, p<0.001$. Additionally, the standard deviation of the ratings was higher for the bitmapped interface $(s=2.15)$ than for the object-oriented interface $(s=1.61)$. Thus, the ratings assigned to the bit-mapped interface were fairly dispersed whereas those assigned to the object-oriented interface were less varied around their relatively high mean rating (7.66). Subject experience and the experience-by-interface interaction were not significant, $F(1,22)=.01$, $p=0.983$, and $F(1,22)=1.30, p=0.266$, respectively. 


\section{DISCUSSION AND CONCLUSIONS}

The results presented in the previous section consistently indicate that the object-oriented interface is superior to the bit-mapped interface for the graphics applications considered in this study. The superiority of the object-oriented interface is reflected in both performance and preference data.

\section{Task Completion Time}

Interface effect. The significant Interface effect in favor of the objectoriented interface indicates the advantages of this interface. Review of the subjects' task performances provides two possible explanations for these time differences.

First, a review of sample subject performances revealed that the essential difference in manipulating graphics is in the selection (or designation) of the graphic to be manipulated. To select a graphic, users of bit-mapped systems must explicitly select the pixels that comprise the graphic(s) by completely surrounding the component pixels with a selection box. In contrast, to perform the same operation, object-oriented users point to any part of the graphic with the cursor. As a result, selecting a graphic requires more time with the bit-mapped interface than with the objectoriented interface. For instance, to move a circle in the bit-mapped 
interface, the user must surround all of the pixels that constitute that circle, then move the circle. The circle selection task must be done carefully if the circle of interest is located among or near other graphics. A user may accidentally include portions of other graphics with the pixels that constitute the circle, at which point he/she must start the selection task anew. As a result, graphic selection in the bit-mapped interface tends to be a time consuming and error prone operation. In contrast, object-oriented interface users need only point to any part of the circle to select it, then move the circle. The system will select only that graphic primitive; none of the nearby graphics are affected. This process is less time consuming and less prone to error than that of the bit-mapped interface

A second explanation is that the graphic handling capacity of the objectoriented interface is superior to that of the bit-mapped interface due to the former's ability to manipulate graphics as single units. This is especially noticeable for tasks that require overlaying graphics or positioning graphics near one another. In the bit-mapped interface once graphics are overlapped or superimposed the pixels of the graphics are no longer distinguishable from each other. On the other hand, in the object-oriented interface, graphics retain their integrity despite any manipulations. For instance, if a user of the bit-mapped interface positioned circle $A$ on top of circle $B$ the constituent pixels of the two circles would no longer be separable. Thus, the user would have difficulty in manipulating circle $A$ after positioning it on $\mathrm{B}$. Conversely, users of object-oriented interfaces simply point to any part of circle A (to select the circle) and are able to 
manipulate A independently of circle B. This difference also contributed to the significantly longer task completion times for the bit-mapped interface.

Experience effects. Experienced subjects' task completion times were significantly shorter than those of novices for 26 of 29 tasks. This result may be due to the expert subjects' familiarity with both interfaces. This point is further supported by the scarcity of interface-by-experience interactions (5 cases). For most (24 of 29) tasks, experts' task completion times were consistently shorter on both interfaces. That is, across both interface types, experienced subjects had consistently shorter task completion times due to their knowledge of the interfaces. Newman-Keuls tests for the 5 instances where the interface-by-experience interaction was significant indicated that the novices performed significantly slower than experts on the bit-mapped interface $(p<0.05)$, but equivalent $(p>0.05)$ on the object-oriented interface. These five tasks were comprised of moving lines and boxes. For these tasks novices improved their performance on the object-oriented interface such that their completion times were similar to those of experts.

For 10 tasks the trial-by-experience interaction was significant. Newman-Keuls tests revealed that for these tasks expert task completion times dropped more rapidly over the five trials than did those of novices. This effect may also be attributable to the experienced subjects knowledge of the interfaces. As a result of their expertise, experienced subjects 
attained lower task completion times more quickly than their novice counterparts.

Trial effect. The trial effect is explained by learning due to repeated practice. Both novice and expert subjects became more familiar with the tasks as they repeated the tasks. Subjects reached asymptotic performance after the third trial. Although asymptotic levels were achieved for novices it is possible that over numerous repetitions novice task completion times may equal those of experts. Five trials are not sufficient to examine this possibility.

\section{Learning}

Tasks with significant interface-by-trial interactions indicated the presence of differential learning effects. Results show that for 25 of the 29 task completion times this interaction was not significant. In fact, task completion times on the object-oriented interface are significantly shorter than those on the bit-mapped interface across all five trials. The comparative drop in completion time (object-oriented vs. bit-mapped) over ensuing trials is relatively similar, resulting in the lack of interface-by-trial interactions. The object-oriented interface may be so superior for ease of use that task completion times on this interface for all trials are consistently shorter on most tasks. 
Four tasks yielded differential learning effects (Figures 12 and 13). In all four cases these effects point to the advantages of the object oriented interface. For three tasks (Figures 12a, 12b, and 13a) the interaction is due to the object-oriented interface attaining asymptotic performance levels on the second trial while task times were still decreasing for the bit-mapped interface over ensuing trials. In all cases task completion times for the object-oriented interface are significantly faster than those of the bitmapped interface. In these three tasks subjects were required to move graphics, and position them in specified areas. The difference may be due to the differences between the interfaces in the selection of graphics. Perhaps for these tasks graphic selection in the bit-mapped interface required more skill than the object-oriented interface, thus requiring more trials to master. As described previously, graphic selection is a more tedious process for the bit-mapped interface and, for these tasks, may have been more difficult than the object-oriented during the initial trials. Again, the superiority of the object-oriented interface is illustrated.

The fourth task (Figure 13b) yielding a significant interface-by-trial interaction was the menu drawing task. In this instance task completion time was significantly faster for the object-oriented interface on the initial trials. After the third trial the task completion times were equivalent for the two interfaces. This effect may be due to the similarity between the interfaces in drawing graphics. The complex menu drawing task was dominated by basic drawing subtasks. As discussed earlier, these basic drawing tasks (e.g., draw circle, draw box) did not yield significant 
differences and may explain the similarity in task completion times for the later trials on the menu drawing task.

\section{Repeated/Aborted Attempts}

A review of a random sample of repeated-attempts errors indicated that the differential error results were due to the differences between the interfaces in graphic selection method and graphic handling capacity. To select a graphic(s), users of bit-mapped systems must explicitly select the pixels that comprise the graphic(s) by completely surrounding the component pixels (or grouping them). This action is more error prone and time consuming if the graphic is large or consists of many small graphics. In most instances where repeated attempts were required, subjects had difficulty in correctly surrounding the graphic(s) of interest on the first few attempts. Subjects would either select portions of extraneous graphics or were unable to completely surround the constituent pixels of the graphic of interest. In contrast, to select a graphic in the object-oriented system, users need only point to any part of the graphic, thus reducing the probability of error during selection.

Additionally, the object-oriented interface was found to be superior to that of the bit-mapped interface due to the former's ability to manipulate graphics as single units. This advantage is particularly useful for tasks which require overlaying or superimposing graphics. For many tasks subjects were required to position graphics in overlapped or superimposed 
configurations. Often graphics were not positioned quite correctly and some adjustment was required. With the object-oriented interface subjects who made adjustments could select any graphic (overlaid, superimposed, etc.) and move it into the desired location. In contrast, with the bit-mapped interface once graphics are overlaid or superimposed, the pixels of the graphics are no longer distinguishable. Subjects had no method of selecting only the graphic of interest to take corrective action. Thus, subjects were required to start anew, leading to a high number of repeated attempts.

\section{Size Deviation Errors}

For all 10 errors of deviation the object-oriented interface had significantly less error than the bit-mapped interface. A review of the task requirements (for the 10 tasks in Table 8) and a sample of subjects' performances on these tasks indicated that one action is common to all 10 tasks: resizing (or scaling). For eight of the tasks, resizing was the most important or only action required of the subjects. These differences may, as stated in earlier discussions, be attributable to graphic selection. In the object-oriented interface users point to a graphic to select the item. Users may then resize (scale) the graphic; however, resized graphics maintain their integrity, only their size is altered. In the bit-mapped interface users must surround the graphic to select the constituent pixels before resizing them. If users do not carefully surround the graphic, extraneous pixels will be included with the grouped pixels. For instance, a user may intend to 
resize a 1 - by 2 -in. box. If the user surrounds an area around the box equal to 1.05 - by 2.05 -in., then the pixels in the extraneous area will be included in the resizing process, resulting in a graphic that may not meet specified size criteria.

\section{Preference Measures}

Results from all three preference measures (absolute ratings, comparison questionnaire, and comparative ratings) suggest that subjects preferred the object-oriented interface to the bit-mapped interface. The preference for this interface may be due to the subjects' relatively error free and less time consuming performance on this interface. In other words, possibly, the subjects' performance on the interfaces influenced their subjective preferences.

Conversely, subjects' preference for the object-oriented interface may be a completely cognitive phenomenon as opposed to being influenced by physical factors (such as error free performance). Perhaps, the preference is due to the similarity of the interface to the "real world" in handling graphic objects. A useful analogy would be to compare graphic primitives in the computer interface world to solid objects in the real world. For instance, one does not consider a table to consist of many molecules. The table is a single object and any manipulations of the table must be made to the unit. The bit-mapped interface only recognizes the constituent pixels of a graphic primitive (the molecules). On the other hand, the object-oriented 
interface treats each graphic primitive as a unit. This approach is consistent with one's perception of the real world and may seem more intuitively appealing.

Three additional points regarding the results of the study should be discussed: (1) the consistency of the results, (2) generalization of the results, and (3) the sensitivity and validity of the methodology.

\section{Consistency of Results}

The object-oriented and bit-mapped interfaces differ in performing graphic manipulations (e.g., moving, rotating, resizing); however, drawing graphics is performed similarly in both interfaces (e.g., drawing a single line, drawing a single box, etc.). Thus, differences between the interfaces were expected for most graphic manipulations, but no differences were anticipated for tasks that required drawing a simple graphic. The results of the study fulfilled these expectations and support the validity of the methodology. Additionally, these results are consistent for both performance and preference data. For instance, tasks which consisted of drawing simple graphics yielded no significant differences between the interfaces for task completion time. Likewise, the questionnaire items regarding drawing tasks found no preference differences for performing the tasks. These findings were consistent for both novice and experienced subjects.

A second factor pointing to the consistency of the results is the uniformity of the results across both subject groups (i.e., novices and 
experts). Differences in performance and preference measures were similar for both groups. This was particularly noteworthy since there were very few significant experience-by-interface interactions for the task completion times and none for the error data. Moreover, the subjective responses of the two groups to the preference measures were well matched (see Appendix $X$ ). The consistency of the results is illustrated in the preference measures in that the object-oriented interface was preferred regardless of the users' experience. The superiority of the object-oriented interface was consistent for both levels of user experience.

Finally, the advantages of the object-oriented interface are evident for all levels of task complexity. As stated previously, the tasks were operationally categorized into three groups: basic, mid-range, and complex. Table 3 illustrates that the object-oriented interface is superior for all three groups of tasks. This fact also reaffirms the consistency of the results.

\section{Generalization of Results}

The results of the present study generally show significant advantages of object-oriented graphics interfaces over the bit-mapped interfaces. Although these observations are based on comparisons of two specific packages, it is believed that these results are applicable to similar comparisons for graphics packages using the interfaces investigated in this study. This statement is based on four factors: 
1. The differences between the object-oriented and bit-mapped interfaces, which lead to the differential effects on performance and preference, are common to all software packages using these interfaces. Graphic selection and graphic handling ability are the main differences between the interfaces for performing the types of tasks included in this experiment. All software packages using the bit-mapped interface perform these functions similarly (common to all bit-mapped interfaces). The same holds true for the objectoriented interface.

2. The benchmark tasks were an objectively derived subset of the types of tasks experts perform on direct manipulation interfaces. Thus, the benchmark is fairly representative of the task "population."

3. The observed experts represented a wide variety of educational and professional backgrounds. Therefore, no bias eixsts in the tasks recorded during the expert observations.

4. All experienced subjects participating in the experiment stated that the tasks included in the benchmark were representative of the types of tasks they perform on a regular basis. These subjects also believed that the benchmark tasks were general enough to encompass most of the graphic-action combinations that they use in their regular applications. 


\section{Sensitivity and Validity of Methodology}

The generalizability of the results, coupled with their consistency, suggests that the methodology used in this thesis is both sensitive and valid. Two questions must be addressed in dealing with validity: (1) Is the instrument measuring what it purports to measure? (2) Is the sample being measured adequately representative of the phenomenon of interest?

First, the measurement instruments used in this thesis seem to measure validly. No differences were obtained where none were expected, and significant differences were found where anticipated (for some tasks no specific outcomes were predicted). Secondly, the objectivity of the process for deriving benchmark tasks, the sensitivity of the tasks (as indicated by subjects), and the representativeness of the observed sample suggest that the tasks are highly representative. Thus, the answer to both questions stated above is affirmative.

\section{Conclusions}

The results of the current study lead to some general conclusions:

1. Excluding art applications, the object-oriented graphics interface is superior in performance and user preference for most direct manipulation graphics interface applications. 
2. For tasks that require frequent selection of graphics (e.g., resizing, moving, positioning) the object-oriented interface is superior and should be used for such tasks.

3. Users of direct manipulation interfaces should find the objectoriented interface easier to learn than bit-mapped interfaces. Additionally, they will perform their tasks more rapidly and with smaller and fewer errors using the object-oriented interface rather than the bit-mapped interface. The same may be valid for infrequent or occasional users.

4. The object-oriented interface is not the "cure all" for direct manipulation graphics applications. This interface has limited capabilities for very fine manipulations. Most importantly, objectoriented interfaces do not have the ability to manipulate portions of a graphic primitive. Due to the "all or nothing" principle, described earlier, the object-oriented interface must manipulate a graphic unit in its entirety. For example, a user cannot erase half a circle or box. In fact, erasing a graphic was the only task that was preferred on the bit-mapped interface (see Table 11).

Secondly, the object-oriented interface is not optimized to manipulate single pixels and, thus, does not allow for pixel manipulations. The object-oriented interface is not well suited for tasks dominated by fine detailed graphics and manipulations of portions of graphic primitives. 
Finally, the object-oriented interface is not capable of creating objects where random placement of pixels may be required (e.g., random fill patterns). For these applications the bit-mapped interface is recommended. The reader is reminded that the benchmark tasks used in this study did not include such tasks since the observed experts performed very few of these tasks.

Except art applications, all other factors being equal, the object-oriented interface is superior to the bit-mapped interface in task completion time, errors, and subjective preference. In general, in designing a system or procuring software with direct manipulation graphics capabilities the objectoriented interface should be the interface of choice.

\section{Suggestions for Future Research}

Analysis of elemental times could yield more detailed insight into performance differences in certain graphics tasks. This type of analysis would entail looking at task performance at a level similar to Gilbreth's (1911) concept of "therbligs." Task performance could be divided into its various detailed subtasks, and a comparison of subtask performance for the two interfaces may yield interesting results.

The results from this study can be generalized to most settings where direct manipulations interfaces are employed. However, to gain greater insight into the relative advantages of the interfaces, research should be conducted to compare them with respect to the specific field applications that 
are common in some setting(s) of interest. The results of less controlled, more narrowly focused studies may be helpful in determining differences between the interfaces for a specific set of applications. 


\section{REFERENCES}

Albert, A. E. (1982). The effect of graphic input devices on performance in a cursor positioning task. In Proceedings of the Human Factors Society 26th Annual Meeting (pp. 54-58). Santa Monica CA: Human Factors Society.

Card, S. K., English, W. K., and Burr, B. J. (1978). Evaluation of mouse, ratecontrolled isometric joystick, step keys and text keys for text selection on a CRT. Ergonomics, 21(8), 601-613.

Card, S. K., Moran, T. P., and Newell, A. (1980). The Keystroke-level Model for user performance time with interactive systems. Communications of the ACM, 23(7), 396-410.

Downing, J. V., Jorna G. C., Lloyd, C., Mohageg, M. F., and Snyder H. L. (1987). Typewriter evaluation study (Document Number HFL-87-1).

Blacksburg, VA: Virginia Polytechnic Institute and State University, Human Factors Engineering Laboratory.

Epps, B. W. (1986). A comparison of cursor control devices on target acquisition, text editing, and graphics tasks. Ph. D. Dissertation. Blacksburg, VA: Virginia Polytechnic Institute and State University. 
Epps, B.W. (1987). A comparison of cursor control devices on a graphics editing task. In Proceedings of the Human Factors Society 31st Annual Meeting (pp. 442-446). Santa Monica CA: Human Factors Society.

Foley, J. D., and Van Dam, A. (1982). Fundamentals of interactive computer graphics. Reading, MA: Addison-Wesley.

Gaylin, K. B. (1986). How are windows used? Some notes on creating an empirically-based windowing benchmark task. In $\mathrm{CHI}$ '86 Human Factors in Computing Systems, (pp. 96-100). New York: Association for Computing Machinery.

Gilbreth, F. B. (1911). Motion study. Princeton, NJ: Van Nostrand.

Grillo, J., and Robertson, R. (1985). Graphics for the Macintosh: An idea book. New York: Holt-Reinhart and Winston.

Harris, D. (1984). Computer graphics and applications. London: Chapman and Hall.

Hutchins, E. L., Hollan, J. D., and Norman, D. A. (1986). Direct manipulation interfaces. In D. A. Norman and S. W. Draper (Ed.), User systems design: New perspectives on human-computer interaction. Hillsdale, NJ: Lawrence Earlbaum.

Lewis, B. C., and Crews, A. E. (1985). The evolution of benchmarking as a computer performance evaluation technique. MIS Quarterly, 7-15. 
Magers, C. E. (1983). An experimental evaluation of on-line help for nonprogrammers. In CHI '83 Human Factors in Computing Systems, (pp. 277-281). New York: Association for Computing Machinery.

McComb, G., and Smith, C. S. (1985). Macintosh graphics. New York: Plume Print.

Norman, D. A. (1986). Cognitive engineering. In D. A. Norman and S. W. Draper (Ed.), User systems design: New perspectives on humancomputer interaction. Hillsdale, NJ: Lawrence Earlbaum.

Roberts, T. L. (1980). Evaluation of computer text editors. Ph. D. Dissertation, Palo Alto, CA: Stanford University.

Roberts, T. L. and Moran, T. P. (1983). The evaluation of text editors: Methodology and empirical results. Communications of the ACM, $26(4)$, 265-283.

Rutkowski, C. (1986). An introduction to the Human Applications Standard Computer Interface, Part 1: Theory and principles. BYTE, $7(11), 291$ 310.

Shneiderman, B. (1987). Designing the user interface. Menlo Park, Ca: Addison Wesley Publishing Co.

Sperling B. B., and Tullis, T. S. (1987). Are you a better "mouser" or "trackballer"? A comparison of cursor positioning performance. Paper presented at the CHI and GI '87 Graphics Interface and Human Factors In Computing Systems Conference. 
Scott, J. E. (1982). Introduction to interactive computer graphics. New York: Wiley-Interscience.

Whiteside, J., Jones, S., Levy, P., and Wixon, D. (1985). User performance with command, menu, and iconic interfaces. In Proceedings of $\mathrm{CHI}$ ' 85 Human Factors in Computing Systems. (pp. 185-191). New York: Association for Computing Machinery.

Williges, R. C., Williges, B. H., and Elkerton, J. (1987). Software interface design. In G. Salvendy (Ed.) Handbook of human factors. (pp. 14161449). New York: Wiley. 
93

Appendix I. Subject Work Files 
Each page of this appendix illustrates one of the files that subjects used to perform the benchmark tasks. All necessary instructions and graphics were included in the file. It should be noted that the hard copies in this appendix are more cramped due to the paper space limitations. On the 15-in. monitor there was more space between the tasks in a file. The final file, in which subjects drew a menu, was simply blank and is not included in this appendix. 
1. Draw a straight line between the points $A$ and $B$.

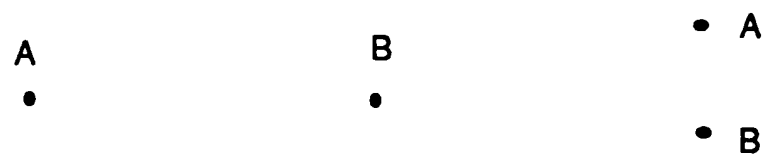

2. Draw a bou so that it covers Bor C, but is surrounded by $\mathrm{BOH} B$.

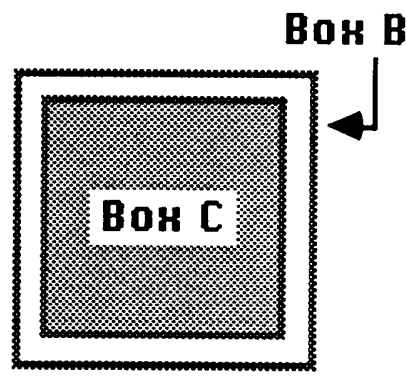

3. Draw a circle that covers Circle $C$, but is surrounded by Circle $B$.

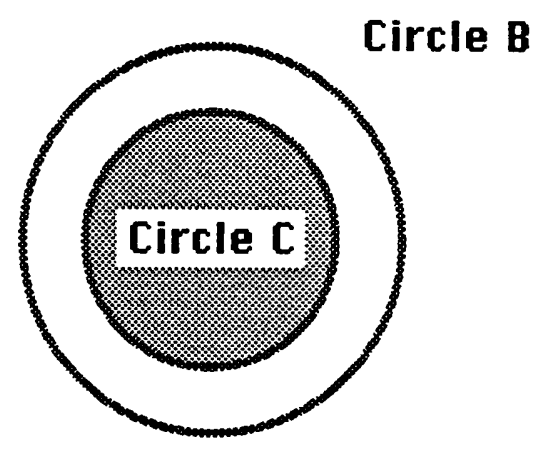

4. Draw a triangle so that it covers Trangle $C$, but is surrounded by $B$.

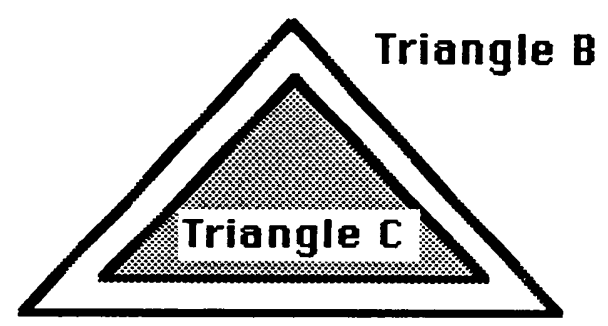


Move the line on the left to the outlined position on the right.

Place the lines on the left inside the rectangles on the right. No part of the lines should touch the sides of the rectangles.
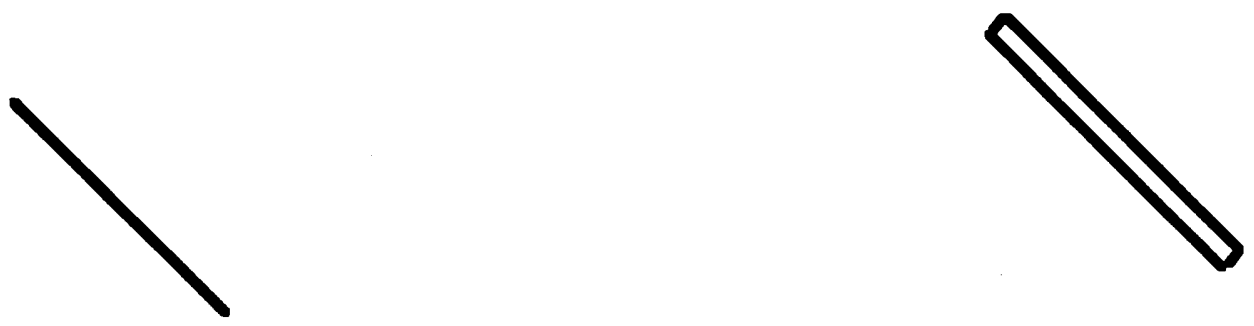

Resize each of these lines so that each is 1 inch long.
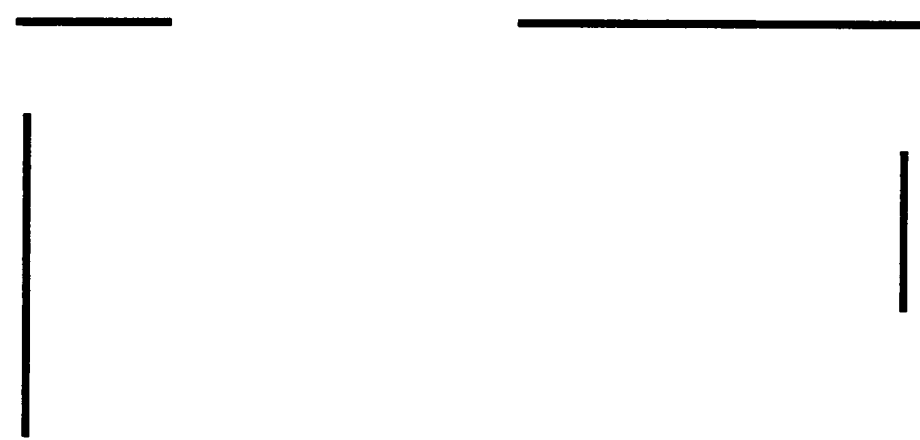

Place line on the left adjacent to the top side of the bor. The line must be positioned between the indicators on the bor.
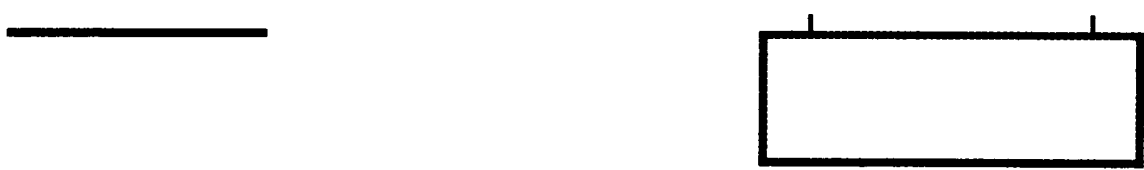
Postion Bor A such that it completely couers Bor C, But is completely surrounded by Вон $\mathrm{B}$.

Вон В
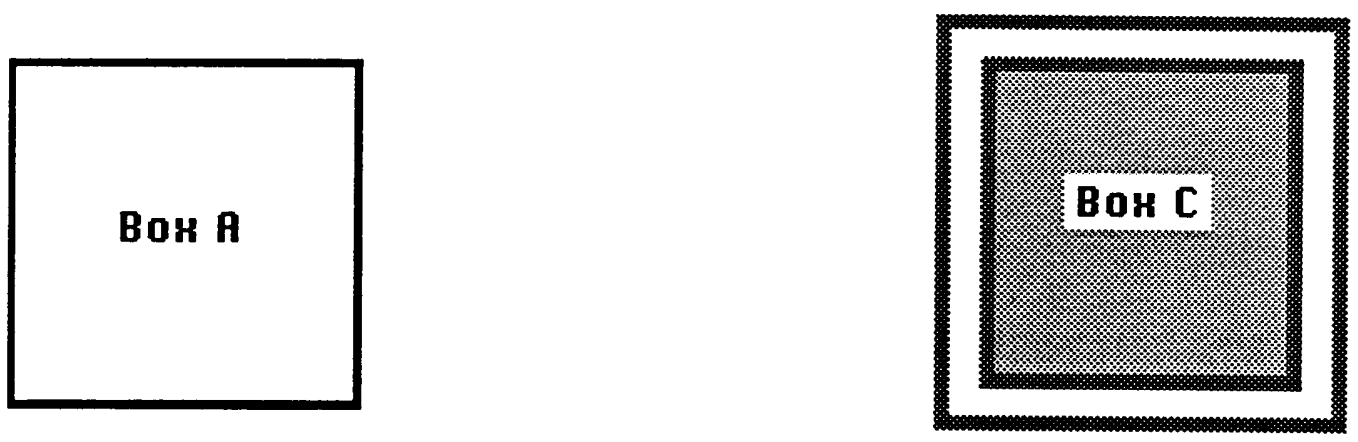

Place Bor $\mathrm{A}$ adjacent to Boy B between the indicators.
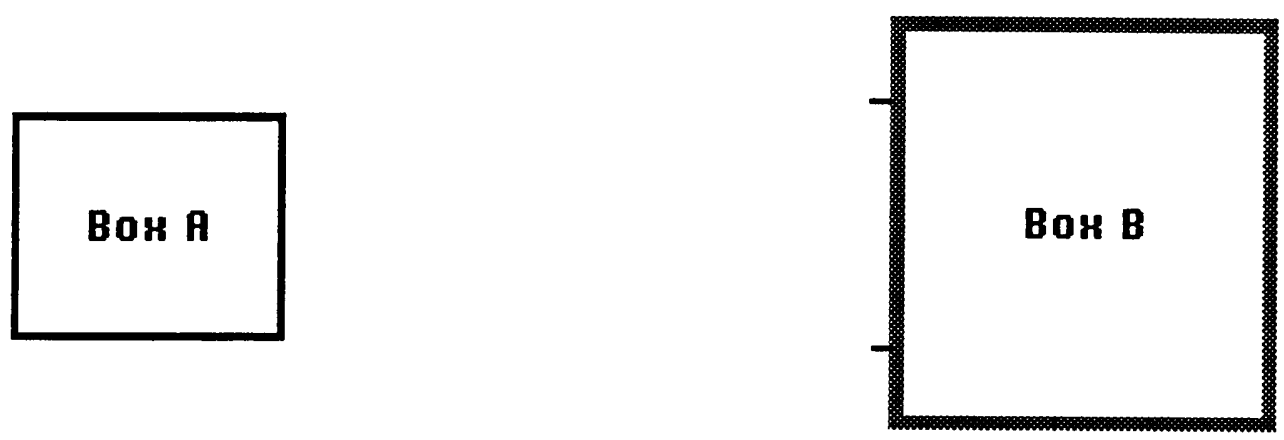

Pesize each bor so that each becomes

1 - by 1 -inch square.

Вон

Вон B

Move Вон $\mathrm{A}$ to the outlined position on the right.
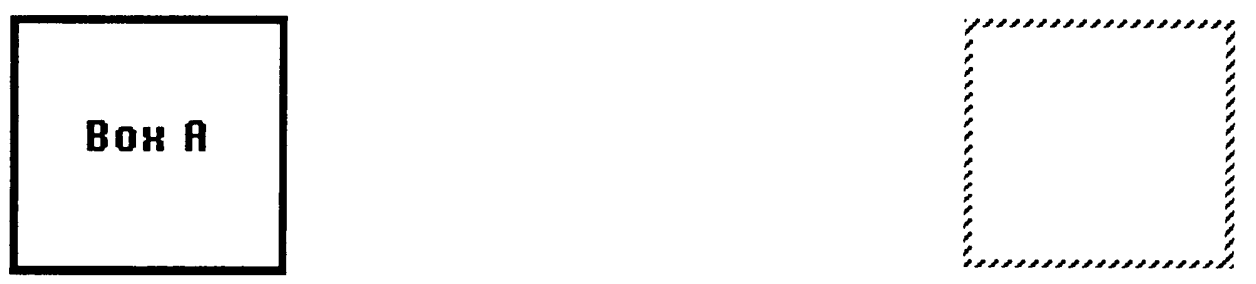
Place the circle on the left adjacent to the circle on the right.
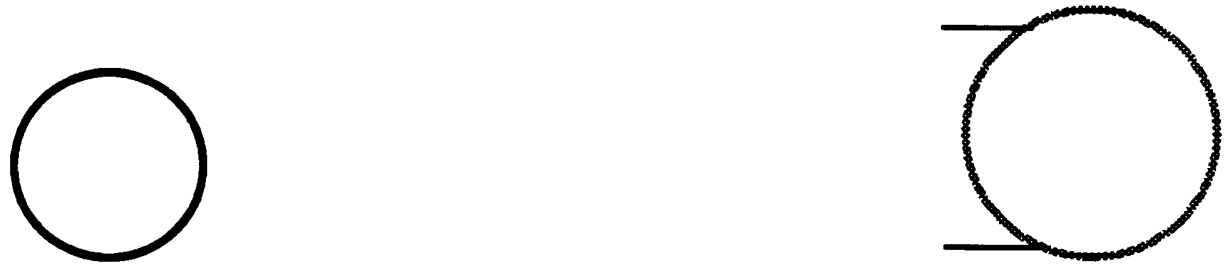

Move the circle on the left to the outlined position on the right.
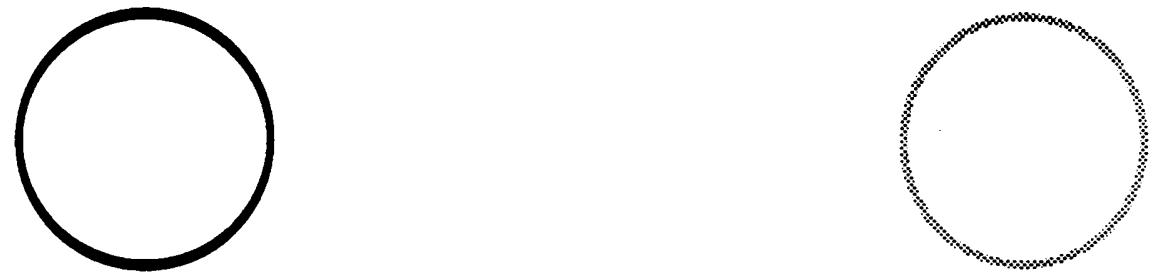

esize each of these ellipses such that they become circles with inch diameters.
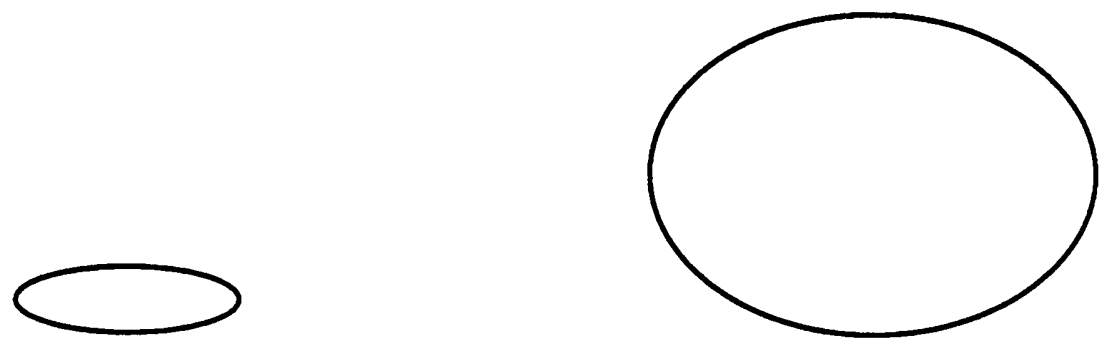

Position Circle A such that it completely covers Circle $C$, but is completely surrounded by Circle B.
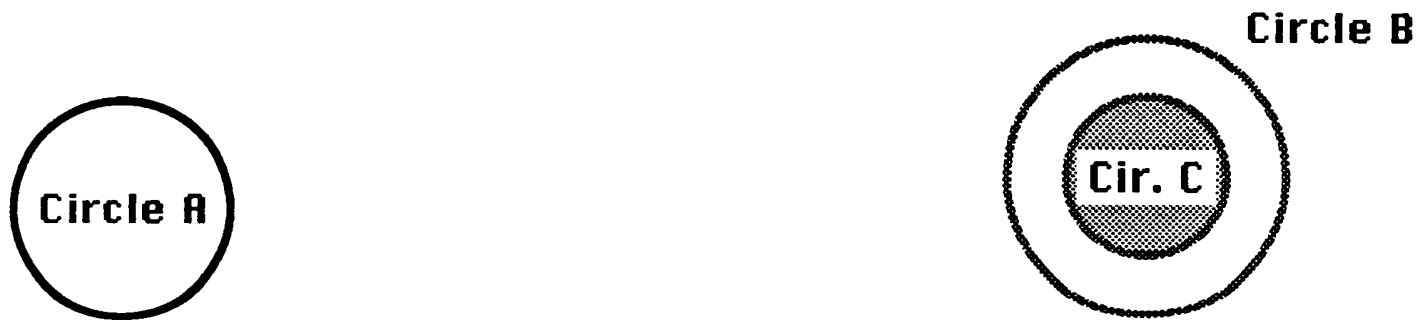
Copy each figure on the left. Resize the copy so that it is the same

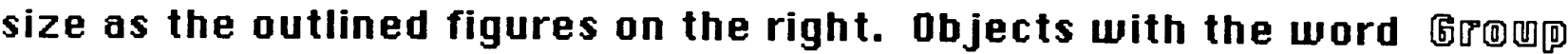
aboue them must be grouped before they are copied and Resized. Finally, move the resized copy to the outlined positions. (Rotate objects if necessary)
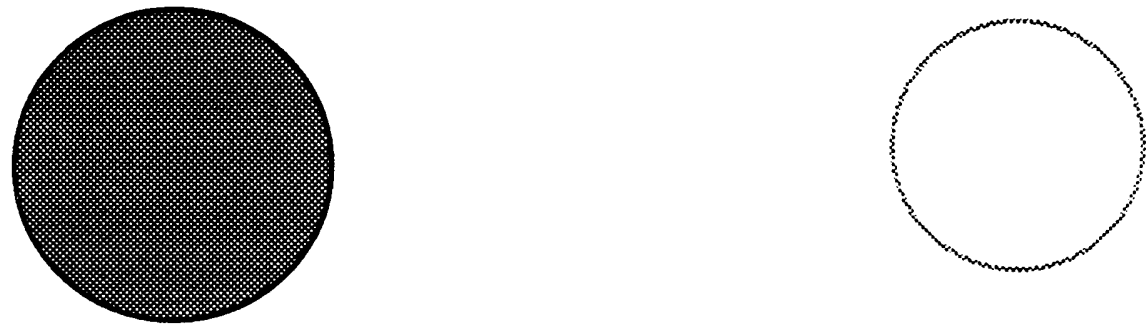

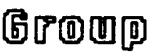

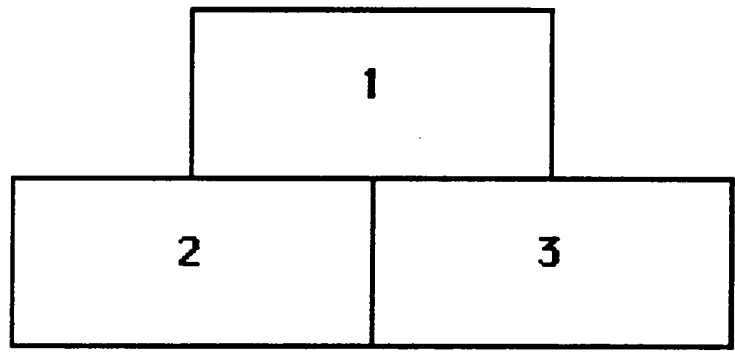

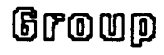
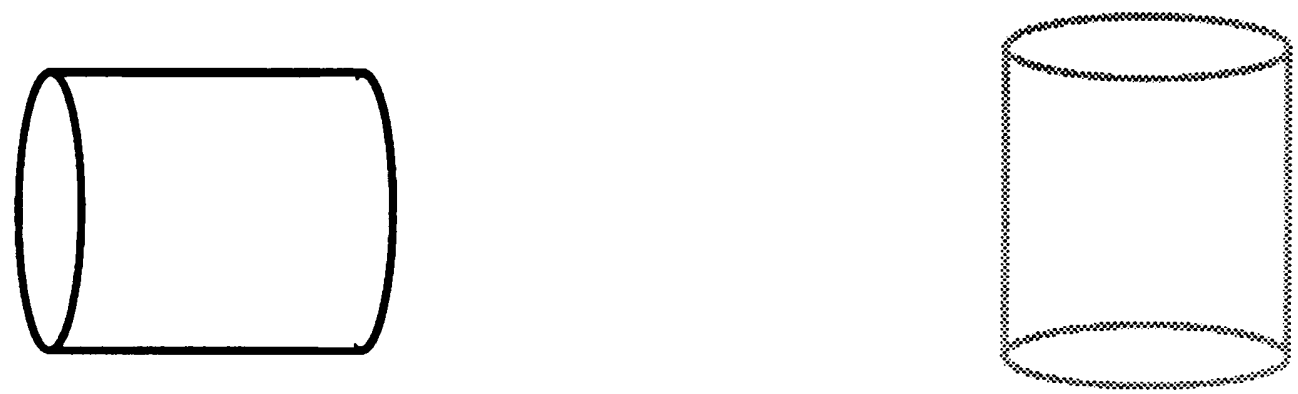
Hdd the necessary components to this chart to make it identical to the one at the bottom of the screen.
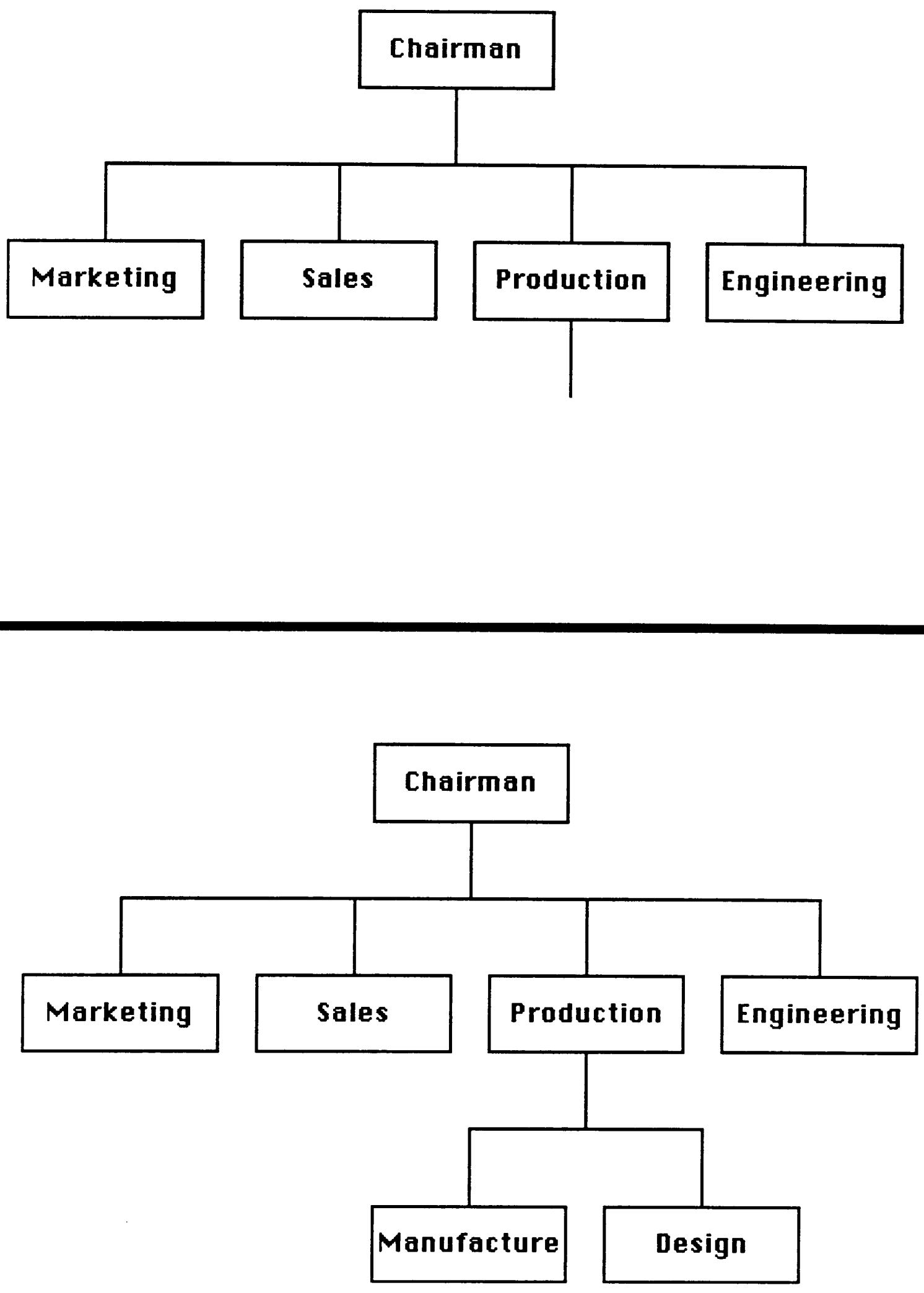
Organize the objects below such that they look identical to Figure $Y$. Some of these objects are smaller, larger, or have a different orientation than those of their counterparts in Figure $Y$. Please manipulate these objects so that they are identical to their counterparts in Figure $Y$.
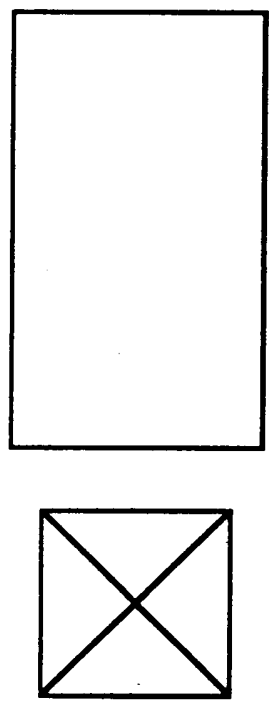
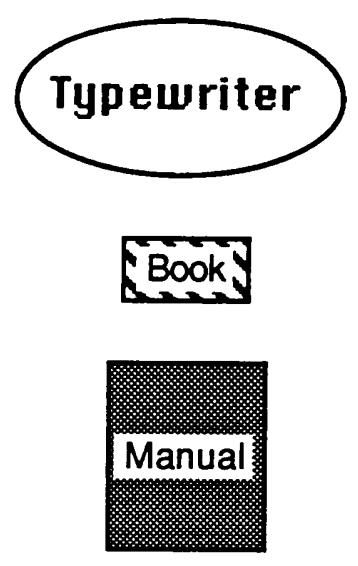

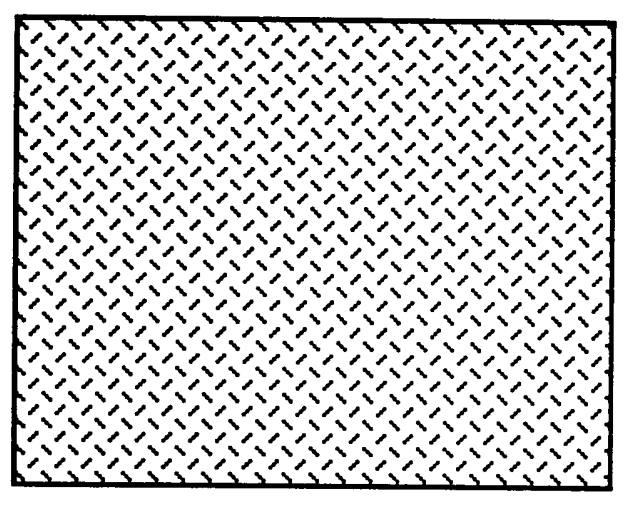

Figure Y

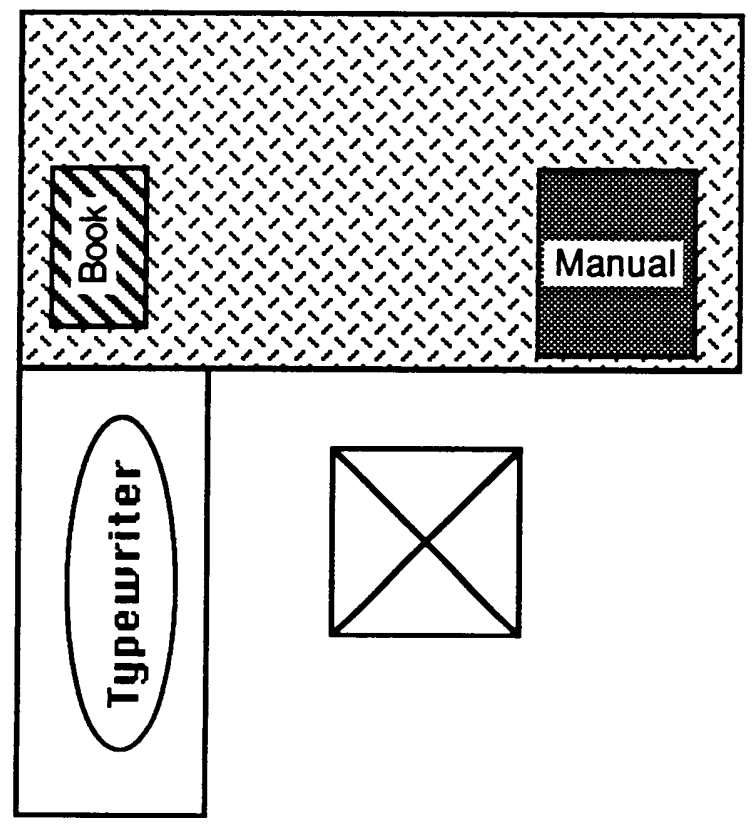


Appendix II. Absolute Ratings Questionnaire 


\section{COMPARISON QUESTIONNAIRE}

Please rank each of the following tasks for ease of performing the task on the package you used. A rank of 1 indicates that the task was easy to perform, a rank of 4 is neutral (not too hard, but not exactly easy), and a rank of 7 means the task was hard to do on this package. Please do not make any marks on the questionnaire. Indicate all of your answers on the opscan sheet. On the opscan, mark a 1, 2, 3,.. 7 for your responses. Remember, you are rating the package, not your skill or ability with the package.

Please rank ease of performing the following tasks with this package:

1. drawing a line,

$\begin{array}{clllllll}1 & 2 & 3 & 4 & 5 & 6 & 7 \\ \text { Easy to do } & & & & & & \text { Hard to do }\end{array}$

2. drawing a box,

$\begin{array}{clllllll}1 & 2 & 3 & 4 & 5 & 6 & 7 \\ \text { Easy to do } & & & & & & \text { Hard to do }\end{array}$

3. drawing a circle,

$\begin{array}{clllllll}1 & 2 & 3 & 4 & 5 & 6 & 7 \\ \text { Easy to do } & & & & & & \text { Hard to do }\end{array}$

4. drawing a polygon (triangle or other multisided shape),

$\begin{array}{ccccccccc}1 & 2 & 3 & 4 & 5 & 6 & 7 \\ \text { Easy to do } & & & & & & & \text { Hard to do }\end{array}$


5. moving a circle,

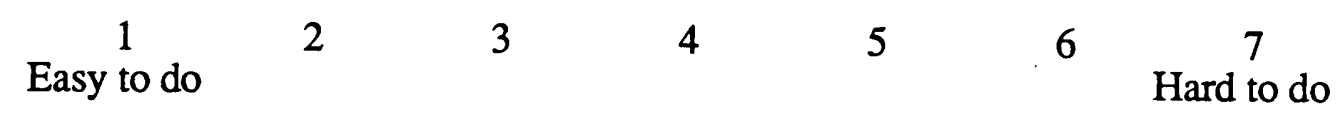

6. fine positioning a circle (e.g. adjacent to another),

$\begin{array}{clllllll}1 & 2 & 3 & 4 & 5 & 6 & 7 \\ \text { Easy to do } & & & & & & \text { Hard to do }\end{array}$

7. resizing a circle (i.e. making it bigger or smaller),

$\begin{array}{cllllllc}1 & 2 & 3 & 4 & 5 & 6 & 7 \\ \text { Easy to do } & & & & & & \text { Hard to do }\end{array}$

8. resizing a group of graphics,

$\begin{array}{clllllll}1 & 2 & 3 & 4 & 5 & 6 & 7 \\ \text { Easy to do } & & & & & & & \text { Hard to do }\end{array}$

9. moving a group of graphics,

$\begin{array}{cllllll}1 & 2 & 3 & 4 & 5 & 6 & 7 \\ \text { Easy to do } & & & & & & \text { Hard to do }\end{array}$

10. rotating a group of graphics,

$\begin{array}{clllllll}1 & 2 & 3 & 4 & 5 & 6 & 7 \\ \text { Easy to do } & & & & & & & \text { Hard to do }\end{array}$


11. rotating an graphic,

$\begin{array}{clllllll}1 & 2 & 3 & 4 & 5 & 6 & 7 \\ \text { Easy to do } & & & & & & \text { Hard to do }\end{array}$

12. copying a group of graphics,

$\begin{array}{clllllll}1 & 2 & 3 & 4 & 5 & 6 & 7 \\ \text { Easy to do } & & & & & & & \text { Hard to do }\end{array}$

13. copying a box,

$\begin{array}{clllllll}1 & 2 & 3 & 4 & 5 & 6 & 7 \\ \text { Easy to do } & & & & & & & \text { Hard to do }\end{array}$

14. copying a line,

$\begin{array}{cccccccc}1 & 2 & 3 & 4 & 5 & 6 & 7 \\ \text { Easy to do } & & & & & & \text { Hard to do }\end{array}$

15. copying a circle,

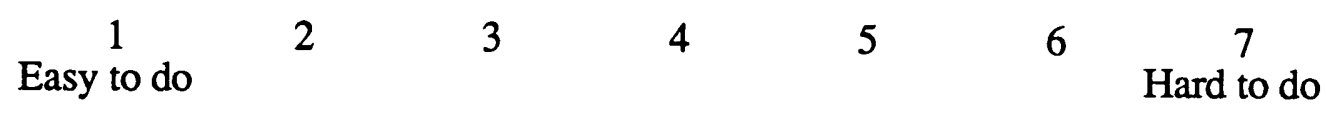

16. copying a polygon,

$\begin{array}{clllllll}1 & 2 & 3 & 4 & 5 & 6 & 7 \\ \text { Easy to do } & & & & & & \text { Hard to do }\end{array}$


17. erasing (or hiding) portions of graphics,

$\begin{array}{cccccccc}1 & 2 & 3 & 4 & 5 & 6 & 7 \\ \text { Easy to do } & & & & & & & \text { Hard to do }\end{array}$

18. moving a line,

$\begin{array}{cllllll}1 & 2 & 3 & 4 & 5 & 6 & 7 \\ \text { Easy to do } & & & & & & \text { Hard to do }\end{array}$

19. resizing a line,

$\begin{array}{cccccccc}1 & 2 & 3 & 4 & 5 & 6 & 7 \\ \text { Easy to do } & & & & & & \text { Hard to do }\end{array}$

20. fine positioning a line,

$\begin{array}{cccccccc}1 & 2 & 3 & 4 & 5 & 6 & 7 \\ \text { Easy to do } & & & & & & & \text { Hard to do }\end{array}$

21. moving a box,
Easy to do
23
4
5
$6 \quad 7^{\text {Hard to do }}$

22. resizing a box (making it larger or smaller),
1
Easy to do
3
4
5
$6 \quad 7^{\text {Hard to do }}$ 
23. fine positioning a box,

$\begin{array}{cllllll}1 & 2 & 3 & 4 & 5 & 6 & 7 \\ \text { Easy to do } & & & & & & \text { Hard to do }\end{array}$

24. typing text,

$\begin{array}{cccccccc}1 & 2 & 3 & 4 & 5 & 6 & 7 \\ \text { Easy to do } & & & & & & \text { Hard to do }\end{array}$

25. moving text,

$\begin{array}{clllllll}1 & 2 & 3 & 4 & 5 & 6 & 7 \\ \text { Easy to do } & & & & & & & \text { Hard to do }\end{array}$

26. fine positioning text,

$\begin{array}{cccccccc}1 & 2 & 3 & 4 & 5 & 6 & 7 \\ \text { Easy to do } & & & & & & \text { Hard to do }\end{array}$


Rate the package for these general tasks:

27. drawing graphics,

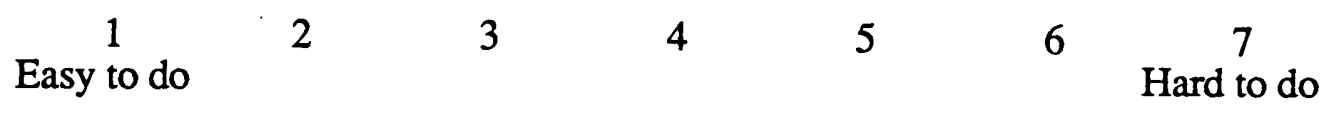

28. moving graphics,

$\begin{array}{cllllll}1 & 2 & 3 & 4 & 5 & 6 & 7 \\ \text { Easy to do } & & & & & & \text { Hard to do }\end{array}$

29. resizing graphics,

$\begin{array}{cccccccc}1 & 2 & 3 & 4 & 5 & 6 & 7 \\ \text { Easy to do } & & & & & & \text { Hard to do }\end{array}$

30. resizing a group of graphics,

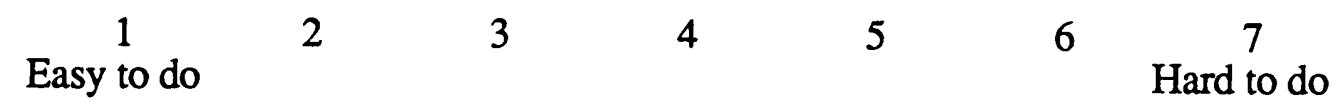

31. erasing/deleting an graphic,

$\begin{array}{cccccccc}1 & 2 & 3 & 4 & 5 & 6 & 7 \\ \text { Easy to do } & & & & & & \text { Hard to do }\end{array}$

32. using text (including all text manipulations),

$\begin{array}{clllllll}1 & 2 & 3 & 4 & 5 & 6 & 7 \\ \text { Easy to do } & & & & & & \text { Hard to do }\end{array}$


33. copying graphics,

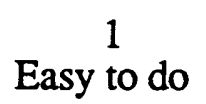

2

Easy to do

34. rotating graphic,
2

Easy to do
3

4

5

6

Hard to do

4

5

6

7

Hard to do 
Appendix III. Comparison Questionnaire 


\section{COMPARISON QUESTIONNAIRE}

For each of the following questions please indicate which package you would prefer for performing the task listed in each question. Please do not make any marks on the questionnaire. Indicate all of your answers on the opscan sheet. On the opscan, mark a 1,2 , or 3 for "Draw", "Paint", or "No difference", respectively. In questions where the "No difference" answer is not one of the choices you may not mark 3 on the opscan; you must select either 1 or 2 .

Which interface did you prefer for:

1. drawing a line?

Draw Paint

2. drawing a box?

Draw Paint

3. drawing a circle?

Draw Paint

4. drawing a polygon (triangle or other multisided shape)?

Draw Paint

5. moving a circle?

Draw Paint 
6. fine positioning a circle (e.g. adjacent to another)?

Draw

Paint

7. resizing a circle (i.e. making it bigger or smaller)?

Draw

Paint

8. resizing a group of graphics?

Draw

Paint

9. moving a group of graphics?

Draw

Paint

10. rotating a group of graphics?

Draw

Paint

11. rotating an graphic?

Draw

Paint

12. copying a group of graphics?

Draw

Paint 
13. copying a box?

Draw

Paint

14. copying a line?

Draw

Paint

15. copying a circle?

Draw

Paint

16. copying a polygon?

Draw

Paint

17. erasing (or hiding) portions of graphics?

Draw

Paint

18. moving a line?

Draw

Paint

19. resizing a line?
Paint 
20. fine positioning a line?

Draw Paint

21. moving a box?

Draw

22. resizing a box (making it larger or smaller)?

Draw

23. fine positioning a box?

Draw

Paint

24. moving text?

Draw

Paint

25. fine positioning text?

Draw

Paint 
In general, which interface did you prefer for:

26. drawing an graphic?

Draw

Paint

27. moving graphics?

Draw

Paint

28. resizing a graphic?

Draw

Paint

29. resizing a group of graphics?

Draw

Paint

30. erasing/deleting a graphic?

Draw

Paint

31. using text (including all text manipulations)?

Draw

Paint 
32. copying graphics?

Draw Paint

33. rotating graphics?

Draw Paint

34. If you had to choose one, which interface would you select for performing your graphics work?
Draw
Paint

35. Please rank Draw on a scale of 1 to 10 :

INDICATE YOUR RANKING ON THE OPSCAN

36. Please rank Paint on a scale of 1 to 10 :

INDICATE YOUR RANKING ON THE OPSCAN 
Appendix IV. Informed Consent and Photographic Release Forms 


\section{PARTICIPANT'S INFORMED CONSENT FORM}

This study intends to evaluate two types of graphics software packages. As a participant in this study, you have certain rights as explained below. This form will enumerate these rights and obtain your written consent to participate in the study.

1. You have the right to withdraw from this study at any time and for any reason. If you decide to terminate your participation, you will be paid only for the amount of time you have participated.

2. You have the right to inspect your data and withdraw it from the experiment if you feel that you should for any reason. Data are processed and analyzed after a subject has completed the study. At that time, these data will be treated with anonymity since all identifying information will be removed from the data.

3. You have the right to be informed of the overall results of this study (if you so desire). If you wish to receive an overview of the results, include your address with your signature below.

If you have further comments or questions about your rights as a participant, please contact Mr. Charles Waring, chairman of the Institutional Review Board for the Use of Human Subjects in Research. He may be contacted at:

Mr. Charles Waring

Office of Sponsored Research Programs

301 Burruss Hall

Virginia Polytechnic Inst. and State University 
Blacksburg, VA 24061

Tel. (703) 961-5283

The researcher for this study will be Michael Mohageg, a graduate student in Industrial Engineering and Operations Research. If you have questions about the study or your rights as a participant, please don't hesitate to ask the researcher. Unless the question will somehow affect the study, the researcher will do his best to answer your questions.

Your signature below indicates that you have read this document in its entirety, and understand your rights as a participant, and that you consent to participate. Thanks for your cooperation.

Participant's Signature

Witness' signature

Print your name and address if you wish to receive a summery of the results. 


\section{VIDEO CONSENT FORM}

I, , give permission to be videotaped when being

a participant in the Graphics Software Study. I have been informed about the study in detail and know that the data obtained will be treated with anonymity.

Signature

Name

Date 
Appendix V. Training Manuals 
Lessons for the Draw Program 
O In this handout, the following symbols indicate specific actions.<smiles>ClC(Cl)(Cl)[C@H]1CC[C@H]1C(Cl)(Cl)Cl</smiles>

means Click: Position the pointer, then briefly press and release the mouse button.<smiles>[R16]CC[C@H](C)CC</smiles>

means Drag: Position the pointer, press and hold down the mouse button while you move the mouse, then release the mouse button.

O There are ten icons on the left side of the screen (in the "tool" area). We will be concerned with only the following six icons:

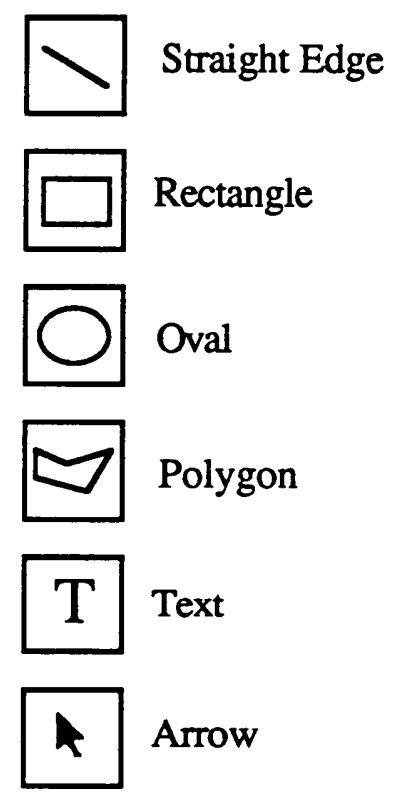


The Straight Edge Icon

Click the cursor arrow in the Straight Edge icon. The icon will become shaded to indicate that you've selected it (this is true for selecting any of the icons). If you move the cursor to the drawing area, it (the cursor) will appear as a + shape.

The Straight Edge icon is used to draw straight lines in various directions. To draw a line, one need only drag the + shaped cursor from point $\mathrm{A}$ to point $\mathrm{B}$, as shown below (see previous page if you don't know what "drag" is). Try it!!
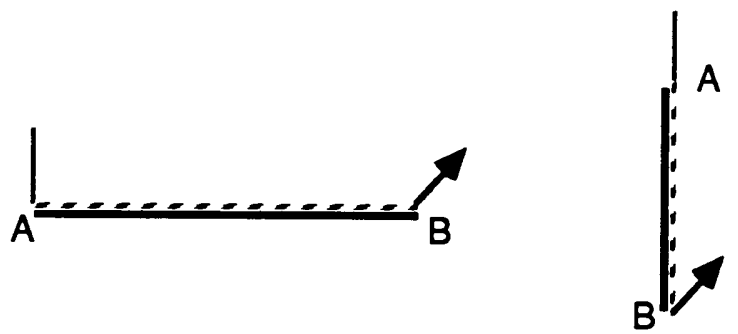

After you've drawn a line, two small squares should appear on the ends of the line. These squares are called "Handles" and indicate that an object is selected.

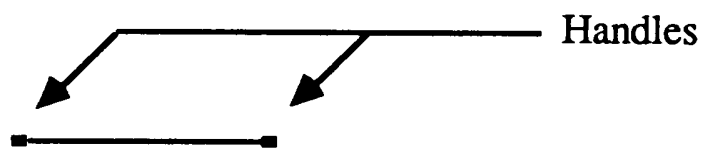

After drawing any object these handles will appear. We will discuss what the handles are used for in a later section, but for now just click the cursor in a free area of the screen to unselect the line (the handles will disappear).

We will be concerned with drawing only perfectly vertical lines, perfectly horizontal lines, and lines with a 45 degree orientation. To draw horizontal, vertical, or 45 degree lines, you must hold down the "Shift" key as you drag the cursor in the drawing area. So: 


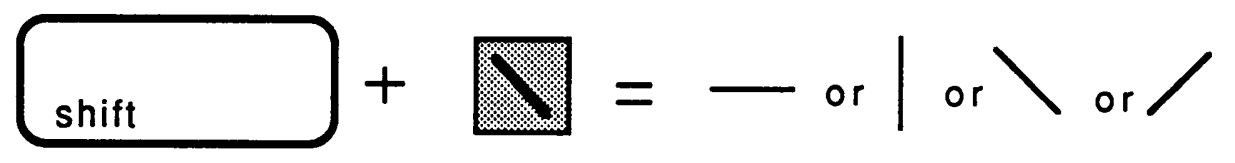

Please try drawing 4 or 5 lines with the "Shift" key held down. 
The Rectangle and Oval Icons

These icons are used to create smooth, symmetrical shapes with a single, diagonal drag of the mouse. Click in the Rectangle icon. Again, the cursor will appear as a + shape when moved to the drawing area. Rectangles and ovals are created as shown below:
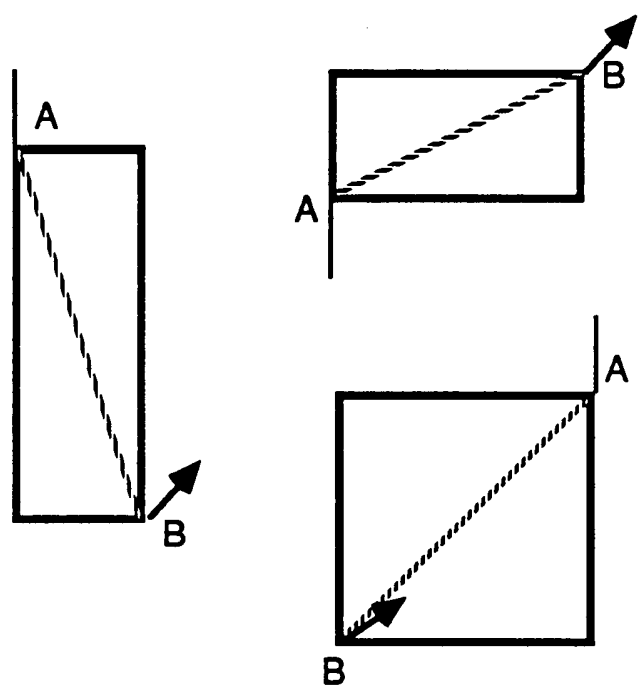

You must drag the mouse from point A to point B to draw a box. Don't forget to click the cursor in a free area to unselect what you've just drawn. Try drawing 3 or 4 boxes (rectangles).

Now, click in the Oval icon. The same principles apply for the ovals. The best way to get the hang of it is to try it. Please try drawing 4 or 5 ovals.

If you need to draw perfectly square boxes or perfectly round circles (as opposed to an ellipse or oval) apply the following steps. Pressing the "Shift" key as you draw a box will yield a perfect square. Pressing "Shift" as you draw an oval will yield a perfect circle. Try drawing some squares and circles.

for a square do 


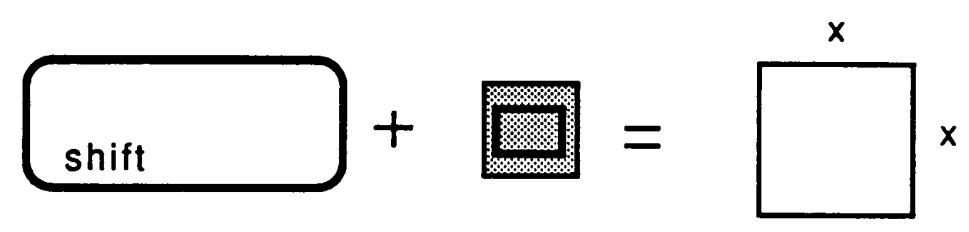

and for a perfect circle do

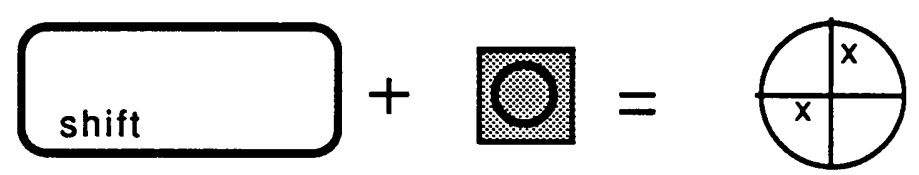


The Text Icon

The Text Icon is for labels, headings, captions, or any other use of text in graphics applications. Click in the Text Icon. Now if you move the cursor, it should appear as an I-bar:

$$
\Upsilon
$$

To insert text, move the I-bar to the desired location and click the mouse button. At that point you will see a flashing vertical line that looks like this:

You are now ready to insert text. Type in the appropriate text. If you wish to type in more text in another location, simply move the I-bar to that location, click the mouse button, and start typing. If you make a mistake you must backtrack using the "Delete" key, and then correct your mistake. If you want to leave the text "mode" you must click on a different icon. Try moving the I-bar to the lower left corner of the screen and typing in your full name. Next, Move the I-bar to another location, type your name, then backtrack (using the "Delete" key, and type in "The Republic of Namibia." Keep practicing with the text feature till you are familiar with its operation.

Two points to remember about text:

O While you're typing letters you may press the "Delete" button to make corrections. However, no other word processing capabilities are available for text in MacPaint.

O The Style and Font items in the menu bar (the top row of the screen) relate to text, but you will not be concerned with either during the coarse of the study. Both of these characteristics will be pre-set for you. 
The Polygon Icon

This icon is used when you need to draw polygons. The only polygons you'll be drawing today are triangles.

Click on the Polygon Icon. Your cursor should have a + shape when it is returned to the drawing area. Move the cursor to the desired spot (point A in illustration), and click the mouse button (don't drag, just click!). Now, as you move the mouse (without pressing the mouse button) the cursor draws a line, but notice that your point of origin remains stationary (or "anchored"). When you click the mouse again (at point $B$ ), the point at which you clicked will become the new anchor point. These operations are demonstrated below:

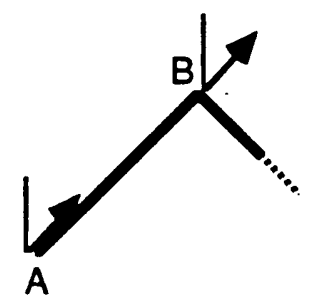

To complete the triangle keep moving the cursor to a third point (point $C$ ), click, then move the cursor back to point $A$ and click again. See the figure below for illustration. Once you have closed the triangle, the cursor no longer draws lines! Again, the handles will appear once you complete the triangle. Click in a free area to unselect the object.

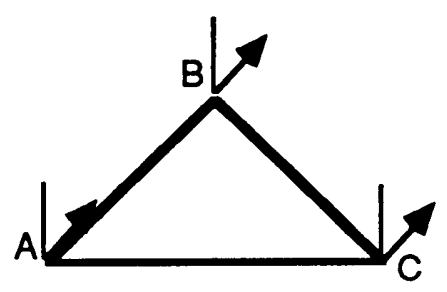

Practice drawing at least 4 or 5 triangles and (try other poly gons if you wish). 
The Arrow Icon

The Arrow icon has five functions: (1) selecting, (2) moving, (3) copying, (4) clearing (or erasing), and (5) "resizing" an object (or group of objects). Resizing means changing the dimensions of an existing object. For instance, one might resize a 1- by 2 inch rectangle to become a 1 - by 1 -inch box.

Let's begin with selecting an object with the Arrow. First, draw an oval in an available area of the screen. Once you've drawn the oval follow the directions given below.

Selecting an oval:

O Click in the Arrow icon. The cursor should appear like an arrow, as shown below.

O To select an object, you should move the cursor to any position within the boundries of the oval, and click.

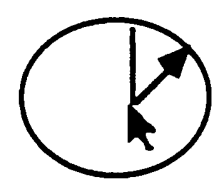

O The oval's handles will appear indicating that the object has been selected.

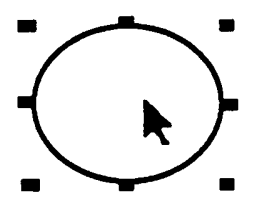

O If you wish to select a different object simply move the cursor to the object, and click. You will notice that the previously selected item will become unselected, and the new object will be selected (as shown by the appearance of the handles).

O You can select more than one item at-a-time. You may wish to select two nearby objects or a few adjacent objects. To accomplish this task you should move the cursor 
to an area near the objects, but not actually touching any of the objects. When you press the mouse button (and hold it down), the cursor will change to the shape of a hand.

O As you drag a dashed rectangle will appear. Drag diagonally (A to B in the illustration) to completely surround the objects of interest with the dashed rectangle.

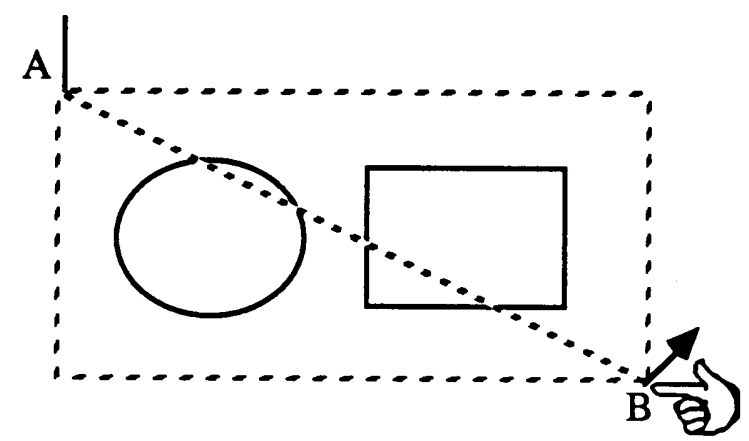

When you release the button both the oval and rectangle will be selected. Any time you perform this maneuver any item that is completely surrounded by the dashed rectangle will be selected. Selecting more than one item is called "grouping."

O If you do not completely surround the objects of interest, not all will be selected. For instance, in the illustration below only the oval will be selected:

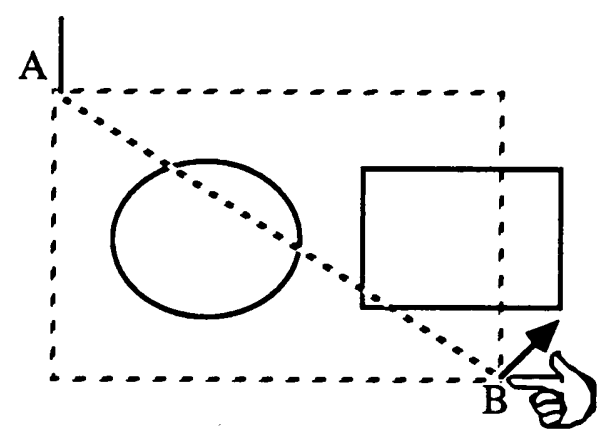

When the mouse button is released the result will look like this.

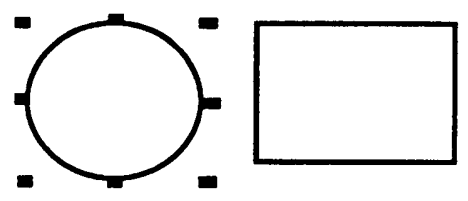

Please try selecting objects singularly, and as groups (i.e., grouping). 
Once the object(s) has been selected, it is ready to be copied, deleted, or resized (these functions will work with groups of objects as well). However, we shall begin with the task of moving an object. 
Moving an oval:

O Draw an oval

O Move the arrow shaped cursor inside the oval.

O While the cursor is inside the oval (it looks like an arrow), drag the mouse in any direction (A to B in the illustration). The oval will move with the cursor in the same direction. Once you release the mouse button the oval will remain in its new position.

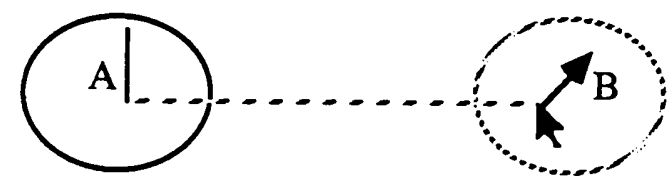

Try moving the oval and any of your other drawings or text. You need not select the object(s), before moving them. 
Next we'll consider copying.

Copying an oval:

O Draw an oval.

O Select the oval.

O Move your cursor to the menu bar on the top line of the screen. Your cursor will retain its arrow shape. Now, pick on the word Edit. If you hold down the mouse button a menu should appear. You must drag the cursor to the word Copy then release the mouse button.

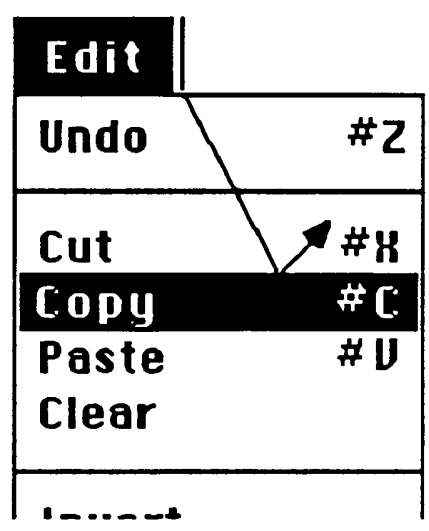

The object(s) you selected will be copied and kept in a "buffer" memory.

O The next step is to "paste" the copied material onto the screen. To do this, you must drag to the word Paste in the Edit menu.

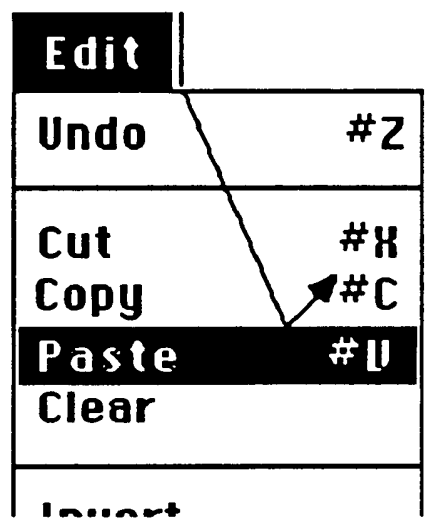


The material will be pasted partially covering the object you copied. Now, the new (pasted) item will be selected; you may manipulate the copied material as you wish (i.e., move, copy again, etc.). Try copying 4 or 5 things that you've drawn or typed also try copying and pasting groups of objects. Please practice with this feature till you are quite familiar with it.

Next, we'll look at clearing something form the screen (or deleting). 
Clearing an oval:

O Draw an oval.

O Select the oval.

O Now press the "Delete" key. The selected item will be cleared form the screen.

Please try drawing things, and then clear them. Do this for at least 4 or 5 items with both objects and text. Finally, we'll learn how to resize and rotate objects. 


\section{Resizing a rectangle:}

O Draw a rectangle.

O Select the rectangle.

O Move the cursor to the middle handle (little black squares) on the right side.

Position the tip of the cursor on the handle, press the mouse button, and hold it down. The handle should disappear. Now, drag to the right side (A to B in the illustration). The image on the screen will look like this:

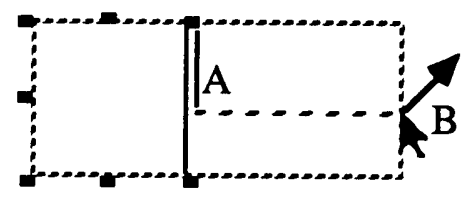

When you release the mouse button at point B the resized box will look like this:

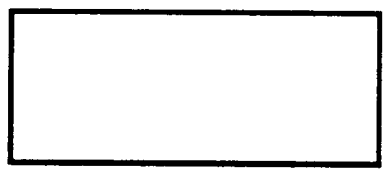

Notice that you've resized the box without moving it out of position. Additionally, the upper and lower sides have retained their relative positions. Only their length has been altered.

O If you wish to resize the box on two dimension (i.e., both width and length) you must follow these steps. Select the box, as before. Now, move the cursor to one of the corner handles (lower right in the illustration). Perform the same actions as before (drag from $A$ to $B$ ) with this handle, and you'll change both length and width.

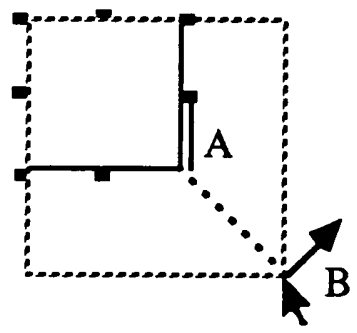


Try drawing 5-6 lines, boxes, and ovals, then resize them to different dimensions. Group some objects and try resizing the group as well. Practice with resizing till you become quite familiar with it. 
Rotating a rectangle:

O Draw a rectangle.

O Select the rectangle.

O Move your cursor to the menu bar (top row of the screen), and pick on the word Arrange. Hold the mouse button down and drag to Ro tate Right.

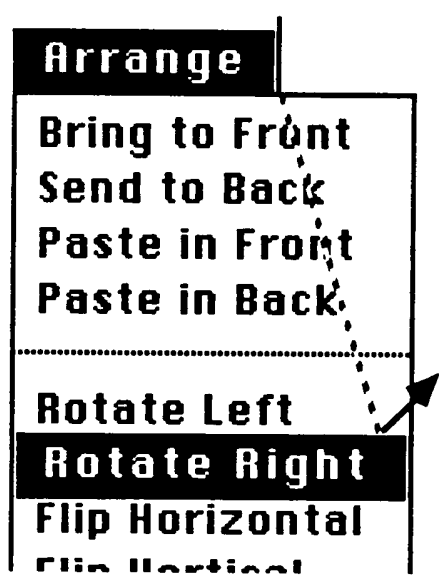

Your rectangle will be rotated 90 degrees around its center (i.e. the axis for rotation). Rotate Left will rotate the object 90 degrees in the opposite direction. Try drawing a variety of different objects and rotating them; try rotating grouped objects as well. Do this at least 4 or 5 times. 
The Undo command.

O The first item under the Edit menu is the Undo command. Selecting this command will "undo" your latest (last) action. Let's use an example to explain this command.

O Draw a rectangle.

O Now, draw a circle inside the rectangle. Perhaps you're not satisfied with this circle, and you wish to draw it over again. Move your cursor to the Edit menu and select Undo. The circle will disappear (if it doesn't please notify the researcher).

O The Undo command works for the last action you performed. So if you drew the circle, moved it, and then selected Undo the circle would simply move back to its original location. 
Some Last Words on File Management

O After you've finished working with a file you must save the changes or manipulations you've made. To save your file move the cursor to File in the menu bar and drag to the word Save (do not pick on the words Save As...). All of the changes to the file will be recorded.

O Once you've saved your file, you must close it. To close a file move your cursor to the small box in the upper left corner and click in the box. The file will close automatically.

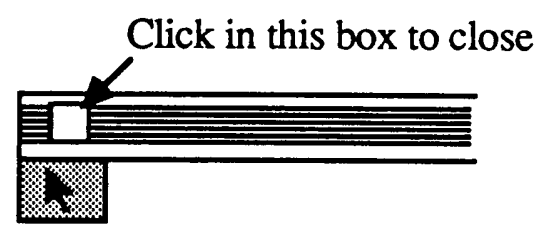

If you haven't saved your changes, the computer will ask you if you wish to save. Please pick on the word Yes. It is essential that you save your file before closing it. You may also close the file by dragging to the word Close in the File menu.

O To open a file drag to the word Open in the File menu. In a few moments you will see a directory of the files. Scroll to the file name of interest, and click on it. A black rectangular bar will surround the name, indicating that it has been selected. Next, move the cursor to the word Open (on the right side of the directory) and click. The file will appear on your screen in a matter of seconds. There is only one page of material in each file.

O If you open a file and the entire page is not visible, you should resize the file itself. this is done very simply. Move your cursor to the lower right corner of the screen. Position the cursor inside the square with the two small boxes (shown below). 


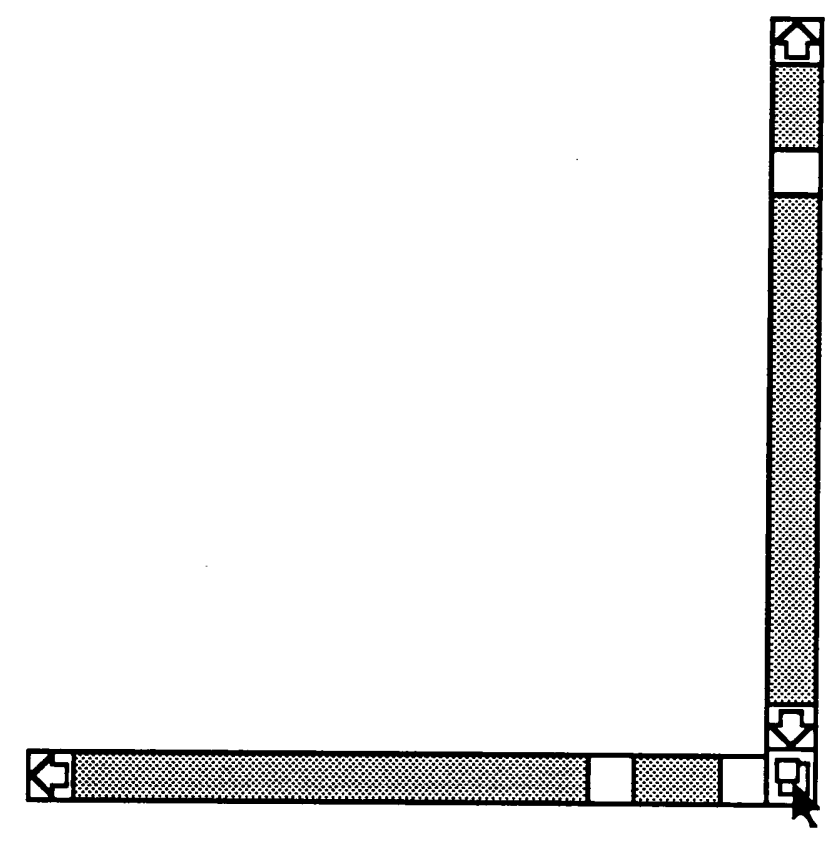

Now, slowly drag the corner to the left and lower sides of the screen. The entire file will be presented. 
Lessons For the Paint Program 
O In this handout, the following symbols indicate specific actions.

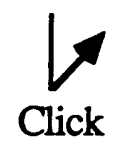

means Click: Position the pointer, then briefly press and release the mouse button.

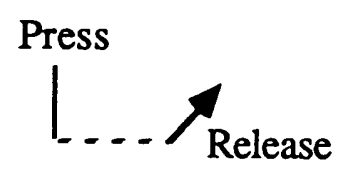

means Drag: Position the pointer, press and hold down the mouse button while you move the mouse, then release the mouse button.

O There are twenty icons on the left side of the screen (in the "tool" area). We will be concerned with only the following 8 icons:

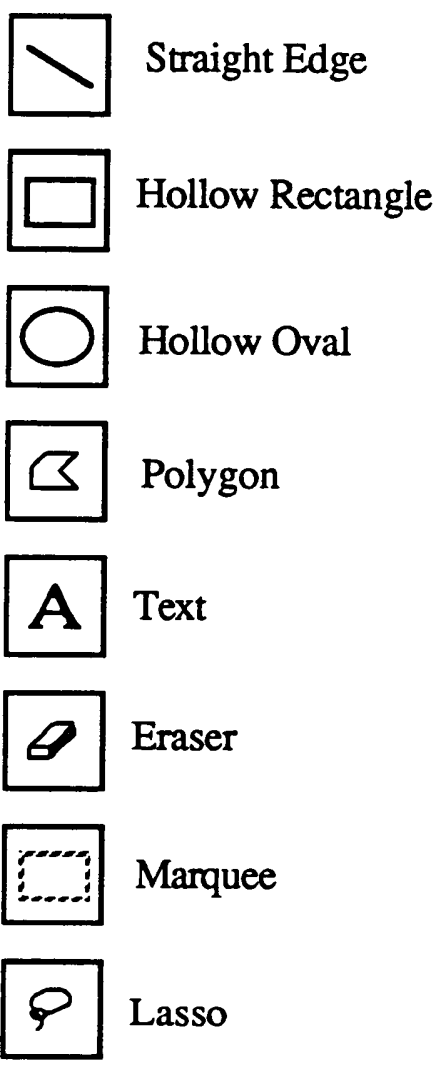


O There is one step that you must do before starting to draw anything on a newly opened Paint file. Move the cursor to the lower left corner of the screen. Your cursor should take on the shape of an arrow.

O Now position the cursor in the white box as illustrated below.

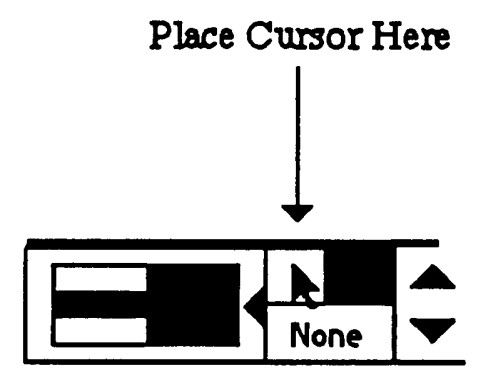

O Click in the white box, and the area will appear as shown below.

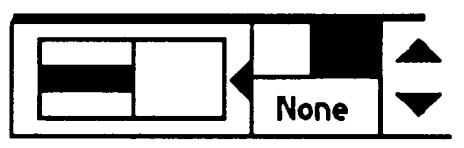

This step is done to make sure you will draw light colored objects. Notice the color of the box on the left has hanged form dark to bright. 
The Straight Edge Icon

Click the cursor arrow in the Straight Edge icon. The icon will turn black to indicate that you've selected it (this is true for selecting any of the icons). If you move the cursor to the drawing area, it (the cursor) will appear as a + shape.

The Straight Edge icon is used to draw straight lines in various directions. To draw a line, one need only drag the + shaped cursor from point $\mathrm{A}$ to point $\mathrm{B}$, as shown below (see previous page if you don't know what "drag" is). Try it!!
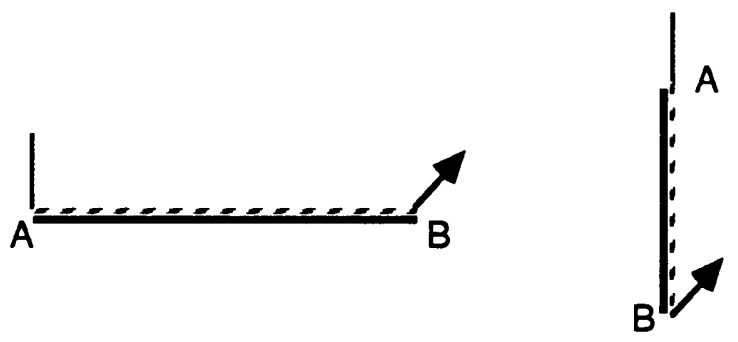

We are concerned with drawing only perfectly vertical lines, perfectly horizontal lines, and lines with a 45 degree orientation. To draw horizontal, vertical, or 45 degree lines, you must hold down the "Shift" key as you drag the cursor in the drawing area. So:

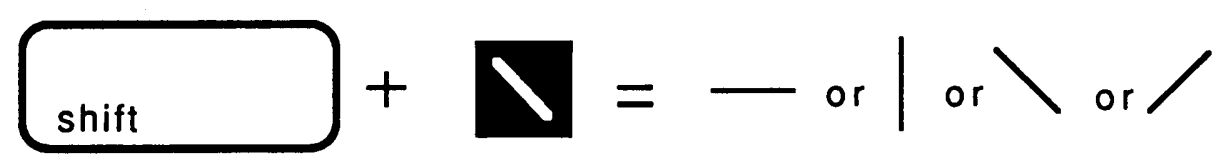

Please try drawing 4 or 5 lines with the "Shift" key held down. 
The Rectangle and Oval Icons

These icons are used to create smooth, symmetrical shapes with a single, diagonal drag of the mouse. Click in the Rectangle icon. Again, the cursor will appear as a + shape when moved to the drawing area. Rectangles and ovals are created as shown below:
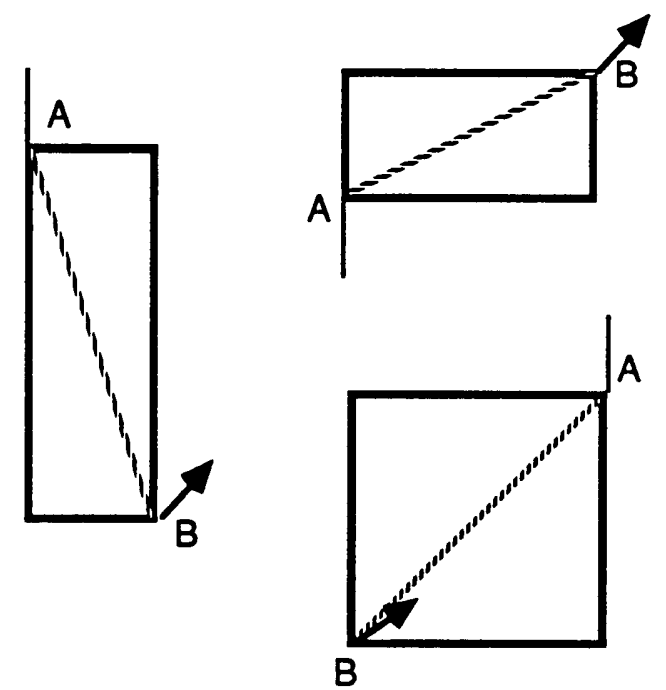

You must drag the mouse from point A to point B to draw a box. Try drawing 3 or 4 boxes.

Now, click in the Oval icon. The same principles apply for the ovals. The best way to get the hang of it is to try it. Please try drawing 3 or 4 ovals.

If you need to draw perfectly square boxes or perfectly round circles (as opposed to an ellipse or oval) apply the following steps. Pressing the "Shift" key as you draw a box will yield a perfect square. Pressing "Shift" as you draw an oval will yield a perfect circle. Try drawing some squares and circles.

for a square do 


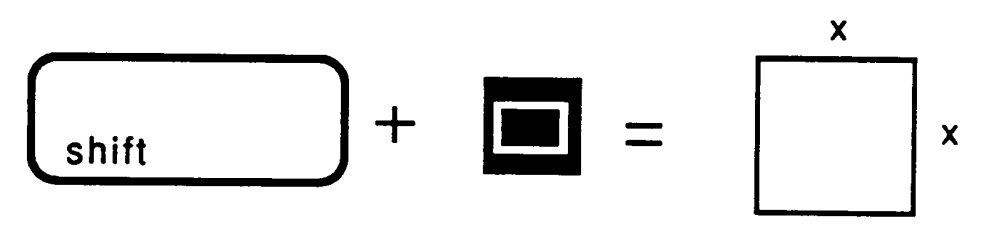

and for a perfect circle do

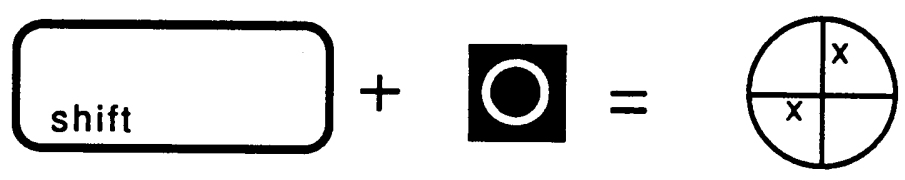


The Text Icon

The Text Icon is for labels, headings, captions, or any other use of text in graphics applications. The Text Icon's capabilities should not be mistaken for word processing. Although this icon uses letters form the keyboard, each letter is a graphic form.

Click in the Text Icon. Now if you move the cursor, it should appear as an I-bar:

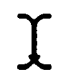

To insert text, move the I-bar to the desired location and click the mouse button. At that point you will see a flashing vertical line that looks like this:

You are now ready to insert text. Type in the appropriate text. If you wish to type in more text in another location, simply move the I-bar to that location, click the mouse button, and start typing. If you make a mistake you must backtrack using the "Delete" key, and then correct your mistake. If you want to leave the text "mode" you must click on a different icon. Try moving the I-bar to the lower left comer of the screen and typing in your full name. Next, Move the I-bar to another location, type your name, then backtrack (using the "Delete" key, and type in "The Republic of Namibia." Keep practicing with the text feature till you are familiar with its operation.

Two points to remember about text:

O While you're typing letters you may press the "Delete" button to make corrections. However, no other word processing capabilities are available for text in MacPaint.

O The Font and FontSize items in the menu bar (the top row of the screen) relate to text, but you will not be concerned with either during the coarse of the study. Both of these characteristics will be pre-set for you. 
The Polygon Icon

This icon is used when you need to draw polygons. The only polygons you'll be drawing today are triangles.

Click on the Polygon Icon. Your cursor should have a + shape when it is returned to the drawing area. Move the cursor to the desired spot (point A in illustration), and click the mouse button (don't drag, just click!). Now, as you move the mouse (without pressing the mouse button) the cursor draws a line, but notice that your point of origin remains stationary (or "anchored"). When you click the mouse again (at point B), the point at which you clicked will become the new anchor point. These operations are demonstrated below:

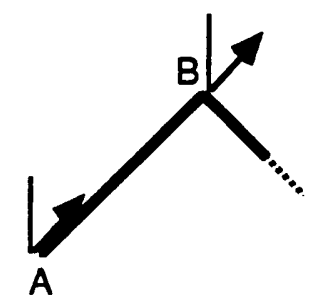

To complete the triangle keep moving the cursor to a third point (point $\mathrm{C}$ ), click, then move the cursor back to point A and click again. See the figure below for illustration. Once you have closed the triangle, the cursor no longer draws lines!

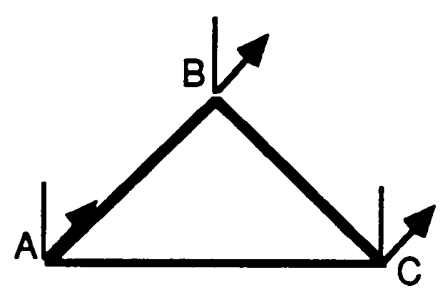

Practice drawing at least 4 or 5 triangles and (try other polygons if you wish). 
The Eraser Icon

Click in the Eraser Icon, and return your cursor to the drawing area. The cursor should appear as a square like the one below:

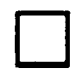

Your cursor will behave like an eraser. To erase something you must drag the mouse in the drawing area. As you drag, the square-shaped cursor erases everything in its path. In the illustration, as the cursor is dragged from point A to Point B everything the cursor passes over is erased.

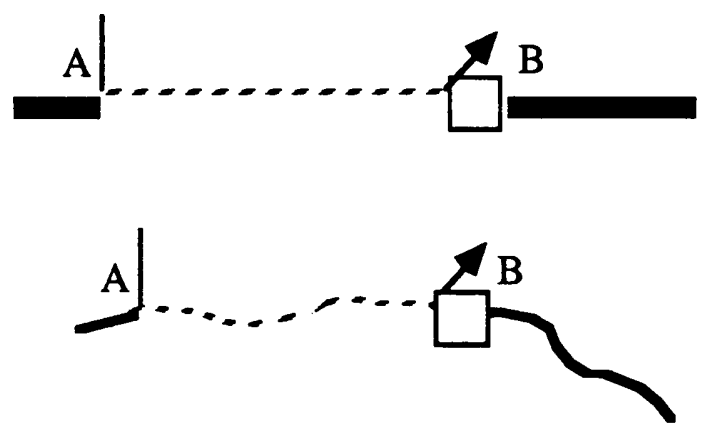

Try drawing some objects or typing text, and then erase parts of them (or all of them). You will learn a quicker way of erasing an entire object later in the lesson (using the Lasso and Marquee icons). 
The Lasso Icon

The Lasso icon has four basic functions: (1) selecting, (2) moving, (3) copying, and (4) clearing (or erasing) an object (or group of objects). Let's begin with selecting an object with the Lasso. First, draw an oval in an available area of the screen. Once you've drawn the oval follow the directions given below.

Selecting an oval:

O Click in the Lasso icon. The cursor should appear like a "lasso," as shown below.<smiles>[18OH]</smiles>

O Drag the Lasso around the oval, as illustrated below.

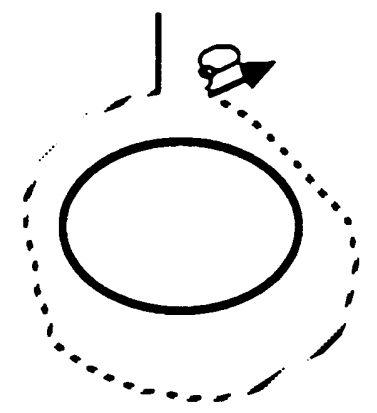

O The oval should start to blink, indicating that it has been selected.

O The Lasso may be dragged around any number of objects. Thus, if you wish to select an oval and part of a nearby box you drag the lasso around the desired parts. This action is called "grouping."

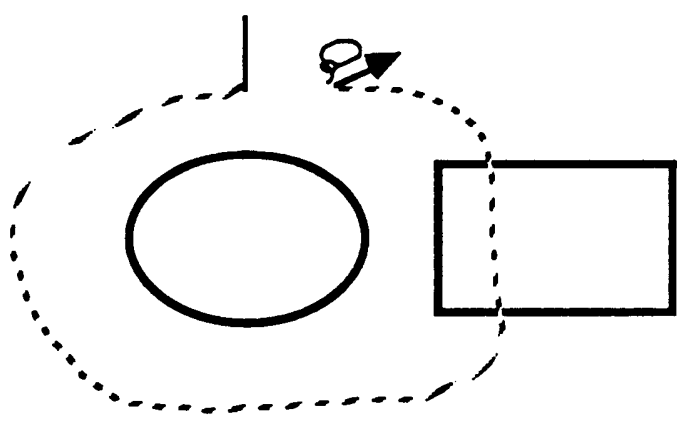


Once the object(s) has been selected, it is ready to be moved, copied, or deleted (these functions will work with groups of objects as well). Try selecting single items. Also practice selecting groups of objects (grouping). We shall begin with moving an object. 
Moving an oval:

O Select an oval.

O Move the lasso shaped cursor inside the selected oval. The cursor should change shape and appear as an arrow when moved inside the oval.

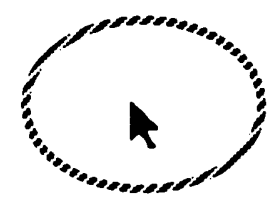

O While the cursor is inside the oval (it looks like an arrow), drag the mouse in any direction. The oval will move with the cursor in the same direction. Once you release the mouse button the oval will remain in its new position.

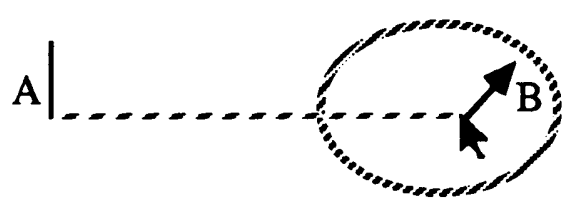

Try moving the oval and any of your other drawings or text. You must select the object(s), and then move them. 
Next we'll consider copying.

Copying an oval:

O Select an oval.

O Move your cursor to the menu bar on the top line of the screen. Your cursor will change back to an arrow shape. Now, pick on the word Edit. If you hold down the mouse button a menu should appear. You must drag the cursor to the word Copy then release the mouse button.

\begin{tabular}{|l|r|}
\hline Edit & \\
\hline Undo & $\# Z$ \\
\hline Cut & $\# 4$ \\
\hline Copy & $\# \mathrm{C}$ \\
\hline $\begin{array}{l}\text { Paste } \\
\text { Clear }\end{array}$ \\
\hline Innort \\
\hline
\end{tabular}

The object(s) you selected will be copied and kept in a "buffer" memory.

O The next step is to "paste" the copied material onto the screen. To do this, you must drag to the word Paste in the Edit menu.

\begin{tabular}{|c|c|}
\hline Edit & \\
\hline Undo & \#2 \\
\hline $\begin{array}{l}\text { Cut } \\
\text { Copy }\end{array}$ & $\begin{array}{r}\# \mathrm{~K} \\
\# \mathrm{C}\end{array}$ \\
\hline Paste & \#I \\
\hline Clear & \\
\hline
\end{tabular}


The material will be pasted in the middle of the screen, and will be blinking. Now, you may manipulate the copied material as you wish (i.e., move, copy again, etc.). Try copying 4 or 5 things that you've drawn or typed; also try copying and pasting groups of objects. Please practice with this feature till you are quite familiar with it.

Finally, we'll look at clearing something form the screen (or deleting).

Clearing an oval:

O Draw an oval.

O Select the oval with the Lasso.

O Now press the "Delete" key. The selected item will be cleared form the screen.

Please try drawing things, and then clear them. Do this for at least 4 or 5 items. 
The Marquee Icon

Everything that you learned about the Lasso icon is applicable for the Marquee. Both of these tools operate in a similar fashion. As with the Lasso, the Marquee may be used for selecting, moving, copying, and clearing an object (or group of objects). The Marquee also allows you the capability to "resize" and rotate objects. Resizing means changing the dimensions of an existing object. For instance, one might resize a 1- by 2 inch rectangle to become a 1- by 1 -inch box. First, let's look at the functions in the Marquee that are similar to the Lasso.

Selecting a rectangle (or oval, whichever you like better!):

O Draw a rectangle (or oval).

O Click the cursor in the Marquee Icon. The cursor should have a + shape when returned to the drawing area.

O The Marquee tool allows you to select rectangular areas. To select an area you must drag the cursor to surround the area of interest like so:

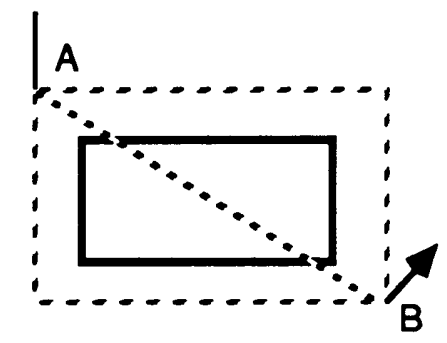

The outlined rectangle shows the selected area. A difference between the Lasso and Marquee should be pointed out. With the Lasso only the surrounded objects were selected; however, with the Marquee the surrounded area is selected. For example, in the case shown above all the area inside the outlined rectangle is selected. The selected area is illustrated below by the shading. 


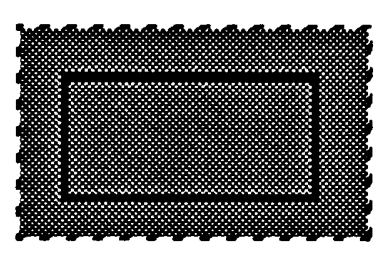

Practice selecting areas with the Marquee.

Moving a rectangle:

O Select a rectangle with the Marquee.

O Move the selected area just as you did with the Lasso. That is, place the cursor in the selected area. the cursor should change the an arrow. Now drag the selected area to any desired position. In the figure below the rectangle (and surrounding blank area) are moved from A to B.

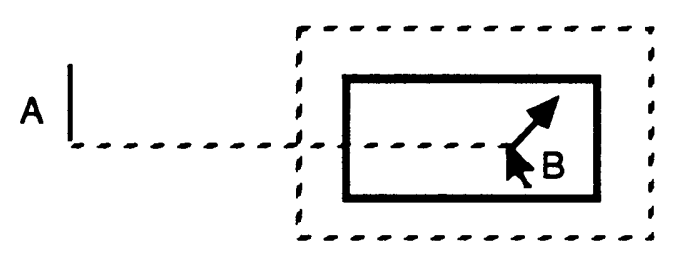

Please draw 4 or 5 shapes and text, then use the Marquee to select and move them (practice moving grouped objects too). 
Copying a rectangle:

O Select a rectangle.

O Select Copy from the Edit menu.

0 Click in a free area of the screen to unselect the rectangle. This step must be done before pasting.

O Finally, select Paste form the Edit menu. The copied material will be pasted in the middle of your screen. 
Clearing a rectangle:

O Clearing a selected area is similar to clearing with the Lasso. First you must select the area with the Marquee.

O Next, you must press the "Delete" key. The selected area will disappear.

Try drawing shapes, them use the Marquee operations to clear them form the screen. 
Resizing a rectangle.

O Draw a rectangle.

O Select the rectangle with the Marquee. Try to surround the rectangle as closely as possible, as shown in the illustration.

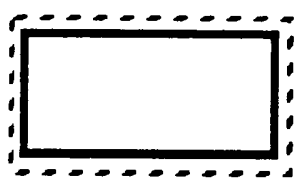

O Move your cursor to the selected rectangle. The cursor will change to an arrow shape. Position the cursor so that it is touching the right side of the rectangle. The illustration indicates the positioning of the cursor.

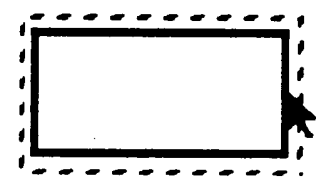

O Hold down the "Apple" key and press the mouse button, and drag the cursor simultaneously. The right side of the rectangle will move with the cursor.

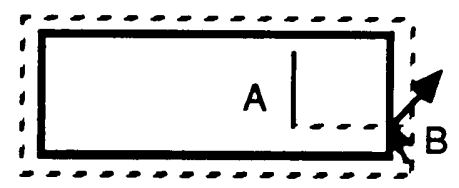

Once you release the mouse button, the side will remain in its new position. Now try moving the lower side of the rectangle, as presented in the illustration.

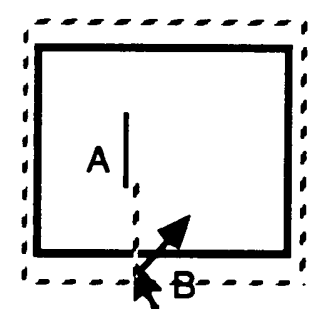

O Note that if you move a side the two sides that are perpendicular to the moving side retain their relative distances. In essence they don't move out of position. If you wish 
to resize two sides simultaneously, you must move the cursor to a corner and drag the corner while you press the "Apple" key.

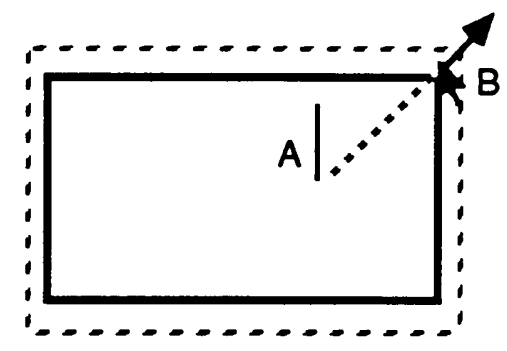

So remember that,

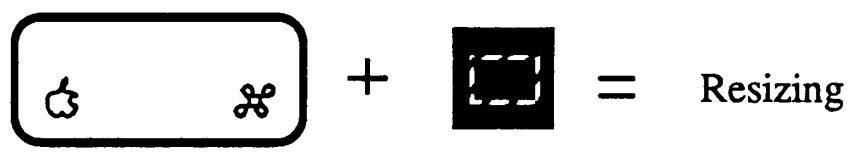

Please draw 7-8 ovals, rectangles, and lines, and resize them for practice. Group some objects and try resizing the group as well. You need to be quite familiar with this function. 
Rotating a rectangle:

O Draw a rectangle.

O Use the Marquee to select it.

O Select Rotate form the Edit menu.

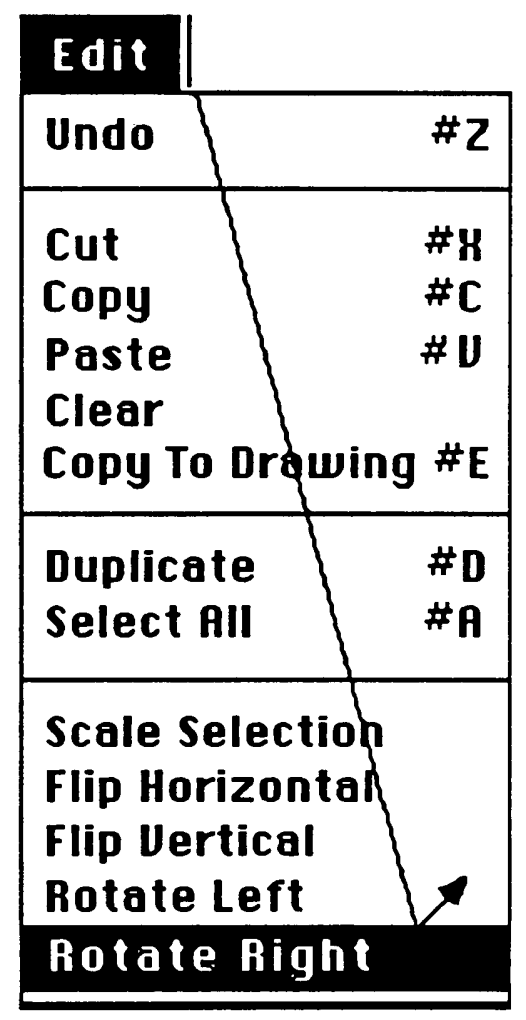

O Your rectangle will be rotated 90 degrees around its center (i.e. the axis for rotation). Rotate Left will rotate the object 90 degrees in the opposite direction. Try drawing a variety of different objects and rotating them; try rotating with groups as well. Do this at least 4 or 5 times. 
The Undo command.

O The first item under the Edit menu is the Undo command. Selecting this command will "undo" your latest (last) action. Let's use an example to explain this command.

O Draw a rectangle.

O Now, draw a circle inside the rectangle. Perhaps you're not satisfied with this circle, and you wish to draw it over again. Move your cursor to the Edit menu and select Undo. The circle will disappear (if it doesn't please notify the researcher).

O The Undo command works for the last action you performed. So if you drew the circle, moved it, and then selected Undo the circle would simply move back to its original location. 
Some Last Words on File Management

O After you've finished working with a file you must save the changes or manipulations you've made. To save your file move the cursor to File in the menu bar and drag to the word Save (do not pick on the words Save As...). All of the changes to the file will be recorded.

O Once you've saved your file, you must close it. To close a file move your cursor to the small box in the upper left corner and click in the box. The file will close automatically.

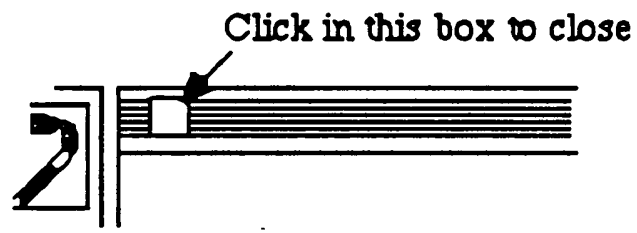

If you haven't saved your changes, the computer will ask you if you wish to save. Please pick on the word Yes. It is essential that you save your file before closing it. You may also close the file by dragging to the word Close in the File menu.

O To open a file, drag to the word Open in the File menu. In a few moments you will see a directory of the files. Scroll to the file name of interest, and click on it. A black rectangular bar will surround the name, indicating that it has been selected. Next, move the cursor to the word Open (on the right side of the directory) and click. The file will appear on your screen in a matter of seconds. There is only one page of material in each file.

O If you open a file and the entire page is not visible, you should resize the file itself. this is done very simply. Move your cursor to the lower right corner of the screen. Position the cursor inside the square with the two small boxes (shown below). 


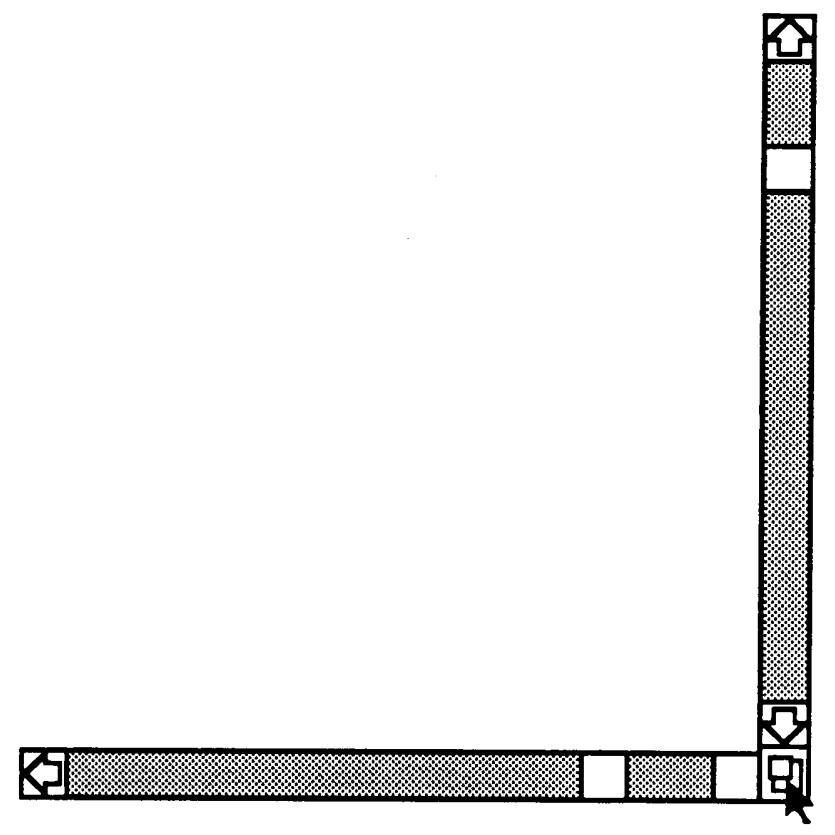

Now, slowly drag the corner to the left and lower sides of the screen. The entire file will be presented. 
Appendix VI. Test Tasks and Time Requirements 
Table A. Time Requirement Criteria used for Different Subject Experience Levels.

\begin{tabular}{|c|c|c|c|c|c|c|c|c|}
\hline \multirow{3}{*}{ TASK DESCRIPTION } & \multicolumn{4}{|c|}{ NOUICES } & \multicolumn{4}{|c|}{ EHPERIENCED } \\
\hline & \multicolumn{2}{|c|}{ OBJ. ORT. } & \multicolumn{2}{|c|}{ BIT-MAP. } & \multicolumn{2}{|c|}{ OBJ. ORT. } & \multicolumn{2}{|c|}{ BIT-MAP. } \\
\hline & $\bar{Z}$ & s & $\overline{\mathbf{X}}$ & s & $\overline{\mathbf{X}}$ & s & $\bar{X}$ & $\mathbf{s}$ \\
\hline $\begin{array}{l}\text { Draw a } 1 \text { - by } 1 \text {-inch box, and move it } \\
\text { to specified location. }\end{array}$ & 60.0 & 10.3 & 64.5 & 12.1 & 21.4 & 4.6 & 22.3 & 5.4 \\
\hline $\begin{array}{l}\text { Draw a circle with a } 1 \text {-inch diameter, } \\
\text { resize the circle to make it } 1.5 \text {-inch } \\
\text { diameter, and move it to specified } \\
\text { location. }\end{array}$ & 74.4 & 8.1 & 91.3 & 9.8 & 30.3 & 7.7 & 41.4 & 8.9 \\
\hline $\begin{array}{l}\text { Draw a large box, draw a perfect } \\
\text { square inside the box, and type the } \\
\text { word "HERE" inside the square. Group } \\
\text { the graphic and move them to the } \\
\text { right side of the screen. Now, resize } \\
\text { the group to make it smaller and } \\
\text { rotate it to the right. }\end{array}$ & 97.9 & 9.2 & 98.3 & 11.8 & 44.8 & 7.1 & 47.5 & 6.4 \\
\hline
\end{tabular}


Appendix VII. ANOVA Summary Tables for Task Completion Time 
Table VII-1: ANOVA Summary Table for Draw a Horizontal Line

\begin{tabular}{|c|c|c|c|c|c|}
\hline SOURCE OF VARIANCE & $d f$ & SS & MS & $\mathbf{F}$ & $p$ \\
\hline \multicolumn{6}{|l|}{ Between-Subjects } \\
\hline Experience (E) & 1 & 28.8982 & 28.8982 & 10.24 & 0.0041 \\
\hline Sub/Experience (S/E) & 22 & 62.1009 & 2.8228 & & \\
\hline \multicolumn{6}{|l|}{ Within-Subjects } \\
\hline Interface (I) & 1 & 0.5264 & 0.5264 & 0.57 & 0.4567 \\
\hline Trial (T) & 4 & 22.9299 & 5.7325 & 21.30 & 0.0001 \\
\hline$I \times E$ & 1 & 0.3286 & 0.3286 & 0.36 & 0.5556 \\
\hline I $\times S / E$ & 22 & 20.1725 & 0.9169 & & \\
\hline$T \times E$ & 4 & 3.4387 & 0.8597 & 3.19 & 0.0169 \\
\hline$T \times S / E$ & 88 & 23.6850 & 0.2691 & & \\
\hline $\mid x T$ & 4 & 0.7856 & 0.1964 & 0.58 & 0.6807 \\
\hline IXTXE & 4 & 1.5153 & 0.3788 & 1.11 & 0.3564 \\
\hline IXT $\times$ S/E & 88 & 30.0026 & 0.3409 & & \\
\hline Total & 239 & 194.3837 & & & \\
\hline
\end{tabular}


Table VII-2: ANOVA Summary Table for Draw a Vertical Line

\begin{tabular}{|c|c|c|c|c|c|}
\hline SOURCE OF VARIANCE & $d f$ & SS & MS & $\mathbf{F}$ & $p$ \\
\hline \multicolumn{6}{|l|}{ Between-Subjects } \\
\hline Experience $(E)$ & 1 & 19.9411 & 19.9411 & 5.68 & 0.0262 \\
\hline Sub/Experience (S/E) & 22 & 77.2186 & 3.5099 & & \\
\hline \multicolumn{6}{|l|}{ Within-Subjects } \\
\hline Interface (I) & 1 & 0.0031 & 0.0031 & 0.00 & 0.9525 \\
\hline Trial (T) & 4 & 19.1210 & 4.7803 & 7.67 & 0.0001 \\
\hline IXE & 1 & 0.7571 & 0.7571 & 0.89 & 0.3552 \\
\hline I $\times S / E$ & 22 & 18.6753 & 0.8489 & & \\
\hline$T \times E$ & 4 & 0.4941 & 0.1235 & 0.20 & 0.9387 \\
\hline$T \times S / E$ & 88 & 54.8263 & 0.6230 & & \\
\hline $\mid x T$ & 4 & 1.2900 & 0.3225 & 0.60 & 0.6643 \\
\hline IXTXE & 4 & 0.5450 & 0.1363 & 0.25 & 0.9071 \\
\hline$I \times T \times S / E$ & 88 & 47.3706 & 0.5383 & & \\
\hline Total & 239 & 240.2422 & & & \\
\hline
\end{tabular}


Table VII-3: ANOVA Summary Table for Draw a Box

\begin{tabular}{|c|c|c|c|c|c|}
\hline SOURCE OF VARIANCE & $d f$ & SS & MS & $\mathbf{F}$ & $p$ \\
\hline \multicolumn{6}{|l|}{ Between-Subjects } \\
\hline Experience (E) & 1 & 43.7675 & 43.7675 & 9.26 & 0.0060 \\
\hline Sub/Experience (S/E) & 22 & 104.0352 & 4.7289 & & \\
\hline \multicolumn{6}{|l|}{ WithIn-Subjects } \\
\hline Interface (I) & 1 & 1.8744 & 1.8744 & 0.70 & 0.4132 \\
\hline Trial (T) & 4 & 129.8678 & 32.4670 & 29.15 & 0.0001 \\
\hline IXE & 1 & 0.5482 & 0.5482 & 0.20 & 0.6563 \\
\hline I $\times S / E$ & 22 & 59.2660 & 2.6939 & & \\
\hline TXE & 4 & 10.4641 & 2.6160 & 2.35 & 0.0604 \\
\hline$T \times S / E$ & 88 & 98.0119 & 1.1138 & & \\
\hline $\mid x T$ & 4 & 6.5091 & 1.6273 & 1.27 & 0.2888 \\
\hline$I \times T \times E$ & 4 & 3.6485 & 0.9121 & 0.71 & 0.5868 \\
\hline I $\times$ T X S/E & 88 & 112.9595 & 1.2836 & & \\
\hline Total & 239 & 570.9522 & & & \\
\hline
\end{tabular}


Table VII-4: ANOVA Summary Table for Draw a Circle

\begin{tabular}{|c|c|c|c|c|c|}
\hline SOURCE OF VARIANCE & $d f$ & SS & MS & $\bar{F}$ & p \\
\hline \multicolumn{6}{|l|}{ Between-Subjects } \\
\hline Experience $(E)$ & 1 & 303.0529 & 303.0529 & 2.79 & 0.1089 \\
\hline Sub/Experience (S/E) & 22 & 2388.4612 & 108.5664 & & \\
\hline \multicolumn{6}{|l|}{ Within-Subjects } \\
\hline Interface (I) & 1 & 13.3529 & 13.3529 & 0.54 & 0.4721 \\
\hline Trial (T) & 4 & 506.1012 & 126.5253 & 4.57 & 0.0021 \\
\hline IXE & 1 & 0.1105 & 0.1105 & 0.00 & 0.9475 \\
\hline IXS/E & 22 & 548.8337 & 24.9470 & & \\
\hline$T \times E$ & 4 & 242.4856 & 60.6214 & 2.19 & 0.0768 \\
\hline$T \times S / E$ & 88 & 2438.3693 & 27.7087 & & \\
\hline $1 \times T$ & 4 & 12.6118 & 3.1530 & 0.31 & 0.8686 \\
\hline IXTXE & 4 & 10.1524 & 2.5381 & 0.25 & 0.9077 \\
\hline $\mathrm{I} \times \mathrm{T} \times \mathrm{S} / \mathrm{E}$ & 88 & 886.4238 & 10.0730 & & \\
\hline Total & 239 & 7349.9553 & & & \\
\hline
\end{tabular}


Table VII-5: ANOVA Summary Table for Draw a Triangle

\begin{tabular}{|c|c|c|c|c|c|}
\hline SOURCE OF VARIANCE & df & SS & MS & $\mathbf{F}$ & $\bar{p}$ \\
\hline \multicolumn{6}{|l|}{ Between-Subjects } \\
\hline Experience (E) & 1 & 46.2882 & 46.2882 & 0.70 & 0.4110 \\
\hline Sub/Experience (S/E) & 22 & 1450.0271 & 65.9103 & & \\
\hline \multicolumn{6}{|l|}{ Within-Subjects } \\
\hline Interface (I) & 1 & 62.9766 & 62.9766 & 2.44 & 0.1326 \\
\hline Trial $(T)$ & 4 & 273.3401 & 68.3350 & 7.48 & 0.0001 \\
\hline IXE & 1 & 6.9428 & 6.9428 & 0.27 & 0.6092 \\
\hline I $\times S / E$ & 22 & 567.8528 & 25.8115 & & \\
\hline$T \times E$ & 4 & 23.0458 & 5.7615 & 0.63 & 0.6418 \\
\hline$T \times S / E$ & 88 & 803.7389 & 9.1334 & & \\
\hline $\mid \times T$ & 4 & 50.9530 & 12.7383 & 1.39 & 0.2446 \\
\hline IXTXE & 4 & 15.9905 & 3.9976 & 0.44 & 0.7825 \\
\hline I $\times T \times S / E$ & 88 & 807.5703 & 9.1769 & & \\
\hline Total & 239 & 4108.7261 & & & \\
\hline
\end{tabular}


Table VII-6: ANOVA Summary Table for Move and Position Line

\begin{tabular}{|c|c|c|c|c|c|}
\hline SOURCE OF VARIANCE & $d f$ & SS & MS & $\mathbf{F}$ & $p$ \\
\hline \multicolumn{6}{|l|}{ Between-Subjects } \\
\hline Experience (E) & 1 & 243.2711 & 243.2711 & 25.93 & 0.0001 \\
\hline Sub/Experience (S/E) & 22 & 206.4316 & 9.3833 & & \\
\hline \multicolumn{6}{|l|}{ WithIn-Subjects } \\
\hline Interface (I) & 1 & 847.0157 & 847.0157 & 71.65 & 0.0001 \\
\hline Trial (T) & 4 & 384.8298 & 96.2075 & 55.76 & 0.0001 \\
\hline $\mid x E$ & 1 & 29.3930 & 29.3930 & 2.49 & 0.1291 \\
\hline $1 \times S / E$ & 22 & 260.0670 & 11.8212 & & \\
\hline$T \times E$ & 4 & 14.9260 & 3.7315 & 2.16 & 0.0797 \\
\hline$T \times S / E$ & 88 & 151.8227 & 1.7253 & & \\
\hline $\mid x T$ & 4 & 5.0208 & 1.2552 & 0.68 & 0.6110 \\
\hline IXTXE & 4 & 6.3179 & 1.5795 & 0.85 & 0.4976 \\
\hline$I \times T \times S / E$ & 88 & 163.6098 & 1.8592 & & \\
\hline Total & 239 & 2312.7054 & & & \\
\hline
\end{tabular}


Table VII-7: ANOVA Summary Table for Move Line 1 (Horizontal)

\begin{tabular}{|c|c|c|c|c|c|}
\hline SOURCE OF VARIANCE & df & SS & MS & $\mathbf{F}$ & $p$ \\
\hline \multicolumn{6}{|l|}{ Between-Subjects } \\
\hline Experience $(E)$ & 1 & 204.6107 & 204.6107 & 24.24 & 0.0001 \\
\hline Sub/Experience (S/E) & 22 & 185.6725 & 8.4397 & & \\
\hline \multicolumn{6}{|l|}{ Within-Subjects } \\
\hline Interface (I) & 1 & 1117.9303 & 1117.9303 & 154.33 & 0.0001 \\
\hline Trial (T) & 4 & 270.4865 & 67.6216 & 38.65 & 0.0001 \\
\hline$I \times E$ & 1 & 90.6265 & 90.6265 & 12.51 & 0.0019 \\
\hline I $\times S / E$ & 22 & 159.3598 & 7.2436 & & \\
\hline$T \times E$ & 4 & 21.8696 & 5.4674 & 3.12 & 0.0188 \\
\hline$T \times S / E$ & 88 & 153.9764 & 1.7497 & & \\
\hline $\mid x T$ & 4 & 65.1694 & 16.2924 & 8.56 & 0.0001 \\
\hline IXTXE & 4 & 9.7505 & 2.4376 & 1.28 & 0.2834 \\
\hline$I \times T \times S / E$ & 88 & 167.4087 & 1.9024 & & \\
\hline Total & 239 & 2446.8609 & & & \\
\hline
\end{tabular}


Table VII-8: ANOVA Summary Table for Move Line $2\left(45^{\circ}\right.$ angle)

\begin{tabular}{|c|c|c|c|c|c|}
\hline SOURCE OF VARIANCE & df & SS & MS & $\bar{F}$ & $p$ \\
\hline \multicolumn{6}{|l|}{ Between-Subjects } \\
\hline Experience $(E)$ & 1 & 188.2750 & 188.2750 & 17.09 & 0.0004 \\
\hline Sub/Experience (S/E) & 22 & 242.3708 & 11.0169 & & \\
\hline \multicolumn{6}{|l|}{ Within-Subjects } \\
\hline Interface (I) & 1 & 1032.7276 & 1032.7276 & 182.14 & 0.0001 \\
\hline Trial $(T)$ & 4 & 208.2536 & 52.0634 & 17.60 & 0.0001 \\
\hline IXE & 1 & 36.0298 & 36.0298 & 6.35 & 0.0195 \\
\hline $\mathrm{I} \times \mathrm{S} / \mathrm{E}$ & 22 & 124.7420 & 5.6701 & & \\
\hline$T \times E$ & 4 & 30.6504 & 7.6626 & 2.59 & 0.0421 \\
\hline$T \times S / E$ & 88 & 260.3511 & 2.9585 & & \\
\hline $\mid x T$ & 4 & 20.2987 & 5.0747 & 2.12 & 0.0845 \\
\hline IXTXE & 4 & 17.7512 & 4.4378 & 1.86 & 0.1250 \\
\hline$I \times T \times S / E$ & 88 & 210.2368 & 2.3891 & & \\
\hline Total & 239 & 2371.6870 & & & \\
\hline
\end{tabular}


Table VII-9: ANOVA Summary Table for Enlarge Line 1

\begin{tabular}{|c|c|c|c|c|c|}
\hline SOURCE OF VARIANCE & $d f$ & SS & MS & $\mathbf{F}$ & $p$ \\
\hline \multicolumn{6}{|l|}{ Between-Subjects } \\
\hline Experience $(E)$ & 1 & 1903.9540 & 1903.9540 & 10.91 & 0.0032 \\
\hline Sub/Experience (S/E) & 22 & 3840.0751 & 174.5489 & & \\
\hline \multicolumn{6}{|l|}{ Within-Subjects } \\
\hline Interface (I) & 1 & 4788.9814 & 4788.9814 & 22.20 & 0.0001 \\
\hline Trial (T) & 4 & 4822.9431 & 1205.7358 & 7.72 & 0.0001 \\
\hline IXE & 1 & 389.7421 & 389.7421 & 1.81 & 0.1926 \\
\hline IXS/E & 22 & 4746.3640 & 215.7438 & & \\
\hline$T \times E$ & 4 & 998.0377 & 249.5094 & 1.60 & 0.1821 \\
\hline$T \times S / E$ & 88 & 13744.2143 & 156.1843 & & \\
\hline $\mid x T$ & 4 & 534.1077 & 133.5269 & 0.85 & 0.4956 \\
\hline $\mid \times T \times E$ & 4 & 683.6151 & 170.9038 & 1.09 & 0.3657 \\
\hline $\mathrm{I} \times \mathrm{T} \times \mathrm{S} / \mathrm{E}$ & 88 & 13776.0142 & 156.5456 & & \\
\hline Total & 239 & 50228.0487 & & & \\
\hline
\end{tabular}


Table VII-10: ANOVA Summary Table for Enlarge Line 2

\begin{tabular}{|c|c|c|c|c|c|}
\hline SOURCE OF VARIANCE & $d f$ & SS & MS & $\mathbf{F}$ & $p$ \\
\hline \multicolumn{6}{|l|}{ Between-Subjects } \\
\hline Experience (E) & 1 & 726.3804 & 726.3804 & 9.67 & 0.0051 \\
\hline Sub/Experience (S/E) & 22 & 1652.8325 & 75.1288 & & \\
\hline \multicolumn{6}{|l|}{ WIthin-Subjects } \\
\hline Interface (I) & 1 & 1152.1593 & 1152.1593 & 18.38 & 0.0003 \\
\hline Trial $(T)$ & 4 & 1108.6947 & 277.1737 & 8.99 & 0.0001 \\
\hline $1 \times E$ & 1 & 0.6376 & 0.6376 & 0.01 & 0.9206 \\
\hline I $\times S / E$ & 22 & 1379.3057 & 62.6957 & & \\
\hline$T \times E$ & 4 & 138.1162 & 34.5291 & 1.12 & 0.3525 \\
\hline$T \times S / E$ & 88 & 2713.8963 & 30.8397 & & \\
\hline $\mid x T$ & 4 & 184.5679 & 46.1420 & 2.50 & 0.0485 \\
\hline IXTXE & 4 & 76.3862 & 19.0966 & 1.03 & 0.3948 \\
\hline$I \times T \times S / E$ & 88 & 1626.7701 & 18.4860 & & \\
\hline Total & 239 & 10759.7469 & & & \\
\hline
\end{tabular}


Table VII-11: ANOVA Summary Table for Reduce Line 3

\begin{tabular}{|c|c|c|c|c|c|}
\hline SOURCE OF VARIANCE & $d f$ & SS & MS & $\mathbf{F}$ & $p$ \\
\hline \multicolumn{6}{|l|}{ Between-Subjects } \\
\hline Experience (E) & 1 & 801.1030 & 801.1030 & 9.42 & 0.0056 \\
\hline Sub/Experience (S/E) & 22 & 1870.9945 & 85.0452 & & \\
\hline \multicolumn{6}{|l|}{ Within-Subjects } \\
\hline Interface (I) & 1 & 3270.0784 & 3270.0784 & 68.80 & 0.0001 \\
\hline Trial (T) & 4 & 496.9082 & 124.2271 & 5.22 & 0.0008 \\
\hline IXE & 1 & 25.4411 & 25.4411 & 0.54 & 0.4721 \\
\hline$I \times S / E$ & 22 & 1045.6205 & 47.5282 & & \\
\hline$T \times E$ & 4 & 101.2704 & 25.3176 & 1.06 & 0.3791 \\
\hline$T \times S / E$ & 88 & 2093.3584 & 23.7882 & & \\
\hline $\mid x T$ & 4 & 173.3568 & 43.3392 & 1.75 & 0.1459 \\
\hline IXTXE & 4 & 198.1578 & 49.5395 & 2.00 & 0.1011 \\
\hline$I \times T \times S / E$ & 88 & 2177.4460 & 24.7437 & & \\
\hline Total & 239 & 12253.7351 & & & \\
\hline
\end{tabular}


Table VII-12: ANOVA Summary Table for Reduce Line 4

\begin{tabular}{|c|c|c|c|c|c|}
\hline SOURCE OF VARIANCE & $d f$ & SS & MS & $F$ & $p$ \\
\hline \multicolumn{6}{|l|}{ Between-Subjects } \\
\hline Experience $(E)$ & 1 & 503.9912 & 503.9912 & 12.26 & 0.0020 \\
\hline Sub/Experience (S/E) & 22 & 904.0411 & 41.0928 & & \\
\hline \multicolumn{6}{|l|}{ WithIn-Subjects } \\
\hline Interface (I) & 1 & 4151.2643 & 4151.2643 & 82.57 & 0.0001 \\
\hline Trial (T) & 4 & 920.1916 & 230.0479 & 6.42 & 0.0001 \\
\hline$I \times E$ & 1 & 186.7900 & 186.7900 & 3.72 & 0.0669 \\
\hline I $\times S / E$ & 22 & 1106.0874 & 50.2767 & & \\
\hline$T \times E$ & 4 & 68.8721 & 17.2180 & 0.48 & 0.7500 \\
\hline$T \times S / E$ & 88 & 3153.3115 & 35.8331 & & \\
\hline $1 \times T$ & 4 & 306.0686 & 76.5172 & 2.04 & 0.0955 \\
\hline IXTXE & 4 & 53.5763 & 13.3941 & 0.36 & 0.8383 \\
\hline IXTXS/E & 88 & 3298.6501 & 37.4847 & & \\
\hline Total & 239 & 14652.8442 & & & \\
\hline
\end{tabular}


Table VII-13: ANOVA Summary Table for Position Line

\begin{tabular}{|c|c|c|c|c|c|}
\hline SOURCE OF VARIANCE & $d f$ & SS & MS & $\mathbf{F}$ & $\underline{p}$ \\
\hline Between-Subjects & & & & & \\
\hline Experience (E) & 1 & 284.1203 & 284.1203 & 12.68 & 0.0017 \\
\hline Sub/Experience (S/E) & 22 & 492.9264 & 22.4057 & & \\
\hline \multicolumn{6}{|l|}{ Within-Subjects } \\
\hline Interface (I) & 1 & 705.9283 & 705.9283 & 33.40 & 0.0001 \\
\hline Trial (T) & 4 & 529.9087 & 132.4772 & 10.64 & 0.0001 \\
\hline IXE & 1 & 8.1291 & 8.1291 & 0.38 & 0.5415 \\
\hline I $\times S / E$ & 22 & 464.9264 & 21.1330 & & \\
\hline$T \times E$ & 4 & 77.1744 & 19.2936 & 1.55 & 0.1951 \\
\hline$T \times S / E$ & 88 & 1096.0842 & 12.4555 & & \\
\hline $\mid x T$ & 4 & 83.0252 & 20.7563 & 1.38 & 0.2467 \\
\hline IXTXE & 4 & 41.0153 & 10.2538 & 0.68 & 0.6058 \\
\hline I $\times T \times S / E$ & 88 & 1321.6829 & 15.0191 & & \\
\hline Total & 239 & 5104.9212 & & & \\
\hline
\end{tabular}


Table VII-14: ANOVA Summary Table for Move Box

\begin{tabular}{|c|c|c|c|c|c|}
\hline SOURCE OF VARIANCE & $d f$ & SS & MS & $\mathbf{F}$ & $\underline{p}$ \\
\hline \multicolumn{6}{|l|}{ Between-Subjects } \\
\hline Experience (E) & 1 & 292.1185 & 292.1185 & 30.35 & 0.0001 \\
\hline Sub/Experience (S/E) & 22 & 211.7274 & 9.6240 & & \\
\hline \multicolumn{6}{|l|}{ Within-Subjects } \\
\hline Interface (I) & 1 & 1090.0491 & 1090.0491 & 76.74 & 0.0001 \\
\hline Trial $(T)$ & 4 & 612.7814 & 153.1954 & 38.12 & 0.0001 \\
\hline IXE & 1 & 38.4320 & 38.4320 & 2.71 & 0.1142 \\
\hline I $\times S / E$ & 22 & 312.5030 & 14.2047 & & \\
\hline$T \times E$ & 4 & 66.6599 & 16.6650 & 4.15 & 0.0040 \\
\hline$T \times S / E$ & 88 & 353.6340 & 4.0186 & & \\
\hline $\mid \times T$ & 4 & 24.1203 & 6.0301 & 1.27 & 0.2865 \\
\hline$I \times T \times E$ & 4 & 26.2463 & 6.5616 & 1.39 & 0.2454 \\
\hline IXT $\times$ S/E & 88 & 416.6959 & 4.7352 & & \\
\hline Total & 239 & 3444.9678 & & & \\
\hline
\end{tabular}


Table VII-15: ANOVA Summary Table for Position Box

\begin{tabular}{|c|c|c|c|c|c|}
\hline SOURCE OF VARIANCE & df & SS & MS & $\mathbf{F}$ & $\mathbf{p}$ \\
\hline \multicolumn{6}{|l|}{ Between-Subjects } \\
\hline Experience (E) & 1 & 147.6586 & 147.6586 & 15.56 & 0.0007 \\
\hline Sub/Experience (S/E) & 22 & 208.8031 & 9.4911 & & \\
\hline \multicolumn{6}{|l|}{ WIthin-Subjects } \\
\hline Interface (I) & 1 & 790.2148 & 790.2148 & 137.75 & 0.0001 \\
\hline Trial (T) & 4 & 288.6131 & 72.1533 & 33.29 & 0.0001 \\
\hline IXE & 1 & 43.6310 & 43.6310 & 7.61 & 0.0115 \\
\hline $1 \times S / E$ & 22 & 126.2005 & 5.7364 & & \\
\hline$T \times E$ & 4 & 15.4391 & 3.8598 & 1.78 & 0.1398 \\
\hline T $\times$ SIE & 88 & 190.7455 & 2.1676 & & \\
\hline$I \times T$ & 4 & 18.5947 & 4.6487 & 1.97 & 0.1053 \\
\hline IXTXE & 4 & 6.8263 & 1.7066 & 0.72 & 0.5772 \\
\hline$I \times T \times S / E$ & 88 & 207.1632 & 2.3541 & & \\
\hline Total & 239 & 2043.8899 & & & \\
\hline
\end{tabular}


Table VII-16: ANOVA Summary Table for Enlarge Box

\begin{tabular}{|c|c|c|c|c|c|}
\hline SOURCE OF VARIANCE & $d f$ & SS & MS & $\mathbf{F}$ & $p$ \\
\hline \multicolumn{6}{|l|}{ Between-Subjects } \\
\hline Experience (E) & 1 & 7989.9498 & 7989.9498 & 10.79 & 0.0034 \\
\hline Sub/Experience (S/E) & 22 & 16286.3874 & 740.2903 & & \\
\hline \multicolumn{6}{|l|}{ Within-Subjects } \\
\hline Interface (I) & 1 & 20632.2398 & 20632.2398 & 35.02 & 0.0001 \\
\hline Trial (T) & 4 & 6625.6125 & 1656.4031 & 11.12 & 0.0001 \\
\hline IXE & 1 & 1853.8709 & 1853.8709 & 3.15 & 0.0899 \\
\hline I $\times$ S/E & 22 & 12963.0683 & 589.2304 & & \\
\hline$T \times E$ & 4 & 388.1064 & 97.0266 & 0.65 & 0.6274 \\
\hline$T \times S / E$ & 88 & 13106.3025 & 148.9353 & & \\
\hline $1 \times T$ & 4 & 649.2324 & 162.3081 & 1.18 & 0.3271 \\
\hline IXTXE & 4 & 103.7742 & 25.9436 & 0.19 & 0.9441 \\
\hline IXTXS/E & 88 & 12149.1173 & 138.0582 & & \\
\hline Total & 239 & 92747.6615 & & & \\
\hline
\end{tabular}


Table VII-17: ANOVA Summary Table for Reduce Box

\begin{tabular}{|c|c|c|c|c|c|}
\hline SOURCE OF VARIANCE & $d f$ & SS & MS & $\bar{F}$ & $\underline{p}$ \\
\hline \multicolumn{6}{|l|}{ Between-Subjects } \\
\hline Experience (E) & 1 & 5862.3981 & 5862.3981 & 13.87 & 0.0012 \\
\hline Sub/Experience (S/E) & 22 & 9298.6510 & 422.6660 & & \\
\hline \multicolumn{6}{|l|}{ WIthin-Subjects } \\
\hline Interface (I) & 1 & 4690.8578 & 4690.8578 & 20.05 & 0.0002 \\
\hline Trial (T) & 4 & 5362.8747 & 1340.7187 & 10.87 & 0.0001 \\
\hline IXE & 1 & 80.5042 & 80.5042 & 0.34 & 0.5635 \\
\hline IXS/E & 22 & 5147.7328 & 233.9879 & & \\
\hline$T \times E$ & 4 & 605.8715 & 151.4679 & 1.23 & 0.3046 \\
\hline$T \times S / E$ & 88 & 10850.1935 & 123.2977 & & \\
\hline $\mid x T$ & 4 & 152.7633 & 38.1908 & 0.40 & 0.8068 \\
\hline IXTXE & 4 & 127.1969 & 31.7992 & 0.33 & 0.8539 \\
\hline IXTXS/E & 88 & 8361.3151 & 95.0149 & & \\
\hline Total & 239 & 50540.3589 & & & \\
\hline
\end{tabular}


Table VII-18: ANOVA Summary Table for Move and Position Box

\begin{tabular}{|c|c|c|c|c|c|}
\hline SOURCE OF VARIANCE & df & SS & MS & $\mathbf{F}$ & $\underline{p}$ \\
\hline \multicolumn{6}{|l|}{ Between-Subjects } \\
\hline Experience $(E)$ & 1 & 158.8115 & 158.8115 & 13.98 & 0.0011 \\
\hline Sub/Experience (S/E) & 22 & 249.9113 & 11.3596 & & \\
\hline \multicolumn{6}{|l|}{ Within-Subjects } \\
\hline Interface (I) & 1 & 967.3340 & 967.3340 & 87.72 & 0.0001 \\
\hline Trial (T) & 4 & 144.2647 & 36.0662 & 13.87 & 0.0001 \\
\hline IXE & 1 & 47.9631 & 47.9631 & 4.35 & 0.0488 \\
\hline IXS/E & 22 & 242.6110 & 11.0278 & & \\
\hline$T \times E$ & 4 & 33.0178 & 8.2545 & 3.17 & 0.0174 \\
\hline$T \times S / E$ & 88 & 228.8678 & 2.6008 & & \\
\hline $\mid x T$ & 4 & 16.0893 & 4.0223 & 1.69 & 0.1594 \\
\hline$I \times T \times E$ & 4 & 1.9631 & 0.4908 & 0.21 & 0.9343 \\
\hline IXTXS/E & 88 & 209.4113 & 2.3797 & & \\
\hline Total & 239 & 2300.2449 & & & \\
\hline
\end{tabular}


Table VII-19: ANOVA Summary Table for Position Circle

\begin{tabular}{|c|c|c|c|c|c|}
\hline SOURCE OF VARIANCE & $d f$ & SS & MS & $\mathbf{F}$ & $p$ \\
\hline \multicolumn{6}{|l|}{ Between-Subjects } \\
\hline Experience $(E)$ & 1 & 134.5354 & 134.5354 & 10.91 & 0.0032 \\
\hline Sub/Experience (S/E) & 22 & 271.3505 & 12.3341 & & \\
\hline \multicolumn{6}{|l|}{ Within-Subjects } \\
\hline Interface (I) & 1 & 623.9408 & 623.9408 & 53.54 & 0.0001 \\
\hline Trial (T) & 4 & 229.3675 & 57.3419 & 6.83 & 0.0001 \\
\hline IXE & 1 & 64.5740 & 64.5740 & 5.54 & 0.0279 \\
\hline IXS/E & 22 & 256.3862 & 11.6539 & & \\
\hline$T \times E$ & 4 & 44.8955 & 11.2239 & 1.34 & 0.2626 \\
\hline$T \times S / E$ & 88 & 738.7986 & 8.3954 & & \\
\hline $\mid \times T$ & 4 & 31.6268 & 7.9067 & 0.89 & 0.4710 \\
\hline IXTXE & 4 & 31.1411 & 7.7853 & 0.88 & 0.4791 \\
\hline$I \times T \times S / E$ & 88 & 778.1804 & 8.8430 & & \\
\hline Total & 239 & 3204.7968 & & & \\
\hline
\end{tabular}


Table VII-20: ANOVA Summary Table for Move and Position Circle

\begin{tabular}{|c|c|c|c|c|c|}
\hline SOURCE OF VARIANCE & $d f$ & SS & MS & $\bar{F}$ & $p$ \\
\hline \multicolumn{6}{|l|}{ Between-Subjects } \\
\hline Experience $(E)$ & 1 & 111.4525 & 111.4525 & 14.35 & 0.0010 \\
\hline Sub/Experience (S/E) & 22 & 170.8210 & 7.7646 & & \\
\hline \multicolumn{6}{|l|}{ WithIn-Subjects } \\
\hline Interface (I) & 1 & 408.9087 & 408.9087 & 46.28 & 0.0001 \\
\hline Trial (T) & 4 & 177.8512 & 44.4628 & 18.47 & 0.0001 \\
\hline IXE & 1 & 5.8938 & 5.8938 & 0.67 & 0.4228 \\
\hline I $\times$ S/E & 22 & 194.3697 & 8.8350 & & \\
\hline$T \times E$ & 4 & 27.7793 & 6.9448 & 2.89 & 0.0217 \\
\hline$T \times S / E$ & 88 & 211.8335 & 2.4072 & & \\
\hline $\mathbf{I x T}$ & 4 & 2.1475 & 0.5369 & 0.19 & 0.9450 \\
\hline IXTXE & 4 & 7.0235 & 1.7559 & 0.61 & 0.6571 \\
\hline IXTXS/E & 88 & 253.6712 & 2.8826 & & \\
\hline Total & 239 & 1571.7519 & & & \\
\hline
\end{tabular}


Table VII-21: ANOVA Summary Table for Enlarge Circle

\begin{tabular}{|c|c|c|c|c|c|}
\hline SOURCE OF VARIANCE & $d f$ & SS & MS & $\mathbf{F}$ & $\underline{p}$ \\
\hline \multicolumn{6}{|l|}{ Between-Subjects } \\
\hline Experience $(E)$ & 1 & 8084.6238 & 8084.6238 & 16.88 & 0.0005 \\
\hline Sub/Experience (S/E) & 22 & 10536.4956 & 478.9316 & & \\
\hline \multicolumn{6}{|l|}{ Within-Subjects } \\
\hline Interface (l) & 1 & 20205.0015 & 20205.0015 & 42.36 & 0.0001 \\
\hline Trial (T) & 4 & 5521.1510 & 1380.2878 & 11.20 & 0.0001 \\
\hline IXE & 1 & 1118.9234 & 1118.9234 & 2.35 & 0.1399 \\
\hline IXS/E & 22 & 10493.5841 & 476.9811 & & \\
\hline$T \times E$ & 4 & 511.5193 & 127.8798 & 1.04 & 0.3923 \\
\hline$T \times S / E$ & 88 & 10841.6233 & 123.2003 & & \\
\hline $\mid x T$ & 4 & 240.0350 & 60.0088 & 0.38 & 0.8193 \\
\hline IXTXE & 4 & 372.0129 & 93.0032 & 0.60 & 0.6667 \\
\hline IXTXS/E & 88 & 13739.0311 & 156.1254 & & \\
\hline Total & 239 & 81664.0010 & & & \\
\hline
\end{tabular}


Table VII-22: ANOVA Summary Table for Reduce Circle

\begin{tabular}{|c|c|c|c|c|c|}
\hline SOURCE OF VARIANCE & $d f$ & ss & MS & $\bar{F}$ & $\mathbf{p}$ \\
\hline \multicolumn{6}{|l|}{ Between-Subjects } \\
\hline Experience (E) & 1 & 6458.9563 & 6458.9563 & 11.28 & 0.0023 \\
\hline Sub/Experience (S/E) & 22 & 12598.2713 & 572.6487 & & \\
\hline \multicolumn{6}{|l|}{ Within-Subjects } \\
\hline Interface (I) & 1 & 7907.0796 & 7907.0796 & 20.16 & 0.0002 \\
\hline Trial (T) & 4 & 2126.0291 & 531.5073 & 5.77 & 0.0004 \\
\hline IXE & 1 & 246.9496 & 246.9496 & 0.63 & 0.4360 \\
\hline I XS/E & 22 & 8629.2546 & 392.2388 & & \\
\hline TXE & 4 & 370.3439 & 92.5860 & 1.01 & 0.4091 \\
\hline$T \times S / E$ & 88 & 8103.2951 & 92.0829 & & \\
\hline $1 \times T$ & 4 & 352.6558 & 88.1640 & 0.69 & 0.6031 \\
\hline IXTXE & 4 & 30.6310 & 7.6578 & 0.06 & 0.9933 \\
\hline $1 \times T \times S / E$ & 88 & 11170.4178 & 126.9366 & & \\
\hline Total & 239 & 57993.8841 & & & \\
\hline
\end{tabular}


Table VII-23: ANOVA Summary Table for Move Circle

\begin{tabular}{|c|c|c|c|c|c|}
\hline SOURCE OF VARIANCE & $d f$ & SS & MS & $\bar{F}$ & $p$ \\
\hline \multicolumn{6}{|l|}{ Between-Subjects } \\
\hline Experience (E) & 1 & 9.7647 & 9.7647 & 0.75 & 0.3973 \\
\hline Sub/Experience (S/E) & 22 & 288.2012 & 13.1001 & & \\
\hline \multicolumn{6}{|l|}{ WIthIn-Subjects } \\
\hline Interface (I) & 1 & 313.7535 & 313.7535 & 25.49 & 0.0001 \\
\hline Trial (T) & 4 & 143.3391 & 35.8348 & 6.45 & 0.0001 \\
\hline IXE & 1 & 2.6481 & 2.6481 & 0.22 & 0.6473 \\
\hline $1 \times S / E$ & 22 & 270.7767 & 12.3080 & & \\
\hline$T \times E$ & 4 & 32.3353 & 8.0838 & 1.46 & 0.2227 \\
\hline$T \times S / E$ & 88 & 488.8619 & 5.5552 & & \\
\hline $\mid x T$ & 4 & 25.3949 & 6.3487 & 1.05 & 0.3868 \\
\hline IXTXE & 4 & 14.4925 & 3.6231 & 0.60 & 0.6646 \\
\hline $1 \times T \times S / E$ & 88 & 532.6652 & 6.0530 & & \\
\hline Total & 239 & 2122.2331 & & & \\
\hline
\end{tabular}


Table VII-24: ANOVA Summary Table for Copy, Resize, and Move Circle

\begin{tabular}{|c|c|c|c|c|c|}
\hline SOURCE OF VARIANCE & df & SS & MS & $F$ & $p$ \\
\hline \multicolumn{6}{|l|}{ Between-Subjects } \\
\hline Experience (E) & 1 & 27655.2924 & 27655.2924 & 25.34 & 0.0001 \\
\hline Sub/Experience (S/E) & 22 & 24006.0817 & 1091.1855 & & \\
\hline \multicolumn{6}{|l|}{ Within-Subjects } \\
\hline Interface (I) & 1 & 34808.8463 & 34808.8463 & 35.86 & 0.0001 \\
\hline Trial (T) & 4 & 69450.6178 & 17362.6545 & 64.94 & 0.0001 \\
\hline $\operatorname{IXE}$ & 1 & 978.6093 & 978.6093 & 1.01 & 0.3262 \\
\hline I $\times S / E$ & 22 & 21352.6980 & 970.5772 & & \\
\hline$T \times E$ & 4 & 7106.9268 & 1776.7317 & 6.64 & 0.0001 \\
\hline TXS/E & 88 & 23529.6991 & 267.3829 & & \\
\hline $\mid x T$ & 4 & 5765.1584 & 1441.2896 & 3.97 & 0.0052 \\
\hline IXTXE & 4 & 143.2222 & 35.8056 & 0.10 & 0.9827 \\
\hline IXT $\times$ S/E & 88 & 31967.2281 & 363.2640 & & \\
\hline Total & 239 & 246764.3801 & & & \\
\hline
\end{tabular}


Table VII-25: ANOVA Summary Table for Copy, Resize, and Move Group of Boxes

\begin{tabular}{|c|c|c|c|c|c|}
\hline SOURCE OF VARIANCE & df & SS & MS & $\mathbf{F}$ & $p$ \\
\hline \multicolumn{6}{|l|}{ Between-Subjects } \\
\hline Experience $(E)$ & 1 & 88740.6813 & 88740.6813 & 44.85 & 0.0001 \\
\hline Sub/Experience (S/E) & 22 & 43528.8413 & 1978.5837 & & \\
\hline \multicolumn{6}{|l|}{ Within-Subjects } \\
\hline Interface (I) & 1 & 14809.5041 & 14809.5041 & 4.30 & 0.0500 \\
\hline Trial (T) & 4 & 167725.1725 & 41931.2931 & 24.98 & 0.0001 \\
\hline IXE & 1 & 4185.6048 & 4185.6048 & 1.22 & 0.2820 \\
\hline IXS/E & 22 & 75712.3785 & 3441.4718 & & \\
\hline$T \times E$ & 4 & 44755.2214 & 11188.8054 & 6.66 & 0.0001 \\
\hline$T \times S / E$ & 88 & 147742.6138 & 1678.8933 & & \\
\hline $\mid x T$ & 4 & 2568.6390 & 642.1598 & 0.27 & 0.8958 \\
\hline IXTXE & 4 & 6387.0483 & 1596.7621 & 0.67 & 0.6115 \\
\hline IXTXS/E & 88 & 208359.6606 & 2367.7234 & & \\
\hline Total & 239 & 804515.3656 & & & \\
\hline
\end{tabular}


Table VII-26: ANOVA Summary Table for Rotate and Move Cylinder

\begin{tabular}{|c|c|c|c|c|c|}
\hline SOURCE OF VARIANCE & df & SS & MS & $F$ & $\bar{p}$ \\
\hline \multicolumn{6}{|l|}{ Between-Subjects } \\
\hline Experience (E) & 1 & 13244.5698 & 13244.5698 & 22.47 & 0.0001 \\
\hline Sub/Experience (S/E) & 22 & 12969.4150 & 589.5189 & & \\
\hline \multicolumn{6}{|l|}{ WIthin-Subjects } \\
\hline Interface (l) & 1 & 197.2000 & 197.2000 & 0.57 & 0.4588 \\
\hline Trial (T) & 4 & 18801.7617 & 4700.4404 & 40.57 & 0.0001 \\
\hline IXE & 1 & 103.2938 & 103.2938 & 0.30 & 0.5907 \\
\hline$I \times S / E$ & 22 & 7629.6559 & 346.8025 & & \\
\hline$T \times E$ & 4 & 1575.9355 & 393.9839 & 3.40 & 0.0124 \\
\hline$T \times S / E$ & 88 & 10195.3579 & 115.8563 & & \\
\hline $\mid x T$ & 4 & 608.2615 & 152.0654 & 1.25 & 0.2959 \\
\hline IXTXE & 4 & 170.9591 & 42.7398 & 0.35 & 0.8425 \\
\hline IXT $\times S / E$ & 88 & 10706.2901 & 121.6624 & & \\
\hline Total & 239 & 76202.7003 & & & \\
\hline
\end{tabular}


Table VII-27: ANOVA Summary Table for Draw Hierarchy Chart

\begin{tabular}{|c|c|c|c|c|c|}
\hline SOURCE OF VARIANCE & $d f$ & SS & MS & $F$ & $p$ \\
\hline \multicolumn{6}{|l|}{ Between-Subjects } \\
\hline Experience (E) & 1 & 230278.0621 & 230278.0621 & 25.37 & 0.0001 \\
\hline Sub/Experience (S/E) & 22 & 199712.4678 & 9077.8394 & & \\
\hline \multicolumn{6}{|l|}{ Within-Subjects } \\
\hline Interface (I) & 1 & 125708.2208 & 125708.2208 & 13.24 & 0.0014 \\
\hline Trial (T) & 4 & 473133.0165 & 118283.2541 & 47.46 & 0.0001 \\
\hline IXE & 1 & 5.3104 & 5.3104 & 0.00 & 0.9813 \\
\hline I $\times S / E$ & 22 & 208863.3180 & 9493.7872 & & \\
\hline$T \times E$ & 4 & 87844.6234 & 21961.1559 & 8.81 & 0.0001 \\
\hline$T \times S / E$ & 88 & 219323.9474 & 2492.3176 & & \\
\hline $\mid x T$ & 4 & 12686.8177 & 3171.7044 & 1.42 & 0.2347 \\
\hline$I \times T \times E$ & 4 & 1322.9816 & 330.7454 & 0.15 & 0.9635 \\
\hline IXT $\times S / E$ & 88 & 196858.8978 & 2237.0329 & & \\
\hline Total & 239 & 1755737.6635 & & & \\
\hline
\end{tabular}


Table VII-28: ANOVA Summary Table for Rotate, Resize, and Position Necessary Componen

\begin{tabular}{|c|c|c|c|c|c|}
\hline SOURCE OF VARIANCE & $d f$ & SS & MS & $\mathbf{F}$ & $\mathbf{p}$ \\
\hline \multicolumn{6}{|l|}{ Between-Subjects } \\
\hline Experience (E) & 1 & 610333.1098 & 610333.1098 & 22.06 & 0.0001 \\
\hline Sub/Experience (S/E) & 22 & 608790.7893 & 27672.3086 & & \\
\hline \multicolumn{6}{|l|}{ Within-Subjects } \\
\hline Interface (I) & 1 & 1107722.2963 & 1107722.2963 & 54.86 & 0.0001 \\
\hline Trial (T) & 4 & 974430.7015 & 243607.6754 & 53.32 & 0.0001 \\
\hline IXE & 1 & 36782.2180 & 36782.2180 & 1.82 & 0.1909 \\
\hline I $\times S / E$ & 22 & 444253.7394 & 20193.3518 & & \\
\hline TXE & 4 & 53254.6012 & 13313.6503 & 2.91 & 0.0258 \\
\hline$T \times S / E$ & 88 & 402055.4663 & 4568.8121 & & \\
\hline $1 \times T$ & 4 & 18608.7173 & 4652.1793 & 1.31 & 0.2720 \\
\hline IXTXE & 4 & 5736.2756 & 1434.0689 & 0.40 & 0.8051 \\
\hline I $\times T \times S / E$ & 88 & 312150.6277 & 3547.1662 & & \\
\hline Total & 239 & 4574118.5424 & & & \\
\hline
\end{tabular}


Table VII-29: ANOVA Summary Table for Draw Menu

\begin{tabular}{|c|c|c|c|c|c|}
\hline SOURCE OF VARIANCE & df & SS & MS & $F$ & $\mathbf{p}$ \\
\hline \multicolumn{6}{|l|}{ Between-Subjects } \\
\hline Experience (E) & 1 & 384178.4207 & 384178.4207 & 8.36 & 0.0085 \\
\hline Sub/Experience (S/E) & 22 & 1010734.0011 & 45942.4546 & & \\
\hline \multicolumn{6}{|l|}{ WithIn-Subjects } \\
\hline Interface (I) & 1 & 80022.2588 & 80022.2588 & 2.10 & 0.1610 \\
\hline $\operatorname{Trial}(\mathrm{T})$ & 4 & 1794877.5340 & 448719.3835 & 123.00 & 0.0001 \\
\hline IXE & 1 & 50840.3240 & 50840.3240 & 1.34 & 0.2599 \\
\hline I $\times S / E$ & 22 & 836475.7696 & 38021.6259 & & \\
\hline$T \times E$ & 4 & 48591.0813 & 12147.7703 & 3.33 & 0.0137 \\
\hline$T \times S / E$ & 88 & 321033.9088 & 3648.1126 & & \\
\hline $1 \times T$ & 4 & 51835.4805 & 12958.8701 & 2.73 & 0.0338 \\
\hline IXTXE & 4 & 16159.9320 & 4039.9830 & 0.85 & 0.4958 \\
\hline IXT $\times S / E$ & 88 & 417003.6146 & 4738.6774 & & \\
\hline Total & 239 & 5011752.3254 & & & \\
\hline
\end{tabular}


Appendix VIII. Experience-by-Interface Interactions 


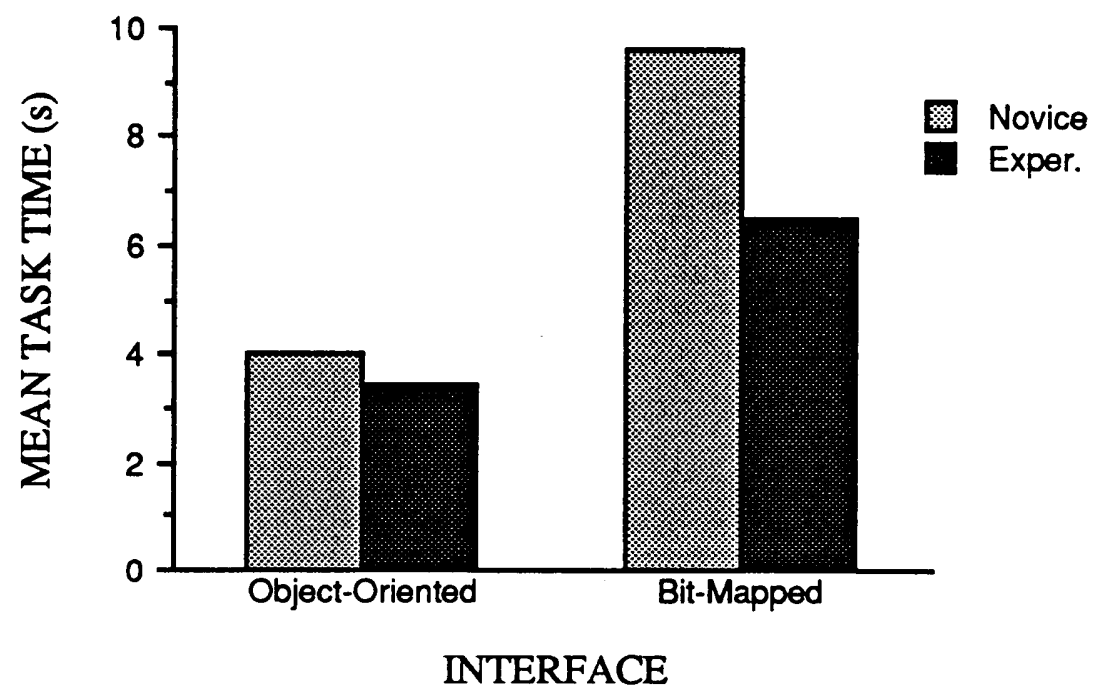

(a)

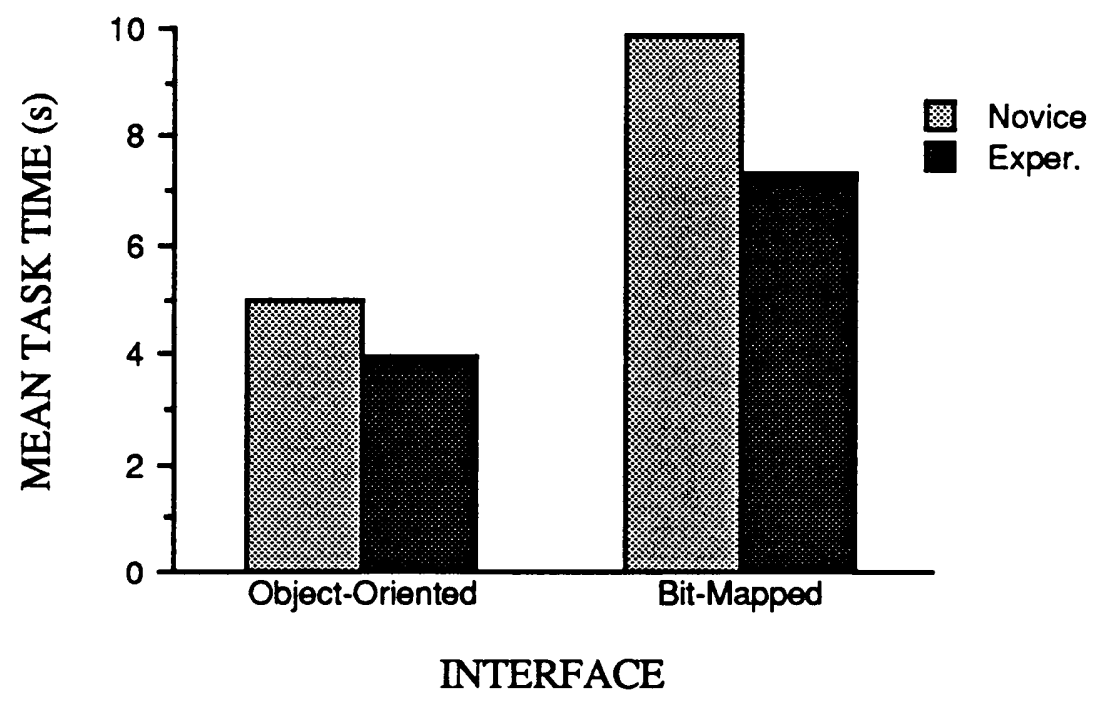

(b)

Figure VIII - 1. Completion times for moving line 1 (a) and moving line 2 (b). 


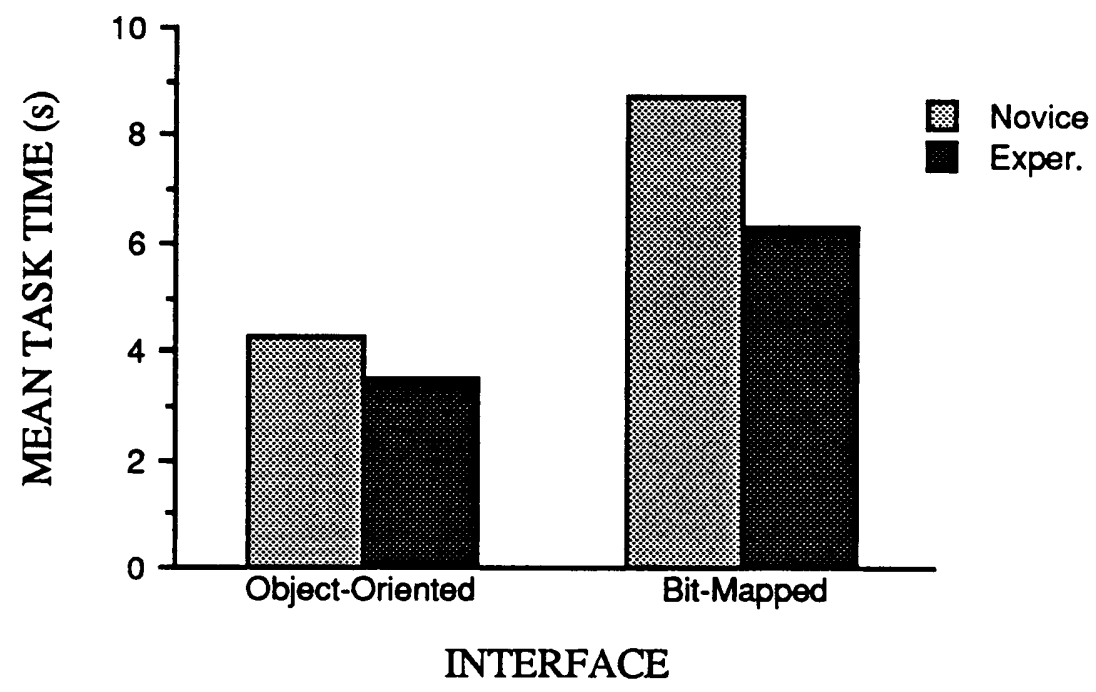

(a)

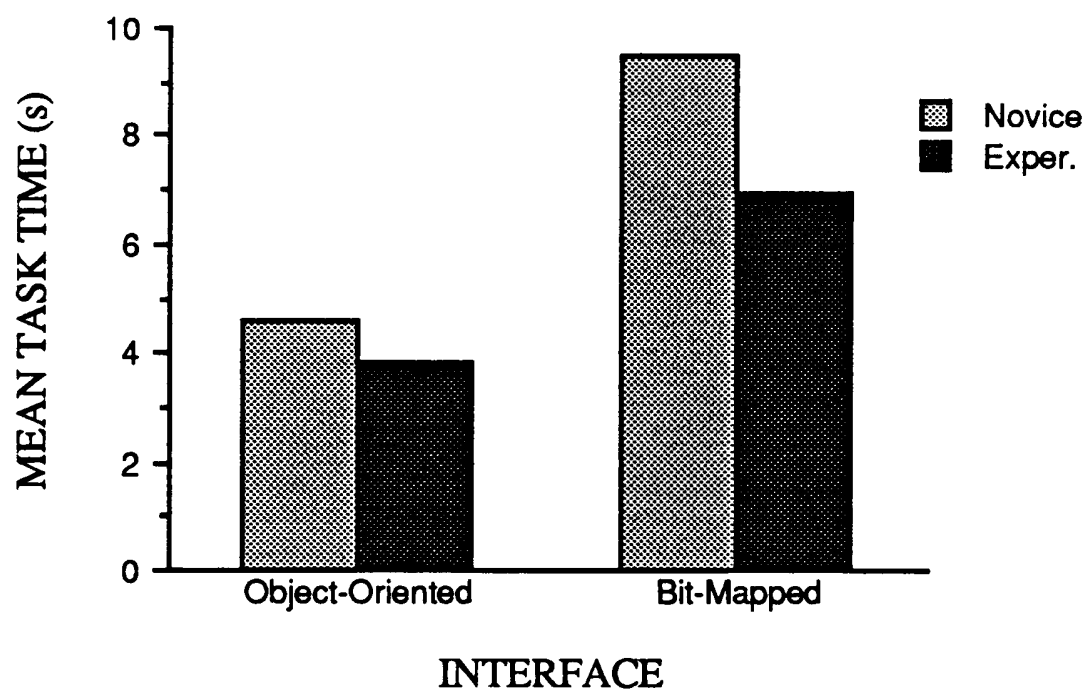

(b)

Figure VIII - ć. Completion times for placing one box adjacent to another (a) and moving and positioning a box(b). 


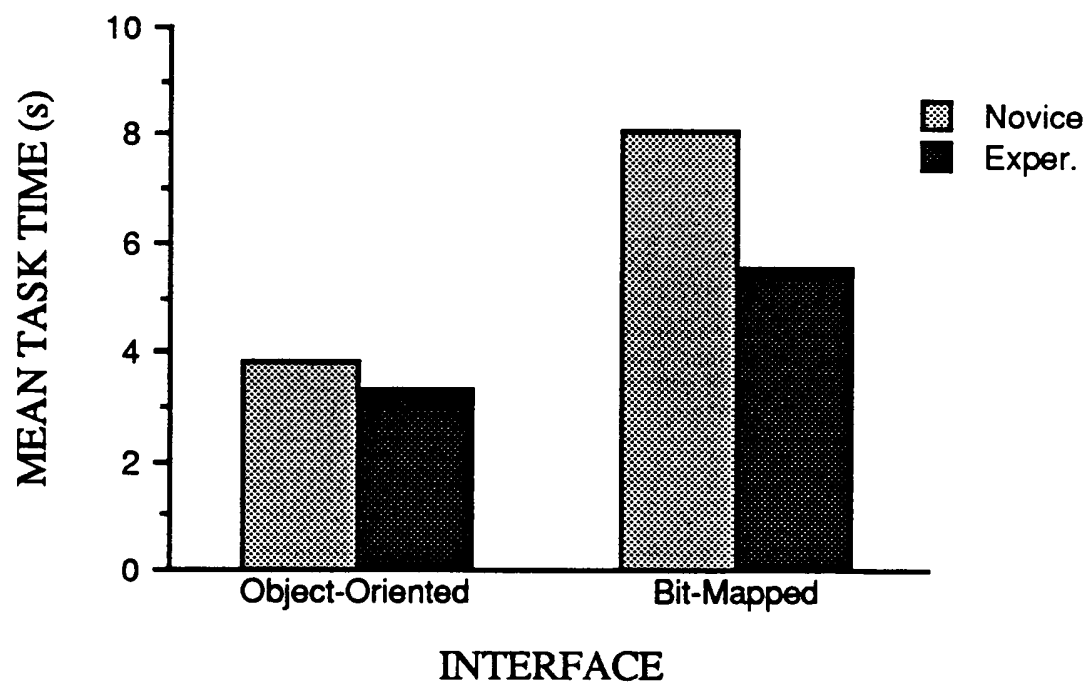

Figure VIII - 3. Completion times for placing one circle adjacent to another. 
Appendix IX. ANOVA Summary Tables for Errors of Commission 
Table IX-1: ANOVA Summary Table for Line Incorrectly Enlarged

\begin{tabular}{|c|c|c|c|c|c|}
\hline SOURCE OF VARIANCE & $d f$ & SS & MS & $\mathbf{F}$ & $p$ \\
\hline \multicolumn{6}{|l|}{ Between-Subjects } \\
\hline Experience (E) & 1 & 0.0248 & 0.0248 & 3.70 & 0.0670 \\
\hline Sub/Experience (S/E) & 22 & 0.1467 & 0.0067 & & \\
\hline \multicolumn{6}{|l|}{ Within-Subjects } \\
\hline Interface (I) & 1 & 0.0567 & 0.0567 & 7.36 & 0.0129 \\
\hline Trial $(T)$ & 4 & 0.0227 & 0.0057 & 0.76 & 0.5556 \\
\hline$I \times E$ & 1 & 0.0001 & 0.0001 & 0.01 & 0.8918 \\
\hline I $\times S / E$ & 22 & 0.1701 & 0.0077 & & \\
\hline$T \times E$ & 4 & 0.0495 & 0.0124 & 1.65 & 0.1684 \\
\hline $\mathrm{T} \times \mathrm{S} / \mathrm{E}$ & 88 & 0.6598 & 0.0075 & & \\
\hline $\mid x T$ & 4 & 0.0290 & 0.0073 & 1.06 & 0.3884 \\
\hline IXTXE & 4 & 0.0139 & 0.0035 & 0.51 & 0.7345 \\
\hline$I \times T \times S / E$ & 88 & 0.6109 & 0.0069 & & \\
\hline Total & 239 & 1.7842 & & & \\
\hline
\end{tabular}


Table IX-2: ANOVA Summary Table for Lines Incorrectly Reduced

\begin{tabular}{|c|c|c|c|c|c|}
\hline SOURCE OF VARIANCE & df & SS & MS & $\mathbf{F}$ & $p$ \\
\hline \multicolumn{6}{|l|}{ Between-Subjects } \\
\hline Experience $(E)$ & 1 & 0.0198 & 0.0198 & 1.25 & \\
\hline Sub/Experience (S/E) & 22 & 0.3467 & 0.0158 & & \\
\hline \multicolumn{6}{|l|}{ Within-Subjects } \\
\hline Interface (I) & 1 & 0.0301 & 0.0301 & 2.55 & \\
\hline Trial (T) & 4 & 0.0127 & 0.0032 & 0.52 & \\
\hline IXE & 1 & 0.0032 & 0.0032 & 0.27 & \\
\hline $1 \times S / E$ & 22 & 0.2601 & 0.0118 & & \\
\hline$T \times E$ & 4 & 0.0285 & 0.0071 & 1.15 & \\
\hline $\mathrm{T} \times \mathrm{S} / \mathrm{E}$ & 88 & 0.5498 & 0.0062 & & \\
\hline $\mid x T$ & 4 & 0.0210 & 0.0053 & 0.80 & \\
\hline IXTXE & 4 & 0.0119 & 0.0030 & 0.45 & \\
\hline IXT $\times S / E$ & 88 & 0.5800 & 0.0066 & & \\
\hline Total & 239 & 1.8638 & & & \\
\hline
\end{tabular}


Table IX-3: ANOVA Summary Table for Square Incorrectly Enlarged

\begin{tabular}{|c|c|c|c|c|c|}
\hline SOURCE OF VARIANCE & df & Ss & MS & $\bar{F}$ & $p$ \\
\hline \multicolumn{6}{|l|}{ Between-Subjects } \\
\hline Experience $(E)$ & 1 & 0.0505 & 0.0505 & 4.51 & 0.0450 \\
\hline Sub/Experience (S/E) & 22 & 0.2457 & 0.0112 & & \\
\hline \multicolumn{6}{|l|}{ Within-Subjects } \\
\hline Interface (l) & 1 & 0.0660 & 0.0660 & 4.89 & 0.0377 \\
\hline Trial (T) & 4 & 0.0233 & 0.0058 & 0.59 & 0.6718 \\
\hline$I \times E$ & 1 & 0.0091 & 0.0091 & 0.67 & 0.4195 \\
\hline $1 \times S / E$ & 22 & 0.2968 & 0.0135 & & \\
\hline$T \times E$ & 4 & 0.0250 & 0.0063 & 0.64 & 0.6400 \\
\hline$T \times S / E$ & 88 & 0.8698 & 0.0099 & & \\
\hline$I x T$ & 4 & 0.0337 & 0.0084 & 1.09 & 0.3659 \\
\hline IXTXE & 4 & 0.0404 & 0.0101 & 1.31 & 0.2741 \\
\hline IXTXS/E & 88 & 0.6800 & 0.0077 & & \\
\hline Total & 239 & 2.3403 & & & \\
\hline
\end{tabular}


Table IX-4: ANOVA Summary Table for Square lincorrectly Reduced

\begin{tabular}{|c|c|c|c|c|c|}
\hline SOURCE OF VARIANCE & df & S S & MS & $\mathbf{F}$ & $p$ \\
\hline \multicolumn{6}{|l|}{ Between-Subjects } \\
\hline Experience (E) & 1 & 0.0063 & 0.0063 & 4.85 & 0.0360 \\
\hline Sub/Experience (S/E) & 22 & 0.0280 & 0.0013 & & \\
\hline \multicolumn{6}{|l|}{ WIthIn-Subjects } \\
\hline Interface (I) & 1 & 0.0077 & 0.0077 & 6.42 & 0.0174 \\
\hline Trial (T) & 4 & 0.0036 & 0.0009 & 1.29 & 0.2514 \\
\hline IXE & 1 & 0.0010 & 0.0010 & 0.83 & 0.3694 \\
\hline$I \times S / E$ & 22 & 0.0256 & 0.0012 & & \\
\hline$T \times E$ & 4 & 0.0037 & 0.0009 & 1.29 & 0.2331 \\
\hline$T \times S / E$ & 88 & 0.0577 & 0.0007 & & \\
\hline $\mid \times T$ & 4 & 0.0023 & 0.0006 & 0.75 & 0.5715 \\
\hline IXTXE & 4 & 0.0014 & 0.0004 & 0.50 & 0.7855 \\
\hline I $\times T \times S / E$ & 88 & 0.0690 & 0.0008 & & \\
\hline Total & 239 & 0.2063 & & & \\
\hline
\end{tabular}


Table IX-5: ANOVA Summary Table for Circle Incorrectly Enlarged

\begin{tabular}{|c|c|c|c|c|c|}
\hline SOURCE OF VARIANCE & df & SS & MS & $\mathbf{F}$ & $\underline{p}$ \\
\hline \multicolumn{6}{|l|}{ Between-Subjects } \\
\hline Experience $(E)$ & 1 & 0.1755 & 0.1755 & 1.86 & 0.1861 \\
\hline Sub/Experience (S/E) & 22 & 2.0732 & 0.0942 & & \\
\hline \multicolumn{6}{|l|}{ Within-Subjects } \\
\hline Interface (I) & 1 & 3.6229 & 3.6229 & 37.39 & 0.0001 \\
\hline Trial (T) & 4 & 0.2083 & 0.0521 & 1.08 & 0.3700 \\
\hline$I \times E$ & 1 & 0.1368 & 0.1368 & 1.41 & 0.2474 \\
\hline $1 \times S / E$ & 22 & 2.1314 & 0.0969 & & \\
\hline$T \times E$ & 4 & 0.0614 & 0.0154 & 0.32 & 0.8646 \\
\hline$T \times S / E$ & 88 & 4.2317 & 0.0481 & & \\
\hline $\mathrm{IxT}$ & 4 & 0.1746 & 0.0437 & 0.88 & 0.4820 \\
\hline$I \times T \times E$ & 4 & 0.1090 & 0.0273 & 0.55 & 0.7022 \\
\hline IXT $\times S / E$ & 88 & 4.3876 & 0.0499 & & \\
\hline Total & 239 & 17.3124 & & & \\
\hline
\end{tabular}


Table IX-6: ANOVA Summary Table for Circle Incorrectly Reduced

\begin{tabular}{|c|c|c|c|c|c|}
\hline SOURCE OF VARIANCE & $d f$ & SS & MS & $F$ & $\underline{p}$ \\
\hline \multicolumn{6}{|l|}{ Between-Subjects } \\
\hline Experience $(E)$ & 1 & 0.1616 & 0.1616 & 1.74 & 0.2006 \\
\hline Sub/Experience (S/E) & 22 & 2.0422 & 0.0928 & & \\
\hline \multicolumn{6}{|l|}{ Within-Subjects } \\
\hline Interface (I) & 1 & 0.7976 & 0.7976 & 12.44 & 0.0019 \\
\hline Trial (T) & 4 & 0.5382 & 0.1346 & 1.75 & 0.1473 \\
\hline IXE & 1 & 0.2630 & 0.2630 & 4.10 & 0.0552 \\
\hline I $\times S / E$ & 22 & 1.4112 & 0.0641 & . & \\
\hline$T \times E$ & 4 & 0.2679 & 0.0670 & 0.87 & 0.4862 \\
\hline$T \times S / E$ & 88 & 6.7856 & 0.0771 & & \\
\hline $\mathbf{I x T}$ & 4 & 0.5091 & 0.1273 & 1.67 & 0.1637 \\
\hline IXTXE & 4 & 0.0486 & 0.0122 & 0.16 & 0.9581 \\
\hline IXTXS/E & 88 & 6.7002 & 0.0761 & & \\
\hline Total & 239 & 19.5252 & & & \\
\hline
\end{tabular}


Table IX-7: ANOVA Summary Table for Circle Incorrectly Resized

\begin{tabular}{|c|c|c|c|c|c|}
\hline SOURCE OF VARIANCE & df & SS & MS & $\bar{F}$ & p \\
\hline \multicolumn{6}{|l|}{ Between-Subjects } \\
\hline Experience (E) & 1 & 0.0006 & 0.0006 & 0.38 & 0.5518 \\
\hline Sub/Experience (S/E) & 22 & 0.0353 & 0.0016 & & \\
\hline \multicolumn{6}{|l|}{ WIthIn-Subjects } \\
\hline Interface (I) & 1 & 0.0110 & 0.0110 & 5.50 & 0.0278 \\
\hline Trial (T) & 4 & 0.0036 & 0.0009 & 1.13 & 0.3561 \\
\hline IXE & 1 & 0.0001 & 0.0001 & 0.05 & 0.8579 \\
\hline I X S/E & 22 & 0.0436 & 0.0020 & & \\
\hline$T \times E$ & 4 & 0.0023 & 0.0006 & 0.75 & 0.5840 \\
\hline$T \times S / E$ & 88 & 0.0721 & 0.0008 & & \\
\hline $1 \times T$ & 4 & 0.0023 & 0.0006 & 0.75 & 0.5805 \\
\hline IXTXE & 4 & 0.0042 & 0.0011 & 1.38 & 0.2840 \\
\hline$I \times T \times S / E$ & 88 & 0.0716 & 0.0008 & & \\
\hline Total & 239 & 0.2467 & & & \\
\hline
\end{tabular}


Table IX-8: ANOVA Summary Table for Group Horizontal Dimension is Incorrect

\begin{tabular}{|c|c|c|c|c|c|}
\hline SOURCE OF VARIANCE & $d f$ & SS & MS & $\mathbf{F}$ & $p$ \\
\hline \multicolumn{6}{|l|}{ Between-Subjects } \\
\hline Experience (E) & 1 & 0.0010 & 0.0010 & 0.91 & 0.3387 \\
\hline Sub/Experience (S/E) & 22 & 0.0240 & 0.0011 & & \\
\hline \multicolumn{6}{|l|}{ Within-Subjects } \\
\hline Interface (I) & 1 & 0.0042 & 0.0042 & 3.82 & 0.0633 \\
\hline Trial (T) & 4 & 0.0069 & 0.0017 & 1.42 & 0.2140 \\
\hline $1 \times E$ & 1 & 0.0000 & 0.0000 & 0.00 & 1.0000 \\
\hline $1 \times S / E$ & 22 & 0.0240 & 0.0011 & & \\
\hline$T \times E$ & 4 & 0.0126 & 0.0032 & 2.67 & 0.0349 \\
\hline$T \times S / E$ & 88 & 0.1023 & 0.0012 & & \\
\hline IXT & 4 & 0.0030 & 0.0008 & 0.62 & 0.6934 \\
\hline IXTXE & 4 & 0.0072 & 0.0018 & 1.38 & 0.2631 \\
\hline IXTXS/E & 88 & 0.1180 & 0.0013 & & \\
\hline Total & 239 & 0.3032 & & & \\
\hline
\end{tabular}


Table IX-9: ANOVA Summary Table for Group Vertical Dimension is Incorrect

\begin{tabular}{|c|c|c|c|c|c|}
\hline SOURCE OF VARIANCE & df & SS & MS & $\mathbf{F}$ & $p$ \\
\hline \multicolumn{6}{|l|}{ Between-Subjects } \\
\hline Experience (E) & 1 & 0.0010 & 0.0010 & 1.25 & 0.2641 \\
\hline Sub/Experience (S/E) & 22 & 0.0174 & 0.0008 & & \\
\hline \multicolumn{6}{|l|}{ Within-Subjects } \\
\hline Interface (I) & 1 & 0.0042 & 0.0042 & 5.25 & 0.0365 \\
\hline Trial (T) & 4 & 0.0033 & 0.0008 & 1.60 & 0.1841 \\
\hline IXE & 1 & 0.0023 & 0.0023 & 2.88 & 0.1091 \\
\hline I $\times S / E$ & 22 & 0.0185 & 0.0008 & & \\
\hline$T \times E$ & 4 & 0.0048 & 0.0012 & 2.40 & 0.0601 \\
\hline$T \times S / E$ & 88 & 0.0451 & 0.0005 & & \\
\hline $\mid x T$ & 4 & 0.0043 & 0.0011 & 2.20 & 0.0815 \\
\hline IXTXE & 4 & 0.0048 & 0.0012 & 2.40 & 0.0553 \\
\hline$I \times T \times S / E$ & 88 & 0.0440 & 0.0005 & & \\
\hline Total & 239 & 0.1497 & & & \\
\hline
\end{tabular}


Table IX-10: ANOVA Summary Table for Chart's Vertical Lines are Incorrect

\begin{tabular}{|c|c|c|c|c|c|}
\hline SOURCE OF VARIANCE & $d f$ & SS & MS & $\bar{F}$ & $\mathbf{p}$ \\
\hline \multicolumn{6}{|l|}{ Between-Subjects } \\
\hline Experience (E) & 1 & 0.0065 & 0.0065 & 2.32 & 0.1427 \\
\hline Sub/Experience (S/E) & 22 & 0.0620 & 0.0028 & & \\
\hline \multicolumn{6}{|l|}{ Within-Subjects } \\
\hline Interface (I) & 1 & 0.0003 & 0.0003 & 0.08 & 0.7898 \\
\hline Trial (T) & 4 & 0.0016 & 0.0004 & 0.27 & 0.8976 \\
\hline IXE & 1 & 0.0023 & 0.0023 & 0.64 & 0.4268 \\
\hline IXS/E & 22 & 0.0786 & 0.0036 & & \\
\hline TXE & 4 & 0.0078 & 0.0020 & 1.33 & 0.2611 \\
\hline$T \times S / E$ & 88 & 0.1281 & 0.0015 & & \\
\hline $\mathbf{I X T}$ & 4 & 0.0089 & 0.0022 & 1.57 & 0.1819 \\
\hline IXTXE & 4 & 0.0068 & 0.0017 & 1.21 & 0.3072 \\
\hline IXTXS/E & 88 & 0.1219 & 0.0014 & & \\
\hline Total & 239 & 0.4248 & & & \\
\hline
\end{tabular}


Table IX-11: ANOVA Summary Table for Chart's Horizontal Lines are Incorrect

\begin{tabular}{|c|c|c|c|c|c|}
\hline SOURCE OF VARIANCE & df & SS & MS & $\mathbf{F}$ & $\underline{p}$ \\
\hline \multicolumn{6}{|l|}{ Between-Subjects } \\
\hline Experience (E) & 1 & 0.0001 & 0.0001 & 0.17 & 0.7369 \\
\hline Sub/Experience (S/E) & 22 & 0.0124 & 0.0006 & & \\
\hline \multicolumn{6}{|l|}{ Within-Subjects } \\
\hline Interface (I) & 1 & 0.0001 & 0.0001 & 0.17 & 0.7469 \\
\hline Trial (T) & 4 & 0.0013 & 0.0003 & 0.50 & 0.6995 \\
\hline IXE & 1 & 0.0006 & 0.0006 & 1.00 & 0.3376 \\
\hline I $\times$ S/E & 22 & 0.0134 & 0.0006 & & \\
\hline$T \times E$ & 4 & 0.0029 & 0.0007 & 1.17 & 0.3123 \\
\hline$T \times S / E$ & 88 & 0.0521 & 0.0006 & & \\
\hline $\mid x T$ & 4 & 0.0029 & 0.0007 & 1.17 & 0.3021 \\
\hline$I \times T \times E$ & 4 & 0.0023 & 0.0006 & 1.00 & 0.4066 \\
\hline IXTXS/E & 88 & 0.0510 & 0.0006 & & \\
\hline Total & 239 & 0.1391 & & & \\
\hline
\end{tabular}


Table IX-12: ANOVA Summary Table for Chart's Left Box is Incorrect

\begin{tabular}{|c|c|c|c|c|c|}
\hline SOURCE OF VARIANCE & $d f$ & SS & MS & $F$ & $p$ \\
\hline \multicolumn{6}{|l|}{ Between-Subjects } \\
\hline Experience (E) & 1 & 0.0008 & 0.0008 & 2.00 & 0.1538 \\
\hline Sub/Experience (S/E) & 22 & 0.0080 & 0.0004 & & \\
\hline \multicolumn{6}{|l|}{ WIthin-Subjects } \\
\hline Interface (l) & 1 & 0.0016 & 0.0016 & 3.20 & 0.0824 \\
\hline Trial (T) & 4 & 0.0104 & 0.0026 & 6.50 & 0.0001 \\
\hline IXE & 1 & 0.0001 & 0.0001 & 0.20 & 0.7193 \\
\hline $1 \times S / E$ & 22 & 0.0108 & 0.0005 & & \\
\hline$T \times E$ & 4 & 0.0061 & 0.0015 & 3.75 & 0.0048 \\
\hline$T \times S / E$ & 88 & 0.0335 & 0.0004 & & \\
\hline $\mid x T$ & 4 & 0.0039 & 0.0010 & 2.00 & 0.1125 \\
\hline IXTXE & 4 & 0.0016 & 0.0004 & 0.80 & 0.5463 \\
\hline IXT $\times S / E$ & 88 & 0.0445 & 0.0005 & & \\
\hline Total & 239 & 0.1213 & & & \\
\hline
\end{tabular}


Table IX-13: ANOVA Summary Table for Chart's Right Box is Incorrect

\begin{tabular}{|c|c|c|c|c|c|}
\hline SOURCE OF VARIANCE & $d f$ & SS & MS & $\mathbf{F}$ & $p$ \\
\hline \multicolumn{6}{|l|}{ Between-Subjects } \\
\hline Experience (E) & 1 & 0.0009 & 0.0009 & 2.25 & 0.1434 \\
\hline Sub/Experience (S/E) & 22 & 0.0087 & 0.0004 & & \\
\hline \multicolumn{6}{|l|}{ Within-Subjects } \\
\hline Interface (I) & 1 & 0.0015 & 0.0015 & 3.00 & 0.0877 \\
\hline Trial (T) & 4 & 0.0102 & 0.0026 & 6.50 & 0.0001 \\
\hline IXE & 1 & 0.0000 & 0.0000 & 0.00 & 0.7804 \\
\hline I $\times$ S/E & 22 & 0.0101 & 0.0005 & & \\
\hline$T \times E$ & 4 & 0.0060 & 0.0015 & 3.75 & 0.0051 \\
\hline$T \times S / E$ & 88 & 0.0332 & 0.0004 & & \\
\hline $\mid x T$ & 4 & 0.0041 & 0.0010 & 2.00 & 0.1064 \\
\hline IXTXE & 4 & 0.0016 & 0.0004 & 0.80 & 0.5436 \\
\hline IXTXS/E & 88 & 0.0457 & 0.0005 & & \\
\hline Total & 239 & 0.1220 & & & \\
\hline
\end{tabular}


Table IX-14: ANOVA Summary Table for Workstation Desk Size is Incorrect

\begin{tabular}{|c|c|c|c|c|c|}
\hline SOURCE OF VARIANCE & df & SS & MS & $\mathbf{F}$ & $\underline{p}$ \\
\hline \multicolumn{6}{|l|}{ Between-Subjects } \\
\hline Experience (E) & 1 & 0.0054 & 0.0054 & 0.10 & 0.7580 \\
\hline Sub/Experience (S/E) & 22 & 1.2250 & 0.0557 & & \\
\hline \multicolumn{6}{|l|}{ Within-Subjects } \\
\hline Interface (I) & 1 & 0.6494 & 0.6494 & 12.05 & 0.0022 \\
\hline Trial (T) & 4 & 0.0209 & 0.0052 & 0.18 & 0.9490 \\
\hline IXE & 1 & 0.0149 & 0.0149 & 0.28 & 0.6044 \\
\hline I $\times$ S/E & 22 & 1.1861 & 0.0539 & & \\
\hline$T \times E$ & 4 & 0.0433 & 0.0108 & 0.37 & 0.8304 \\
\hline$T \times S / E$ & 88 & 2.5822 & 0.0293 & & \\
\hline $\mid x T$ & 4 & 0.0878 & 0.0220 & 0.68 & 0.6104 \\
\hline IXTXE & 4 & 0.1783 & 0.0446 & 1.37 & 0.2500 \\
\hline IXTXS/E & 88 & 2.8584 & 0.0325 & & \\
\hline Total & 239 & 8.8517 & & & \\
\hline
\end{tabular}


Table IX-15: ANOVA Summary Table for Workstation Desk Return Size is Incorrect

\begin{tabular}{|c|c|c|c|c|c|}
\hline SOURCE OF VARIANCE & df & SS & MS & $\mathbf{F}$ & $p$ \\
\hline \multicolumn{6}{|l|}{ Between-Subjects } \\
\hline Experience (E) & 1 & 0.0013 & 0.0013 & 0.16 & 0.6902 \\
\hline Sub/Experience (S/E) & 22 & 0.1778 & 0.0081 & & \\
\hline \multicolumn{6}{|l|}{ Within-Subjects } \\
\hline Interface (I) & 1 & 0.0327 & 0.0327 & 4.36 & 0.0486 \\
\hline Trial (T) & 4 & 0.0264 & 0.0066 & 0.80 & 0.5323 \\
\hline IXE & 1 & 0.0037 & 0.0037 & 0.49 & 0.4919 \\
\hline I $\times$ S/E & 22 & 0.1649 & 0.0075 & & \\
\hline$T \times E$ & 4 & 0.0358 & 0.0090 & 1.08 & 0.3737 \\
\hline$T \times S / E$ & 88 & 0.7316 & 0.0083 & & \\
\hline $1 \times T$ & 4 & 0.0311 & 0.0078 & 0.91 & 0.4623 \\
\hline IXTXE & 4 & 0.0288 & 0.0072 & 0.84 & 0.5027 \\
\hline I $\times T \times S / E$ & 88 & 0.7537 & 0.0086 & & \\
\hline Total & 239 & 1.9878 & & & \\
\hline
\end{tabular}


Table IX-16: ANOVA Summary Table for Workstation Book Size is Incorrect

\begin{tabular}{|c|c|c|c|c|c|}
\hline SOURCE OF VARIANCE & df & SS & MS & $\mathbf{F}$ & $\mathbf{p}$ \\
\hline \multicolumn{6}{|l|}{ Between-Subjects } \\
\hline Experience (E) & 1 & 0.0001 & 0.0001 & 0.05 & 0.7992 \\
\hline Sub/Experience (S/E) & 22 & 0.0408 & 0.0019 & & \\
\hline \multicolumn{6}{|l|}{ Within-Subjects } \\
\hline Interface (I) & 1 & 0.0244 & 0.0244 & 12.20 & 0.0019 \\
\hline Trial (T) & 4 & 0.0029 & 0.0007 & 0.41 & 0.7874 \\
\hline IXE & 1 & 0.0004 & 0.0004 & 0.20 & 0.6696 \\
\hline$I \times S / E$ & 22 & 0.0432 & 0.0020 & & \\
\hline$T \times E$ & 4 & 0.0036 & 0.0009 & 0.53 & 0.7077 \\
\hline$T \times S / E$ & 88 & 0.1485 & 0.0017 & & \\
\hline $\mid x T$ & 4 & 0.0034 & 0.0009 & 0.53 & 0.7357 \\
\hline IXT $\times E$ & 4 & 0.0036 & 0.0009 & 0.53 & 0.7155 \\
\hline IXT $\times S / E$ & 88 & 0.1481 & 0.0017 & & \\
\hline Total & 239 & 0.4190 & & & \\
\hline
\end{tabular}


Table IX-17: ANOVA Summary Table for Menu Upper Bar Size is Incorrect

\begin{tabular}{|c|c|c|c|c|c|}
\hline SOURCE OF VARIANCE & df & SS & MS & $\mathbf{F}$ & $p$ \\
\hline \multicolumn{6}{|l|}{ Between-Subjects } \\
\hline Experience (E) & 1 & 0.2115 & 0.2115 & 2.28 & 0.1449 \\
\hline Sub/Experience (S/E) & 22 & 2.0371 & 0.0926 & & \\
\hline \multicolumn{6}{|l|}{ Within-Subjects } \\
\hline Interface (l) & 1 & 0.0010 & 0.0010 & 0.01 & 0.9120 \\
\hline Trial (T) & 4 & 0.1916 & 0.0479 & 0.99 & 0.4164 \\
\hline IXE & 1 & 0.0086 & 0.0086 & 0.10 & 0.7510 \\
\hline $1 \times S / E$ & 22 & 1.8351 & 0.0834 & & \\
\hline$T \times E$ & 4 & 0.2094 & 0.0524 & 1.08 & 0.3694 \\
\hline$T \times S / E$ & 88 & 4.2494 & 0.0483 & & \\
\hline $\mathrm{I} \times \mathrm{T}$ & 4 & 0.1101 & 0.0275 & 0.76 & 0.5566 \\
\hline IXTXE & 4 & 0.1173 & 0.0293 & 0.80 & 0.5251 \\
\hline IXT $\times S / E$ & 88 & 3.2042 & 0.0364 & & \\
\hline Total & 239 & 12.1753 & & & \\
\hline
\end{tabular}


Table IX-18: ANOVA Summary Table for Menu Size is Incorrect

\begin{tabular}{|c|c|c|c|c|c|}
\hline SOURCE OF VARIANCE & $d f$ & SS & MS & $F$ & $\underline{p}$ \\
\hline \multicolumn{6}{|l|}{ Between-Subjects } \\
\hline Experience (E) & 1 & 0.0093 & 0.0093 & 0.55 & 0.4662 \\
\hline Sub/Experience (S/E) & 22 & 0.3712 & 0.0169 & & \\
\hline \multicolumn{6}{|l|}{ Within-Subjects } \\
\hline Interface (l) & 1 & 0.0046 & 0.0046 & 0.36 & 0.5548 \\
\hline Trial (T) & 4 & 0.0925 & 0.0231 & 2.36 & 0.0590 \\
\hline IXE & 1 & 0.0011 & 0.0011 & 0.09 & 0.7743 \\
\hline I $\times$ S/E & 22 & 0.2825 & 0.0128 & & \\
\hline$T \times E$ & 4 & 0.0170 & 0.0043 & 0.44 & 0.7835 \\
\hline$T \times S / E$ & 88 & 0.8608 & 0.0098 & & \\
\hline $\mid x T$ & 4 & 0.0220 & 0.0055 & 0.54 & 0.7034 \\
\hline IXTXE & 4 & 0.0577 & 0.0144 & 1.43 & 0.2325 \\
\hline$I \times T \times S / E$ & 88 & 0.8907 & 0.0101 & & \\
\hline Total & 239 & 2.6094 & & & \\
\hline
\end{tabular}


Table IX-19: ANOVA Summary Table for Menu Location is Incorrect

\begin{tabular}{|c|c|c|c|c|c|}
\hline SOURCE OF VARIANCE & $d f$ & SS & MS & $\mathbf{F}$ & $p$ \\
\hline \multicolumn{6}{|l|}{ Between-Subjects } \\
\hline Experience (E) & 1 & 0.0059 & 0.0059 & 0.33 & 0.5724 \\
\hline Sub/Experience (S/E) & 22 & 0.3936 & 0.0179 & & \\
\hline \multicolumn{6}{|l|}{ Within-Subjects } \\
\hline Interface (I) & 1 & 0.0606 & 0.0606 & 3.22 & 0.0867 \\
\hline Trial (T) & 4 & 0.0163 & 0.0041 & 0.67 & 0.6123 \\
\hline IXE & 1 & 0.0020 & 0.0020 & 0.11 & 0.7495 \\
\hline I $\times S / E$ & 22 & 0.4144 & 0.0188 & & \\
\hline$T \times E$ & 4 & 0.0215 & 0.0054 & 0.89 & 0.4747 \\
\hline$T \times S / E$ & 88 & 0.5340 & 0.0061 & & \\
\hline $\mid x T$ & 4 & 0.0215 & 0.0054 & 0.89 & 0.4747 \\
\hline IXTXE & 4 & 0.0163 & 0.0041 & 0.67 & 0.6123 \\
\hline$I \times T \times S / E$ & 88 & 0.5340 & 0.0061 & & \\
\hline Total & 239 & 2.0201 & & & \\
\hline
\end{tabular}


Table IX-20: ANOVA Summary Table for Menu Circle Size is Incorrect

\begin{tabular}{|c|c|c|c|c|c|}
\hline SOURCE OF VARIANCE & df & SS & MS & $F$ & $\mathbf{p}$ \\
\hline \multicolumn{6}{|l|}{ Between-Subjects } \\
\hline Experience $(E)$ & 1 & 0.0166 & 0.0166 & 0.99 & 0.3292 \\
\hline Sub/Experience (S/E) & 22 & 0.3667 & 0.0167 & & \\
\hline \multicolumn{6}{|l|}{ Within-Subjects } \\
\hline Interface (l) & 1 & 0.0169 & 0.0169 & 1.01 & 0.3252 \\
\hline Trial (T) & 4 & 0.0666 & 0.0167 & 1.00 & 0.4126 \\
\hline IXE & 1 & 0.0165 & 0.0165 & 0.99 & 0.3312 \\
\hline I $\times S / E$ & 22 & 0.3667 & 0.0167 & & \\
\hline$T \times E$ & 4 & 0.0667 & 0.0167 & 1.00 & 0.4115 \\
\hline$T \times S / E$ & 88 & 1.4667 & 0.0167 & & \\
\hline $\mid x T$ & 4 & 0.0665 & 0.0166 & 0.99 & 0.4198 \\
\hline$I \times T \times E$ & 4 & 0.0669 & 0.0167 & 1.00 & 0.4165 \\
\hline IXTXS/E & 88 & 1.4667 & 0.0167 & & \\
\hline Total & 239 & 3.9835 & & & \\
\hline
\end{tabular}


Appendix X. ANOVA Summary Table for Absolute Questionnaire Ratings 
Table X-1: ANOVA Summary Table for Ease of Drawing a Line

\begin{tabular}{|c|c|c|c|c|c|}
\hline SOURCE OF VARIANCE & $d f$ & SS & MS & $\bar{F}$ & $\bar{p}$ \\
\hline Between - Subjects & & & & & \\
\hline Order (0) & 1 & 0.1875 & 0.1875 & 0.92 & 0.3493 \\
\hline Experience (E) & 1 & 0.1875 & 0.1875 & 0.92 & 0.3493 \\
\hline$O \times E$ & 1 & 0.0208 & 0.0208 & 0.10 & 0.7527 \\
\hline Sub/Order Experience (S/OE) & 20 & 4.0833 & 0.2042 & & \\
\hline Within - Subjects & & & & & \\
\hline Interface (I) & 1 & 0.0208 & 0.0208 & 0.12 & 0.7306 \\
\hline$I \times E$ & 1 & 0.0208 & 0.0208 & 0.12 & 0.7306 \\
\hline $1 \times 0$ & 1 & 0.0208 & 0.0208 & 0.12 & 0.7306 \\
\hline$I \times E \times O$ & 1 & 0.0208 & 0.0208 & 0.12 & 0.7306 \\
\hline I x S/OE & 20 & 3.4166 & 0.1708 & & \\
\hline Total & 47 & 7.9789 & & & \\
\hline
\end{tabular}


Table X-2: ANOVA Summary Table for Ease of Drawing a Box

\begin{tabular}{|c|c|c|c|c|c|}
\hline SOURCE OF VARIANCE & df & SS & MS & $\mathbf{F}$ & $p$ \\
\hline Between - Subjects & & & & & \\
\hline Order (0) & 1 & 0.0833 & 0.0833 & 0.18 & 0.6798 \\
\hline Experience (E) & 1 & 0.3333 & 0.3333 & 0.70 & 0.4121 \\
\hline OXE & 1 & 0.0833 & 0.0833 & 0.18 & 0.6798 \\
\hline Sub/Order Experience (S/OE) & 20 & 9.5000 & 0.4750 & & \\
\hline Within - Subjects & & & & & \\
\hline Interface (I) & 1 & 0.3333 & 0.3333 & 1.48 & 0.2377 \\
\hline$I \times E$ & 1 & 0.0000 & 0.0000 & 0.00 & 1.0000 \\
\hline $1 \times 0$ & 1 & 0.0833 & 0.0833 & 0.37 & 0.5497 \\
\hline $1 \times E \times O$ & 1 & 0.0833 & 0.0833 & 0.37 & 0.5497 \\
\hline I $\times$ S/OE & 20 & 4.5000 & 0.2250 & & \\
\hline Total & 47 & 14.9998 & & & \\
\hline
\end{tabular}


Table X-3: ANOVA Summary Table for Ease of Drawing a Circle

\begin{tabular}{|c|c|c|c|c|c|}
\hline SOURCE OF VARIANCE & $d f$ & SS & MS & $\mathbf{F}$ & $p$ \\
\hline \multicolumn{6}{|l|}{ Between - Subjects } \\
\hline Order $(0)$ & 1 & 6.0208 & 6.0208 & 3.73 & 0.0676 \\
\hline Experience (E) & 1 & 4.6875 & 4.6875 & 2.91 & 0.1037 \\
\hline OXE & 1 & 6.0208 & 6.0208 & 3.73 & 0.0676 \\
\hline Sub/Order Experience (S/OE) & 20 & 32.2500 & 1.6125 & & \\
\hline \multicolumn{6}{|l|}{ Within - Subjects } \\
\hline Interface (I) & 1 & 7.5208 & 7.5208 & 5.66 & 0.0274 \\
\hline IXE & 1 & 0.1875 & 0.1875 & 0.14 & 0.7112 \\
\hline $1 \times 0$ & 1 & 0.4875 & 0.4875 & 0.37 & 0.5497 \\
\hline$I \times E \times O$ & 1 & 1.6875 & 1.6875 & 1.27 & 0.2732 \\
\hline I $\times S / O E$ & 20 & 26.5833 & 1.3292 & & \\
\hline Total & 47 & 85.4457 & & & \\
\hline
\end{tabular}


Table X-4: ANOVA Summary Table for Ease of Drawing a Polygon

\begin{tabular}{|c|c|c|c|c|c|}
\hline SOURCE OF VARIANCE & $d f$ & SS & MS & $\mathbf{F}$ & $p$ \\
\hline Between - Subjects & & & & & \\
\hline Order (O) & 1 & 0.0208 & 0.0208 & 0.01 & 0.9168 \\
\hline Experience (E) & 1 & 0.1875 & 0.1875 & 0.10 & 0.7543 \\
\hline$O \times E$ & 1 & 2.5208 & 2.5208 & 1.35 & 0.2584 \\
\hline Sub/Order Experience (S/OE) & 20 & 37.2500 & 1.8625 & & \\
\hline Within - Subjects & & & & & \\
\hline Interface (I) & 1 & 0.5208 & 0.5208 & 0.58 & 0.4547 \\
\hline$I \times E$ & 1 & 0.5208 & 0.5208 & 0.58 & 0.4547 \\
\hline $1 \times 0$ & 1 & 3.5208 & 3.5208 & 3.93 & 0.0613 \\
\hline$I \times E \times O$ & 1 & 0.0208 & 0.0208 & 0.02 & 0.8803 \\
\hline I $\times$ S/OE & 20 & 17.9166 & 0.8958 & & \\
\hline Total & 47 & 62.4789 & & & \\
\hline
\end{tabular}


Table X-5: ANOVA Summary Table for Ease of Drawing a Circle

\begin{tabular}{|c|c|c|c|c|c|}
\hline SOURCE OF VARIANCE & $d f$ & $\overline{S S}$ & MS & $\mathbf{F}$ & $p$ \\
\hline \multicolumn{6}{|l|}{ Between - Subjects } \\
\hline Order (0) & 1 & 0.0833 & 0.0833 & 0.14 & 0.7074 \\
\hline Experience (E) & 1 & 1.3333 & 1.3333 & 2.32 & 0.1435 \\
\hline OXE & 1 & 2.2583 & 2.2583 & 3.93 & 0.0613 \\
\hline Sub/Order Experience (S/OE) & 20 & 11.5000 & 0.5750 & & \\
\hline \multicolumn{6}{|l|}{ Within - Subjects } \\
\hline Interface (I) & 1 & 4.0833 & 4.0833 & 7.31 & 0.0136 \\
\hline$I \times E$ & 1 & 0.0833 & 0.0833 & 0.15 & 0.7033 \\
\hline $1 \times 0$ & 1 & 1.3333 & 1.3333 & 2.39 & 0.1379 \\
\hline$I \times E \times O$ & 1 & 0.3333 & 0.3333 & 0.60 & 0.4488 \\
\hline I $\times S / O E$ & 20 & 11.1666 & 0.5583 & & \\
\hline Total & 47 & 32.1747 & & & \\
\hline
\end{tabular}


Table X-6: ANOVA Summary Table for Ease of Fine Positioning a Circle

\begin{tabular}{|c|c|c|c|c|c|}
\hline SOURCE OF VARIANCE & $d f$ & SS & MS & $\mathbf{F}$ & $\underline{p}$ \\
\hline Between - Subjects & & & & & \\
\hline Order (0) & 1 & 0.3333 & 0.3333 & 0.29 & 0.5936 \\
\hline Experience (E) & 1 & 0.0000 & 0.0000 & 0.00 & 1.0000 \\
\hline OXE & 1 & 0.0000 & 0.0000 & 0.00 & 1.0000 \\
\hline Sub/Order Experience (S/OE) & 20 & 22.6667 & 1.1333 & & \\
\hline Within - Subjects & & & & & \\
\hline Interface (I) & 1 & 2.0833 & 2.0833 & 2.36 & 0.1403 \\
\hline$I \times E$ & 1 & 2.0833 & 2.0833 & 2.36 & 0.1403 \\
\hline $1 \times 0$ & 1 & 0.0833 & 0.0833 & 0.09 & 0.7619 \\
\hline $1 \times E \times O$ & 1 & 0.0833 & 0.0833 & 0.09 & 0.7619 \\
\hline I $\times$ S/OE & 20 & 17.6667 & 0.8833 & & \\
\hline Total & 47 & 44.9999 & & & \\
\hline
\end{tabular}


Table X-7: ANOVA Summary Table for Ease of Resizing a Circle

\begin{tabular}{|c|c|c|c|c|c|}
\hline SOURCE OF VARIANCE & $d f$ & SS & MS & $\mathbf{F}$ & $p$ \\
\hline Between - Subjects & & & & & \\
\hline Order (O) & 1 & 0.0208 & 0.0208 & 0.01 & 0.9271 \\
\hline Experience (E) & 1 & 0.1875 & 0.1875 & 0.08 & 0.7840 \\
\hline OXE & 1 & 4.6875 & 4.6875 & 1.93 & 0.1801 \\
\hline Sub/Order Experience (S/OE) & 20 & 48.5833 & 2.4292 & & \\
\hline Within - Subjects & & & & & \\
\hline Interface (I) & 1 & 50.0208 & 50.0208 & 30.09 & 0.0001 \\
\hline$I \times E$ & 1 & 6.0208 & 6.0208 & 3.62 & 0.0715 \\
\hline $1 \times 0$ & 1 & 2.8333 & 2.8333 & 1.70 & $\cdots * *$ \\
\hline I $\times E \times O$ & 1 & 0.1875 & 0.1875 & 0.11 & 0.7405 \\
\hline I $\times$ S/OE & 20 & 33.2500 & 1.6625 & & \\
\hline Total & 47 & 145.7915 & & & \\
\hline
\end{tabular}


Table X-8: ANOVA Summary Table for Ease of Resizing a Group of Graphics

\begin{tabular}{|c|c|c|c|c|c|}
\hline SOURCE OF VARIANCE & $d f$ & SS & MS & $\mathbf{F}$ & $\mathbf{p}$ \\
\hline \multicolumn{6}{|l|}{ Between - Subjects } \\
\hline Order (O) & 1 & 2.0833 & 2.0833 & 0.57 & 0.4572 \\
\hline Experience (E) & 1 & 14.0833 & 14.0833 & 3.89 & 0.0627 \\
\hline OXE & 1 & 5.3333 & 5.3333 & 1.47 & 0.2393 \\
\hline Sub/Order Experience (S/OE) & 20 & 72.5000 & 3.6250 & & \\
\hline \multicolumn{6}{|l|}{ Within - Subjects } \\
\hline Interface (I) & 1 & 18.7500 & 18.7500 & 9.49 & 0.0059 \\
\hline$I \times E$ & 1 & 1.3333 & 1.3333 & 0.68 & 0.4210 \\
\hline $1 \times 0$ & 1 & 8.3333 & 8.3333 & 4.22 & 0.0533 \\
\hline$I \times E \times O$ & 1 & 4.0833 & 4.0833 & 2.07 & 0.1659 \\
\hline I $\times S / O E$ & 20 & 39.5000 & 1.9750 & & \\
\hline Total & 47 & 165.9998 & & & \\
\hline
\end{tabular}


Table X-9: ANOVA Summary Table for Ease of Moving a Group of Graphics

\begin{tabular}{|c|c|c|c|c|c|}
\hline SOURCE OF VARIANCE & $d f$ & SS & MS & $\bar{F}$ & $p$ \\
\hline Between - Subjects & & & & & \\
\hline Order (0) & 1 & 1.6875 & 1.6875 & 1.07 & 0.3136 \\
\hline Experience (E) & 1 & 0.0208 & 0.0208 & 0.01 & 0.9097 \\
\hline OXE & 1 & 1.6875 & 1.6875 & 1.07 & 0.3136 \\
\hline Sub/Order Experience (S/OE) & 20 & 31.5833 & 1.5792 & & \\
\hline Within - Subjects & & & & & \\
\hline Interface (I) & 1 & 1.6875 & 1.6875 & 0.70 & 0.4128 \\
\hline$I \times E$ & 1 & 2.5208 & 2.5208 & 1.04 & 0.3189 \\
\hline $1 \times 0$ & 1 & 0.0208 & 0.0208 & 0.01 & 0.9269 \\
\hline $1 \times E \times O$ & 1 & 1.0208 & 1.0208 & 0.42 & 0.5228 \\
\hline I $\times$ S/OE & 20 & 48.2500 & 2.4125 & & \\
\hline Total & 47 & 88.4790 & & & \\
\hline
\end{tabular}


Table X-10: ANOVA Summary Table for Ease of Rotating a Group of Graphics

\begin{tabular}{|c|c|c|c|c|c|}
\hline SOURCE OF VARIANCE & $d f$ & SS & MS & $\mathbf{F}$ & $p$ \\
\hline \multicolumn{6}{|l|}{ Between - Subjects } \\
\hline Order $(0)$ & 1 & 0.0000 & 0.0000 & 0.00 & 1.0000 \\
\hline Experience (E) & 1 & 0.3333 & 0.3333 & 0.24 & 0.6278 \\
\hline OXE & 1 & 2.0833 & 2.0833 & 1.52 & 0.2326 \\
\hline Sub/Order Experience (S/OE) & 20 & 27.5000 & 1.3750 & & \\
\hline \multicolumn{6}{|l|}{ Within - Subjects } \\
\hline Interface (I) & 1 & 0.0000 & 0.0000 & 0.00 & 1.0000 \\
\hline$I \times E$ & 1 & 0.7500 & 0.7500 & 0.89 & 0.3564 \\
\hline $1 \times 0$ & 1 & 0.0833 & 0.0833 & 0.10 & 0.7563 \\
\hline $1 \times E \times O$ & 1 & 0.3333 & 0.3333 & 0.40 & 0.5363 \\
\hline $1 \times S / O E$ & 20 & 16.8333 & 0.8417 & & \\
\hline Total & 47 & 47.9165 & & & \\
\hline
\end{tabular}


Table X-11: ANOVA Summary Table for Ease of Rotating a Graphic

\begin{tabular}{|c|c|c|c|c|c|}
\hline SOURCE OF VARIANCE & df & SS & MS & $\bar{F}$ & $p$ \\
\hline \multicolumn{6}{|l|}{ Between - Subjects } \\
\hline Order (0) & 1 & 0.1875 & 0.1875 & 0.27 & 0.6072 \\
\hline Experience (E) & 1 & 2.5208 & 2.5208 & 3.67 & 0.0699 \\
\hline OXE & 1 & 1.0208 & 1.0208 & 1.48 & 0.2372 \\
\hline Sub/Order Experience (S/OE) & 20 & 13.7500 & 0.6875 & & \\
\hline \multicolumn{6}{|l|}{ Within - Subjects } \\
\hline Interface (I) & 1 & 2.5208 & 2.5208 & 6.80 & 0.0169 \\
\hline IXE & 1 & 0.0208 & 0.0208 & 0.06 & 0.8151 \\
\hline $1 \times 0$ & 1 & 0.5208 & 0.5208 & 1.40 & 0.2499 \\
\hline $1 \times E \times O$ & 1 & 0.0208 & 0.0208 & 0.06 & 0.8151 \\
\hline I $\times S / O E$ & 20 & 7.4166 & 0.3708 & & \\
\hline Total & 47 & 27.9789 & & & \\
\hline
\end{tabular}


Table X-12: ANOVA Summary Table for Ease of Copying a Group of Graphics

\begin{tabular}{|c|c|c|c|c|c|}
\hline SOURCE OF VARIANCE & $d f$ & SS & MS & $\mathbf{F}$ & $p$ \\
\hline \multicolumn{6}{|l|}{ Between - Subjects } \\
\hline Order (0) & 1 & 0.0833 & 0.0833 & 0.03 & 0.8588 \\
\hline Experience (E) & 1 & 6.7500 & 6.7500 & 2.63 & 0.1205 \\
\hline OXE & 1 & 0.7500 & 0.7500 & 0.29 & 0.5948 \\
\hline Sub/Order Experience (S/OE) & 20 & 51.3333 & 2.5667 & & \\
\hline \multicolumn{6}{|l|}{ Within - Subjects } \\
\hline Interface (1) & 1 & 3.0000 & 3.0000 & 3.46 & 0.0776 \\
\hline$I \times E$ & 1 & 1.3333 & 1.3333 & 1.54 & 0.2292 \\
\hline $1 \times 0$ & 1 & 3.1833 & 3.1833 & 3.67 & 0.0699 \\
\hline $1 \times E \times O$ & 1 & 0.0000 & 0.0000 & 0.00 & 1.0000 \\
\hline$I \times S / O E$ & 20 & 17.3333 & 0.8667 & & \\
\hline Total & 47 & 83.7665 & & & \\
\hline
\end{tabular}


Table X-13: ANOVA Summary Table for Ease of Copying a Box

\begin{tabular}{lccccc}
\hline SOURCE OF VARIANCE & df & SS & MS & F & p \\
\hline Between - Subjects & & & & & \\
Order (O) & 1 & 0.0833 & 0.0833 & 0.04 & 0.8416 \\
Experience (E) & 1 & 2.0833 & 2.0833 & 1.02 & 0.3235 \\
OxE & 1 & 0.0833 & 0.0833 & 0.04 & 0.8416 \\
Sub/Order Experience (S/OE) & 20 & 40.6667 & 2.0333 & & \\
Within - Subjects & & & & & \\
Interface (I) & 1 & 8.3333 & 8.3333 & 8.93 & 0.0073 \\
IxE & 1 & 3.0000 & 3.0000 & 3.21 & 0.0881 \\
IxO & 1 & 3.0000 & 3.0000 & 3.21 & 0.0881 \\
IxExO & 1 & 0.0000 & 0.0000 & 0.00 & 1.0000 \\
Ix S/OE & 20 & 18.6667 & 0.9333 & &
\end{tabular}


Table X-14: ANOVA Summary Table for Ease of Copying a Line

\begin{tabular}{|c|c|c|c|c|c|}
\hline SOURCE OF VARIANCE & df & SS & MS & $\mathbf{F}$ & $p$ \\
\hline \multicolumn{6}{|l|}{ Between - Subjects } \\
\hline Order (0) & 1 & 0.0000 & 0.0000 & 0.00 & 1.0000 \\
\hline Experience (E) & 1 & 2.0833 & 2.0833 & 0.97 & 0.3358 \\
\hline OXE & 1 & 0.0833 & 0.0833 & 0.04 & 0.8456 \\
\hline Sub/Order Experience (S/OE) & 20 & 42.8333 & 2.1417 & & \\
\hline \multicolumn{6}{|l|}{ Within - Subjects } \\
\hline Interface (I) & 1 & 8.3333 & 8.3333 & 10.10 & 0.0047 \\
\hline$I \times E$ & 1 & 2.0833 & 2.0833 & 2.53 & 0.1277 \\
\hline $1 \times 0$ & 1 & 3.0000 & 3.0000 & 3.64 & 0.0710 \\
\hline$I \times E \times O$ & 1 & 0.0833 & 0.0833 & 0.10 & 0.7539 \\
\hline I $\times$ S/OE & 20 & 16.5000 & 0.8250 & & \\
\hline Total & 47 & 74.9998 & & & \\
\hline
\end{tabular}


Table X-15: ANOVA Summary Table for Ease of Copying a Circle

\begin{tabular}{|c|c|c|c|c|c|}
\hline SOURCE OF VARIANCE & $d f$ & SS & MS & $\mathbf{F}$ & $p$ \\
\hline \multicolumn{6}{|l|}{ Between - Subjects } \\
\hline Order $(0)$ & 1 & 0.0208 & 0.0208 & 0.01 & 0.9225 \\
\hline Experience (E) & 1 & 1.0208 & 1.0208 & 0.48 & 0.4983 \\
\hline OXE & 1 & 0.0208 & 0.0208 & 0.01 & 0.9225 \\
\hline Sub/Order Experience (S/OE) & 20 & 42.9166 & 2.1458 & & \\
\hline \multicolumn{6}{|l|}{ Within - Subjects } \\
\hline Interface (I) & 1 & 7.5208 & 7.5208 & 6.97 & 0.0157 \\
\hline IXE & 1 & 3.5208 & 3.5208 & 3.26 & 0.0860 \\
\hline $1 \times 0$ & 1 & 1.6875 & 1.6875 & 1.56 & 0.2256 \\
\hline$I \times E \times O$ & 1 & 0.1875 & 0.1875 & 0.17 & 0.6812 \\
\hline$I \times S / O E$ & 20 & 21.5833 & 1.0792 & & \\
\hline Total & 47 & 78.4789 & & & \\
\hline
\end{tabular}


Table X-16: ANOVA Summary Table for Ease of Copying a Polygon

\begin{tabular}{|c|c|c|c|c|c|}
\hline SOURCE OF VARIANCE & $d f$ & SS & MS & $\bar{F}$ & $p$ \\
\hline \multicolumn{6}{|l|}{ Between - Subjects } \\
\hline Order (O) & 1 & 0.0208 & 0.0208 & 0.01 & 0.9232 \\
\hline Experience (E) & 1 & 2.5208 & 2.5208 & 1.15 & 0.2958 \\
\hline OXE & 1 & 0.5208 & 0.5208 & 0.24 & 0.6309 \\
\hline Sub/Order Experience (S/OE) & 20 & 43.7500 & 2.1875 & & \\
\hline \multicolumn{6}{|l|}{ Within - Subjects } \\
\hline Interface (I) & 1 & 6.0208 & 6.0208 & 5.54 & 0.0290 \\
\hline$I \times E$ & 1 & 1.6875 & 1.6875 & 1.55 & 0.2273 \\
\hline $1 \times 0$ & 1 & 1.0208 & 1.0208 & 0.94 & 0.3442 \\
\hline$I \times E \times O$ & 1 & 0.0208 & 0.0208 & 0.02 & 0.8913 \\
\hline I $\times$ S/OE & 20 & 21.7500 & 1.0875 & & \\
\hline Total & 47 & 77.3123 & & & \\
\hline
\end{tabular}


Table X-17: ANOVA Summary Table for Ease of Erasing Portions of Graphics

\begin{tabular}{|c|c|c|c|c|c|}
\hline SOURCE OF VARIANCE & $d f$ & SS & MS & $\mathbf{F}$ & $p$ \\
\hline \multicolumn{6}{|l|}{ Between - Subjects } \\
\hline Order (0) & 1 & 0.0208 & 0.0208 & 0.01 & 0.9195 \\
\hline Experience $(E)$ & 1 & 13.0208 & 13.0208 & 6.55 & 0.0187 \\
\hline OXE & 1 & 0.1875 & 0.1875 & 0.09 & 0.7619 \\
\hline Sub/Order Experience (S/OE) & 20 & 39.7500 & 1.9875 & & \\
\hline \multicolumn{6}{|l|}{ Within - Subjects } \\
\hline Interface (I) & 1 & 25.5208 & 25.5208 & 8.84 & 0.0075 \\
\hline$I \times E$ & 1 & 2.5208 & 2.5208 & 0.87 & 0.3613 \\
\hline $1 \times 0$ & 1 & 1.6875 & 1.6875 & 0.58 & 0.4535 \\
\hline $1 \times E \times O$ & 1 & 0.0208 & 0.0208 & 0.01 & 0.9332 \\
\hline I $\times S / O E$ & 20 & 57.7500 & 2.8875 & & \\
\hline Total & 47 & 140.4790 & & & \\
\hline
\end{tabular}


Table X-18: ANOVA Summary Table for Ease of Moving a Line

\begin{tabular}{|c|c|c|c|c|c|}
\hline SOURCE OF VARIANCE & df & SS & MS & $\mathbf{F}$ & $\mathbf{p}$ \\
\hline Between - Subjects & & & & & \\
\hline Order (O) & 1 & 1.3333 & 1.3333 & 2.46 & 0.1324 \\
\hline Experience (E) & 1 & 0.7500 & 0.7500 & 1.38 & 0.2531 \\
\hline OXE & 1 & 1.3333 & 1.3333 & 2.46 & 0.1324 \\
\hline Sub/Order Experience (S/OE) & 20 & 10.8333 & 0.5417 & & \\
\hline Within - Subjects & & & & & \\
\hline Interface (I) & 1 & 4.0833 & 4.0833 & 18.15 & 0.0004 \\
\hline$I \times E$ & 1 & 0.0833 & 0.0833 & 0.37 & 0.5497 \\
\hline $1 \times 0$ & 1 & 0.3833 & 0.3833 & 1.70 & $* * * *$ \\
\hline $1 \times E \times O$ & 1 & 0.3333 & 0.3333 & 1.48 & 0.2377 \\
\hline I $\times$ S/OE & 20 & 4.5000 & 0.2250 & & \\
\hline Total & 47 & 23.6331 & & & \\
\hline
\end{tabular}


Table X-19: ANOVA Summary Table for Ease of Resizing a Line

\begin{tabular}{|c|c|c|c|c|c|}
\hline SOURCE OF VARIANCE & $d f$ & SS & MS & $\mathbf{F}$ & $\bar{p}$ \\
\hline \multicolumn{6}{|l|}{ Between - Subjects } \\
\hline Order $(0)$ & 1 & 0.7500 & 0.7500 & 0.23 & 0.6375 \\
\hline Experience $(E)$ & 1 & 5.3333 & 5.3333 & 1.63 & 0.2165 \\
\hline OXE & 1 & 5.3333 & 5.3333 & 1.63 & 0.2165 \\
\hline Sub/Order Experience (S/OE) & 20 & 65.5000 & 3.2750 & & \\
\hline \multicolumn{6}{|l|}{ Within - Subjects } \\
\hline Interface (I) & 1 & 24.0833 & 24.0833 & 21.41 & 0.0002 \\
\hline IXE & 1 & 3.0000 & 3.0000 & 20.44 & 0.1181 \\
\hline $1 \times 0$ & 1 & 0.0833 & 0.0833 & 0.07 & 0.7883 \\
\hline $1 \times E \times 0$ & 1 & 1.3333 & 1.3333 & 1.19 & 0.2892 \\
\hline I $\times S / O E$ & 20 & 22.5000 & 1.1250 & & \\
\hline Total & 47 & 127.9165 & & & \\
\hline
\end{tabular}


Table X-20: ANOVA Summary Table for Ease of Fine Positioning a Line

\begin{tabular}{|c|c|c|c|c|c|}
\hline SOURCE OF VARIANCE & $d f$ & SS & MS & $\bar{F}$ & $p$ \\
\hline \multicolumn{6}{|l|}{ Between - Subjects } \\
\hline Order (0) & 1 & 3.5208 & 3.5208 & 3.63 & 0.0713 \\
\hline Experience (E) & 1 & 1.0208 & 1.0208 & 1.05 & 0.3174 \\
\hline OXE & 1 & 0.5208 & 0.5208 & 0.54 & 0.4724 \\
\hline Sub/Order Experience (S/OE) & 20 & 19.4166 & 0.9708 & & \\
\hline \multicolumn{6}{|l|}{ Within - Subjects } \\
\hline Interface (I) & 1 & 2.5208 & 2.5208 & 5.76 & 0.0262 \\
\hline$I \times E$ & 1 & 0.1875 & 0.1875 & 0.43 & 0.5201 \\
\hline $1 \times 0$ & 1 & 0.0208 & 0.0208 & 0.05 & 0.8295 \\
\hline$I \times E \times O$ & 1 & 0.0208 & 0.0208 & 0.05 & 0.8295 \\
\hline I $\times$ S/OE & 20 & 8.7500 & 0.4375 & & \\
\hline Total & 47 & 35.9789 & & & \\
\hline
\end{tabular}


Table X-21: ANOVA Summary Table for Ease of Moving a Box

\begin{tabular}{|c|c|c|c|c|c|}
\hline SOURCE OF VARIANCE & df & SS & MS & $\mathbf{F}$ & $p$ \\
\hline \multicolumn{6}{|l|}{ Between - Subjects } \\
\hline Order (0) & 1 & 0.1875 & 0.1875 & 0.53 & 0.4753 \\
\hline Experience (E) & 1 & 0.0208 & 0.0208 & 0.06 & 0.8108 \\
\hline OXE & 1 & 1.2875 & 1.2875 & 3.63 & 0.0713 \\
\hline Sub/Order Experience (S/OE) & 20 & 7.0833 & 0.3542 & & \\
\hline \multicolumn{6}{|l|}{ Within - Subjects } \\
\hline Interface (I) & 1 & 1.6875 & 1.6875 & 6.64 & 0.0180 \\
\hline IXE & 1 & 0.5208 & 0.5208 & 2.05 & 0.1677 \\
\hline $1 \times 0$ & 1 & 1.6875 & 1.6875 & 6.64 & 0.0180 \\
\hline$I \times E \times O$ & 1 & 0.5208 & 0.5208 & 2.05 & 0.1677 \\
\hline $1 \times S / O E$ & 20 & 5.0833 & 0.2542 & & \\
\hline Total & 47 & 18.0790 & & & \\
\hline
\end{tabular}


Table X-22: ANOVA Summary Table for Ease of Resizing a Box

\begin{tabular}{|c|c|c|c|c|c|}
\hline SOURCE OF VARIANCE & $d f$ & SS & MS & $\bar{F}$ & $p$ \\
\hline \multicolumn{6}{|l|}{ Between - Subjects } \\
\hline Order (O) & 1 & 1.3333 & 1.3333 & 0.36 & 0.5572 \\
\hline Experience (E) & 1 & 0.7500 & 0.7500 & 0.20 & 0.6592 \\
\hline OXE & 1 & 4.0833 & 4.0833 & 1.09 & 0.3086 \\
\hline Sub/Order Experience (S/OE) & 20 & 74.8333 & 3.7417 & & \\
\hline \multicolumn{6}{|l|}{ Within - Subjects } \\
\hline Interface (I) & 1 & 40.3333 & 40.3333 & 34.33 & 0.0001 \\
\hline$I \times E$ & 1 & 6.7500 & 6.7500 & 5.74 & 0.0264 \\
\hline $1 \times 0$ & 1 & 0.3333 & 0.3333 & 0.28 & 0.6002 \\
\hline$I \times E \times O$ & 1 & 0.0833 & 0.0833 & 0.07 & 0.7927 \\
\hline I $\times S / O E$ & 20 & 23.5000 & 1.1750 & & \\
\hline Total. & 47 & 151.9998 & & & \\
\hline
\end{tabular}


Table X-23: ANOVA Summary Table for Ease of Fine Positioning a Box

\begin{tabular}{|c|c|c|c|c|c|}
\hline SOURCE OF VARIANCE & $d f$ & SS & MS & $\mathbf{F}$ & $\underline{p}$ \\
\hline Between - Subjects & & & & & \\
\hline Order (O) & 1 & 2.5208 & 2.5208 & 2.67 & 0.1182 \\
\hline Experience $(E)$ & 1 & 1.0208 & 1.0208 & 1.08 & 0.3113 \\
\hline OXE & 1 & 1.0208 & 1.0208 & 1.08 & 0.3113 \\
\hline Sub/Order Experience (S/OE) & 20 & 18.9166 & 0.9458 & & \\
\hline Within - Subjects & & & & & \\
\hline Interface (I) & 1 & 4.6875 & 4.6875 & 9.15 & 0.0067 \\
\hline$I \times E$ & 1 & 1.0208 & 1.0208 & 1.99 & 0.1735 \\
\hline $1 \times 0$ & 1 & 0.0208 & 0.0208 & 0.04 & 0.8423 \\
\hline$I \times E \times O$ & 1 & 0.5208 & 0.5208 & 1.02 & 0.3254 \\
\hline $1 \times$ S/OE & 20 & 10.2500 & 0.5125 & & \\
\hline Total & 47 & 39.9789 & & & \\
\hline
\end{tabular}


Table X-24: ANOVA Summary Table for Ease of Typing Text

\begin{tabular}{|c|c|c|c|c|c|}
\hline SOURCE OF VARIANCE & df & SS & MS & $\mathbf{F}$ & $p$ \\
\hline \multicolumn{6}{|l|}{ Between - Subjects } \\
\hline Order $(0)$ & 1 & 0.0208 & 0.0208 & 0.01 & 0.9099 \\
\hline Experience (E) & 1 & 0.0208 & 0.0208 & 0.01 & 0.9099 \\
\hline OXE & 1 & 1.6875 & 1.6875 & 1.06 & 0.3148 \\
\hline Sub/Order Experience (S/OE) & 20 & 31.7500 & 1.5875 & & \\
\hline \multicolumn{6}{|l|}{ Within - Subjects } \\
\hline Interface (I) & 1 & 1.0208 & 1.0208 & 0.85 & 0.3682 \\
\hline$I \times E$ & 1 & 0.1875 & 0.1875 & 0.16 & 0.6973 \\
\hline $1 \times 0$ & 1 & 1.0208 & 1.0208 & 0.85 & 0.3682 \\
\hline $1 \times E \times O$ & 1 & 0.1875 & 0.1875 & 0.16 & 0.6973 \\
\hline I $\times S / O E$ & 20 & 24.0833 & 1.2042 & & \\
\hline Total & 47 & 59.9790 & & & \\
\hline
\end{tabular}


Table X-25: ANOVA Summary Table for Ease of Moving Text

\begin{tabular}{|c|c|c|c|c|c|}
\hline SOURCE OF VARIANCE & $d f$ & SS & MS & $\mathbf{F}$ & $p$ \\
\hline \multicolumn{6}{|l|}{ Between - Subjects } \\
\hline Order (O) & 1 & 0.1875 & 0.1875 & 0.13 & 0.7270 \\
\hline Experience (E) & 1 & 0.1875 & 0.1875 & 0.13 & 0.7270 \\
\hline OXE & 1 & 2.5208 & 2.5208 & 1.69 & 0.2090 \\
\hline Sub/Order Experience (S/OE) & 20 & 29.9166 & 1.4958 & & \\
\hline \multicolumn{6}{|l|}{ Within - Subjects } \\
\hline Interface (I) & 1 & 2.5208 & 2.5208 & 2.87 & 0.1059 \\
\hline IXE & 1 & 0.1875 & 0.1875 & 0.21 & 0.6492 \\
\hline $1 \times 0$ & 1 & 0.1875 & 0.1875 & 0.21 & 0.6492 \\
\hline$I \times E \times O$ & 1 & 0.0208 & 0.0208 & 0.02 & 0.8792 \\
\hline I $\times$ S/OE & 20 & 17.5833 & 0.8792 & & \\
\hline Total & 47 & 53.3123 & & & \\
\hline
\end{tabular}


Table X-26: ANOVA Summary Table for Ease of Fine Positioning Text

\begin{tabular}{|c|c|c|c|c|c|}
\hline SOURCE OF VARIANCE & df & SS & MS & $\mathbf{F}$ & $p$ \\
\hline Between - Subjects & & & & & \\
\hline Order (0) & 1 & 7.5208 & 7.5208 & 2.30 & 0.1451 \\
\hline Experience (E) & 1 & 1.0208 & 1.0208 & 0.31 & 0.5826 \\
\hline OXE & 1 & 0.0208 & 0.0208 & 0.01 & 0.9372 \\
\hline Sub/Order Experience (S/OE) & 20 & 65.4166 & 3.2708 & & \\
\hline Within - Subjects & & & & & \\
\hline Interface (I) & 1 & 0.0208 & 0.0208 & 0.01 & 0.9118 \\
\hline$I \times E$ & 1 & 0.1875 & 0.1875 & 0.11 & 0.7399 \\
\hline $1 \times 0$ & 1 & 3.5208 & 3.5208 & 2.13 & 0.1601 \\
\hline IXEXO & 1 & 1.6875 & 1.6875 & 1.02 & 0.3245 \\
\hline$I \times S / O E$ & 20 & 33.0833 & 1.6542 & & \\
\hline Total & 47 & 112.4789 & & & \\
\hline
\end{tabular}


Table X-27: ANOVA Summary Table for Ease of Drawing Graphics

\begin{tabular}{|c|c|c|c|c|c|}
\hline SOURCE OF VARIANCE & $d f$ & SS & MS & $\mathbf{F}$ & $p$ \\
\hline Between - Subjects & & & & & \\
\hline Order (O) & 1 & 1.6875 & 1.6875 & 0.99 & 0.3316 \\
\hline Experience (E) & 1 & 3.5208 & 3.5208 & 2.07 & 0.1661 \\
\hline$O \times E$ & 1 & 4.6875 & 4.6875 & 2.75 & 0.1128 \\
\hline Sub/Order Experience (S/OE) & 20 & 34.0833 & 1.7042 & & \\
\hline Within - Subjects & & & & & \\
\hline Interface (I) & 1 & 0.0208 & 0.0208 & 0.05 & 0.8326 \\
\hline$I \times E$ & 1 & 0.0208 & 0.0208 & 0.05 & 0.8326 \\
\hline $1 \times 0$ & 1 & 0.1875 & 0.1875 & 0.41 & 0.5278 \\
\hline$I \times E \times O$ & 1 & 0.1875 & 0.1875 & 0.41 & 0.5278 \\
\hline I $\times$ S/OE & 20 & 9.0833 & 0.4542 & & \\
\hline Total & 47 & 53.4790 & & & \\
\hline
\end{tabular}


Table X-28: ANOVA Summary Table for Ease of Moving Graphics

\begin{tabular}{|c|c|c|c|c|c|}
\hline SOURCE OF VARIANCE & df & SS & MS & $\mathbf{F}$ & $\underline{p}$ \\
\hline Between - Subjects & & & & & \\
\hline Order (0) & 1 & 2.0833 & 2.0833 & 2.53 & 0.1277 \\
\hline Experience (E) & 1 & 1.3333 & 1.3333 & 1.62 & 0.2182 \\
\hline$O \times E$ & 1 & 1.3333 & 1.3333 & 1.62 & 0.2182 \\
\hline Sub/Order Experience (S/OE) & 20 & 16.5000 & 0.8250 & & \\
\hline Within - Subjects & & & & & \\
\hline Interface (I) & 1 & 6.7500 & 6.7500 & 18.84 & 0.0003 \\
\hline IXE & 1 & 0.0000 & 0.0000 & 0.00 & 1.0000 \\
\hline $1 \times 0$ & 1 & 0.0833 & 0.0833 & 0.23 & 0.6311 \\
\hline$I \times E \times O$ & 1 & 0.0000 & 0.0000 & 0.00 & 1.0000 \\
\hline$I \times S / O E$ & 20 & 7.1667 & 0.3583 & & \\
\hline Total & 47 & 35.2499 & & & \\
\hline
\end{tabular}


Table X-29: ANOVA Summary Table for Ease of Resizing Graphics

\begin{tabular}{|c|c|c|c|c|c|}
\hline SOURCE OF VARIANCE & $d f$ & SS & MS & $\mathbf{F}$ & $p$ \\
\hline \multicolumn{6}{|l|}{ Between - Subjects } \\
\hline Order (0) & 1 & 0.3333 & 0.3333 & 0.13 & 0.7175 \\
\hline Experience (E) & 1 & 0.0833 & 0.0833 & 0.03 & 0.8563 \\
\hline OXE & 1 & 4.0833 & 4.0833 & 1.65 & 0.2137 \\
\hline Sub/Order Experience (S/OE) & 20 & 49.5000 & 2.4750 & & \\
\hline \multicolumn{6}{|l|}{ Within - Subjects } \\
\hline Interface (I) & 1 & 56.3333 & 56.3333 & 27.59 & 0.0001 \\
\hline $1 \times E$ & 1 & 6.7500 & 6.7500 & 3.31 & 0.0840 \\
\hline $1 \times 0$ & 1 & 5.3333 & 5.3333 & 2.61 & 0.1217 \\
\hline$I \times E \times O$ & 1 & 0.7500 & 0.7500 & 0.37 & 0.5513 \\
\hline I $\times$ S/OE & 20 & 40.8333 & 2.0417 & & \\
\hline Total & 47 & 163.9998 & & & \\
\hline
\end{tabular}


Table X-30: ANOVA Summary Table for Ease of Resizing a Group of Graphics

\begin{tabular}{|c|c|c|c|c|c|}
\hline SOURCE OF VARIANCE & $d f$ & SS & MS & $\bar{F}$ & $p$ \\
\hline \multicolumn{6}{|l|}{ Between - Subjects } \\
\hline Order (O) & 1 & 0.3333 & 0.3333 & 0.13 & 0.7175 \\
\hline Experience (E) & 1 & 0.0833 & 0.0833 & 0.03 & 0.8563 \\
\hline OXE & 1 & 4.0833 & 4.0833 & 1.65 & 0.2137 \\
\hline Sub/Order Experience (S/OE) & 20 & 49.5000 & 2.4750 & & \\
\hline \multicolumn{6}{|l|}{ Within - Subjects } \\
\hline Interface (I) & 1 & 56.3333 & 56.3333 & 27.59 & 0.0001 \\
\hline$I \times E$ & 1 & 6.7500 & 6.7500 & 3.31 & 0.0840 \\
\hline $1 \times 0$ & 1 & 5.3333 & 5.3333 & 2.61 & 0.1217 \\
\hline$I \times E \times O$ & 1 & 0.7500 & 0.7500 & 0.37 & 0.5513 \\
\hline$I \times S / O E$ & 20 & 40.8333 & 2.0417 & & \\
\hline Total & 47 & 163.9998 & & & \\
\hline
\end{tabular}


Table X-31: ANOVA Summary Table for Ease of Erasing/Deleting a Graphic

\begin{tabular}{|c|c|c|c|c|c|}
\hline SOURCE OF VARIANCE & df & SS & MS & $\mathbf{F}$ & $\mathbf{p}$ \\
\hline Between - Subjects & & & & & \\
\hline Order (0) & 1 & 4.6875 & 4.6875 & 3.44 & 0.0784 \\
\hline Experience (E) & 1 & 0.0208 & 0.0208 & 0.02 & 0.9028 \\
\hline OXE & 1 & 2.5208 & 2.5208 & 1.85 & 0.1889 \\
\hline Sub/Order Experience (S/OE) & 20 & 27.2500 & 1.3625 & & \\
\hline Within - Subjects & & & & & \\
\hline Interface (I) & 1 & 1.0208 & 1.0208 & 1.12 & 0.3028 \\
\hline$I \times E$ & 1 & 1.6875 & 1.6875 & 1.85 & 0.1890 \\
\hline $1 \times 0$ & 1 & 3.5208 & 3.5208 & 3.86 & 0.0635 \\
\hline IXEXO & 1 & 0.0208 & 0.0208 & 0.02 & 0.8814 \\
\hline I $\times$ S/OE & 20 & 18.2500 & 0.9125 & & \\
\hline Total & 47 & 58.9790 & & & \\
\hline
\end{tabular}


Table X-32: ANOVA Summary Table for Ease of Using Text

\begin{tabular}{|c|c|c|c|c|c|}
\hline SOURCE OF VARIANCE & df & SS & MS & $\mathbf{F}$ & $\underline{p}$ \\
\hline Between - Subjects & & & & & \\
\hline Order (0) & 1 & 1.0208 & 1.0208 & 0.82 & 0.3746 \\
\hline Experience (E) & 1 & 0.1875 & 0.1875 & 0.15 & 0.7012 \\
\hline$O \times E$ & 1 & 0.0208 & 0.0208 & 0.02 & 0.8981 \\
\hline Sub/Order Experience (S/OE) & 20 & 24.7500 & 1.2375 & & \\
\hline Within - Subjects & & & & & \\
\hline Interface (I) & 1 & 1.0208 & 1.0208 & 1.20 & 0.2873 \\
\hline$I \times E$ & 1 & 0.0208 & 0.0208 & 0.02 & 0.8775 \\
\hline $1 \times 0$ & 1 & 0.1875 & 0.1875 & 0.22 & 0.6445 \\
\hline$I \times E \times O$ & 1 & 0.1875 & 0.1875 & 0.22 & 0.6445 \\
\hline $1 \times S / O E$ & 20 & 17.0833 & 0.8542 & & \\
\hline Total & 47 & 44.4790 & & & \\
\hline
\end{tabular}


Table X-33: ANOVA Summary Table for Ease of Copying Graphics

\begin{tabular}{|c|c|c|c|c|c|}
\hline SOURCE OF VARIANCE & $d f$ & SS & MS & $F$ & $p$ \\
\hline \multicolumn{6}{|l|}{ Between - Subjects } \\
\hline Order (O) & 1 & 0.3333 & 0.3333 & 0.13 & 0.7197 \\
\hline Experience (E) & 1 & 1.3333 & 1.3333 & 0.53 & 0.4751 \\
\hline OXE & 1 & 3.0000 & 3.0000 & 1.19 & 0.2879 \\
\hline Sub/Order Experience (S/OE) & 20 & 50.3333 & 2.5167 & & \\
\hline \multicolumn{6}{|l|}{ Within - Subjects } \\
\hline Interface (I) & 1 & 0.0833 & 0.0833 & 0.08 & 0.7827 \\
\hline IXE & 1 & 0.0833 & 0.0833 & 21.56 & 0.7827 \\
\hline $1 \times 0$ & 1 & 0.7500 & 0.7500 & 0.70 & 0.4116 \\
\hline $1 \times E \times O$ & 1 & 0.7500 & 0.7500 & 0.70 & 0.4116 \\
\hline $1 \times S / O E$ & 20 & 21.3333 & 1.0667 & & \\
\hline Total & 47 & 77.9998 & & & \\
\hline
\end{tabular}


Table X-34: ANOVA Summary Table for Ease of Rotating Graphics

\begin{tabular}{|c|c|c|c|c|c|}
\hline SOURCE OF VARIANCE & $d f$ & SS & MS & $\mathbf{F}$ & $p$ \\
\hline \multicolumn{6}{|l|}{ Between - Subjects } \\
\hline Order (O) & 1 & 0.3333 & 0.3333 & 0.14 & 0.7179 \\
\hline Experience (E) & 1 & 0.0833 & 0.0833 & 0.03 & 0.8898 \\
\hline$O \times E$ & 1 & 4.0833 & 4.0833 & 1.68 & 0.2099 \\
\hline Sub/Order Experience (S/OE) & 20 & 48.5000 & 2.4250 & & \\
\hline \multicolumn{6}{|l|}{ Within - Subjects } \\
\hline Interface (I) & 1 & 46.3333 & 46.3333 & 23.86 & 0.0001 \\
\hline$I \times E$ & 1 & 6.7500 & 6.7500 & 3.48 & 0.0738 \\
\hline $1 \times 0$ & 1 & 5.3333 & 5.3333 & 2.75 & 0.1187 \\
\hline $1 \times E \times O$ & 1 & 0.7500 & 0.7500 & 0.39 & 0.5533 \\
\hline I $\times$ S/OE & 20 & 38.8333 & 1.9417 & & \\
\hline Total & 47 & 150.9998 & & & \\
\hline
\end{tabular}


Appendix XI. Comparison Questionnaire Responses 
Table XI-1. Novice Subjects' Preferences as Recorded by the Comparison Questionnaire.




Table XI-1 (cont.).

\begin{tabular}{|l|r|r|c|}
\hline \multicolumn{1}{|c|}{ QUESTION } & $\begin{array}{r}\text { \% PICKING } \\
\text { OBJECT-0RNT. }\end{array}$ & $\begin{array}{c}\text { \% PICKING } \\
\text { BIT-MAPPED }\end{array}$ & p \\
\hline Which interface did you prefer for: & & & \\
Drawing graphics & 66.7 & 33.3 & \\
Moving graphics & 91.7 & 8.3 & 0.006 \\
Resizing a graphic & 91.7 & 8.3 & 0.006 \\
Resizing a group of graphics & 58.3 & 41.7 & \\
Erasing/deleting a graphic & 33.3 & 66.7 & \\
Text manipulations & 41.7 & 58.3 & \\
Copying graphics & 100.0 & 0.0 & 0.001 \\
Rotating graphics & 91.7 & 8.3 & 0.006 \\
Overall which would you select to & 91.7 & 8.3 & 0.006 \\
perform your graphics work? & & & \\
\hline
\end{tabular}


Table XI-2. Experienced Subjects' Preferences as Recorded by the Comparison Questionnaire.

\begin{tabular}{|l|r|r|c|}
\hline \multicolumn{1}{|c|}{ QUESTION } & $\begin{array}{r}\text { \% PICKING } \\
\text { OBJECT-ORNT. }\end{array}$ & $\begin{array}{c}\text { \% PICKING } \\
\text { BITAPPED }\end{array}$ & P \\
\hline Which interface did you prefer for: & & & \\
Drawing a line & 66.7 & 33.3 & \\
Drawing a box & 41.7 & 58.3 & \\
Drawing a circle & 58.3 & 41.7 & \\
Drawing a polygon (triangle) & 50.0 & 50.0 & \\
Moving a circle & 91.7 & 8.3 & 0.006 \\
Fine positioning a circle & 66.7 & 33.3 & \\
Resizing a circle & 100.0 & 0.0 & 0.001 \\
Resizing a group of graphics & 100.0 & 0.0 & 0.001 \\
Moving a group of graphics & 83.3 & 16.7 & 0.038 \\
Rotating a group of graphics & 50.0 & 50.0 & \\
Rotating a single graphic & 66.7 & 33.3 & \\
Copying a group of graphics & 75.0 & 25.0 & \\
Copying a box & 83.3 & 16.7 & 0.038 \\
Copying a line & 83.3 & 16.7 & 0.038 \\
Copying a circle & 83.3 & 16.7 & 0.038 \\
Copying a polygon & 83.3 & 16.7 & 0.038 \\
Erasing graphics & 8.3 & 91.7 & 0.006 \\
Moving a line & 91.7 & 8.3 & 0.006 \\
Resizing a line & 100.0 & 0.0 & 0.001 \\
Fine positioning a line & 58.3 & 41.7 & \\
Moving a box & 91.7 & 8.3 & 0.006 \\
Resizing a box & 91.7 & 8.3 & 0.006 \\
Fine positioning a box & 66.7 & 33.3 & \\
Moving text & 75.0 & 25.0 & \\
Fine positioning text & 50.0 & 50.0 & \\
\hline
\end{tabular}


Table XI-2 (cont.).

\begin{tabular}{|l|r|r|c|}
\hline \multicolumn{1}{|c|}{ QUESTION } & $\begin{array}{r}\text { \% PICKING } \\
\text { OBJECT-0RNT. }\end{array}$ & $\begin{array}{c}\text { \% PICKIN-MAPPED } \\
\text { BIT-MAPE }\end{array}$ & p \\
\hline Which interface did you prefer for: & & & \\
Drawing graphics & 66.7 & 33.3 & \\
Moving graphics & 83.3 & 16.7 & 0.038 \\
Resizing a graphic & 91.7 & 8.3 & 0.006 \\
Resizing a group of graphics & 91.7 & 8.3 & 0.006 \\
Erasing/deleting a graphic & 50.0 & 50.0 & \\
Text manipulations & 75.0 & 25.0 & \\
Copying graphics & 91.7 & 8.3 & 0.006 \\
Rotating graphics & 91.7 & 8.3 & 0.006 \\
Overall which would you select to & 75.0 & 25.0 & \\
perform your graphics work? & & & \\
\hline
\end{tabular}


264

VITA 


\section{The vita has been removed from the scanned document}

